Assessment of Growth, Performance, and End-product Value when High Oleic Soybean Oil is Fed to Market Hogs, Broiler Chickens and Laying Hens

A Thesis presented to The Faculty of the Graduate School at the University of MissouriColumbia

In Partial Fulfillment of the Requirements of the Degree

Master of Science

By

TEAGAN SCHNURBUSCH

Dr. Bryon Wiegand, Thesis Supervisor

MAY, 2021 
The undersigned, appointed by the Dean of the Graduate School, have examined the thesis entitled

\section{ASSESSMENT OF GROWTH, PERFORMANCE, AND END-PRODUCT VALUE WHEN HIGH OLEIC SOYBEAN OIL IS FED TO MARKET HOGS, BROILER CHICKENS AND LAYING HENS}

presented by Teagan Schnurbusch

a candidate for the degree of Master of Science

and hereby certify that, in their opinion, it is worthy of acceptance.

Dr. Bryon Wiegand

Dr. John Tummons

Dr. Janet Snow 


\section{ACKNOWLEDGEMENTS}

My time here at the University of Missouri thus far would not have been possible without several individuals, who not only made it possible, but an experience I will never forget. To my committee, Dr. Wiegand, Dr. Tummons, and Dr. Snow, thank you all for your help and guidance on my thesis. I am sure none of you expected a 160-page Master's thesis to read and edit. I greatly appreciate the edits and conversations we were able to have regarding my research. Dr. Wiegand, by some fate we sat next to each other on that bus in D.C. and everyday I am thankful we did. I would certainly not be where I am today without the conversations from that day that lead to a job in your research laboratory. Thank you for helping develop me into a better student, researcher and all-around person over the past few years.

Zachary Callahan I could write pages on all the reasons I am thankful you were here during my Masters program. Most importantly I am thankful for the friendship we have developed. From countless hours running TBARS to you writing thousands of numbers for yolk colors, it was never a dull moment. Thank you for all the help, I could not have made it through these past two and half years without you. We will always be lifelong friends and lifelong cornhole partners.

Sara Gholson, thank you for being my absolute best friend. You have helped me in so many ways. Keeping me fed, keeping me sane, and keeping me grounded. I will never forget our long phone calls, trips to the barns, or our research talks. I am so proud of how far we have come since high school, and especially excited to see where we go in the next five years. 
Mom and Tab, I cannot thank you both enough for all the support. The amount of positivity and encouragement, even when you had no idea what I was talking about. Thank you both for showing me how important time away from research is and how much family means. Big thanks for watching Sarge during judging trips, research sampling and conferences, he enjoyed his time with his Grandma and Aunt Tabby.

To anyone else that I have met along the way. Thank you. I truly believe every person I have encountered along this journey has helped me in some way get to this point, so thank you. 


\section{TABLE OF CONTENTS}

ACKNOWLEDGEMENTS..................................................................... ii

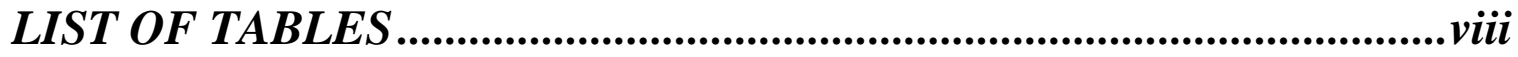

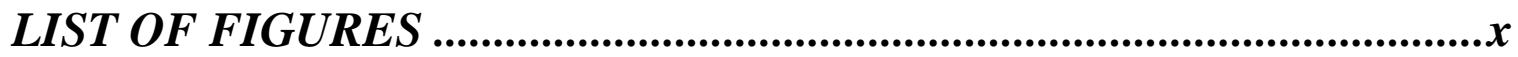

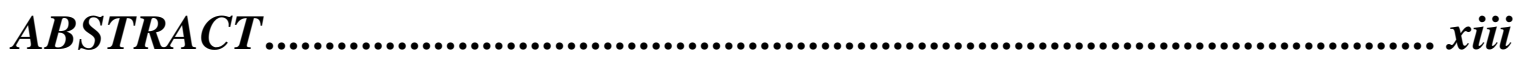

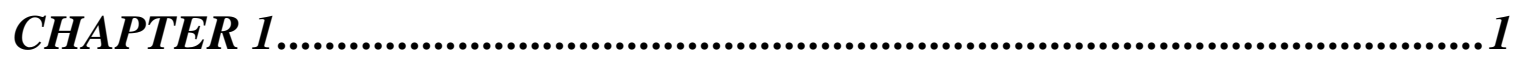

ANIMAL-DERIVED PROTEIN CONSUMPTION ...............................................................1

Global Meat Consumption:............................................................................. 1

Global Chicken Egg Consumption: .............................................................. 2

CONSUMER DEMAND OF ANIMAL DERIVED PROTEINS ........................................2

Consumer Demand for Pork: ......................................................................... 3

Consumer Demand for Broiler Meat: .......................................................... 3

Consumer Demand for Chicken Eggs: ........................................................... 4

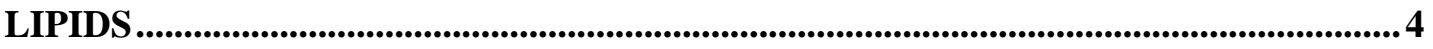

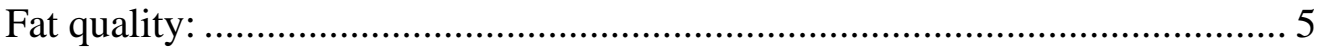

LIPID METABOLISM ..................................................................................................................6

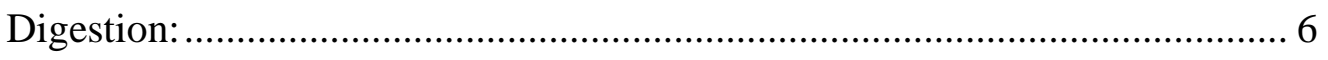

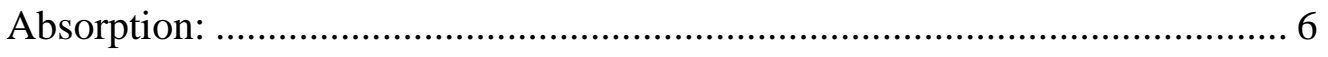

EFFECTS OF DIETARY FAT ALTERATIONS ON PIG PERFORMANCE, PORK

CARCASS COMPOSITION AND PORK QUALITY ...........................................................7

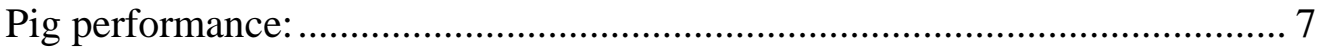

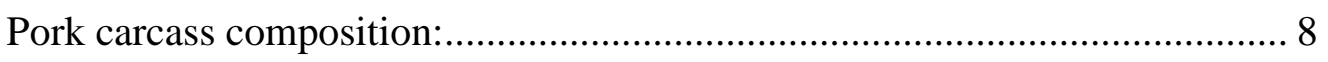

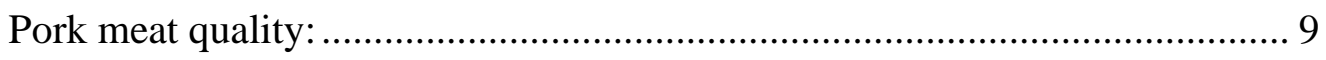

EFFECTS OF DIETARY FAT ALTERATIONS ON BROILER PERFORMANCE, BROILER CARCASS COMPOSITION AND BROILER MEAT QUALITY ...............10

Broiler performance: ...................................................................................... 10 
Broiler carcass composition:.......................................................................... 11

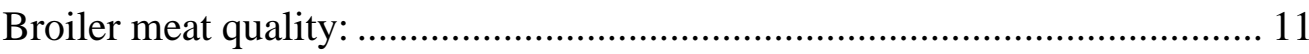

Effects of Dietary Fat Alterations on Laying Hen Performance and Egg Quality ........13

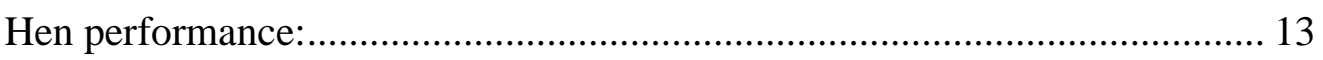

Egg quality:........................................................................................... 14

HIGH OLEIC SOYBEAN OIL ...................................................................................................15

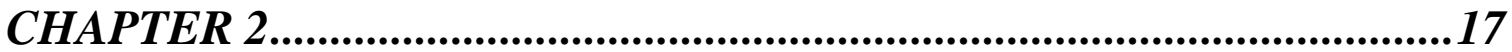

ABSTRACT .................................................................................................................................... 17

INTRODUCTION .......................................................................................................... 19

MATERIALS AND METHODS ..........................................................................................20

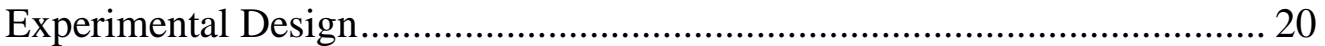

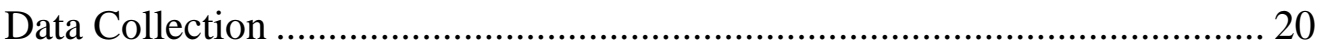

Statistical Analysis.................................................................................. 25

RESULTS ............................................................................................................................26

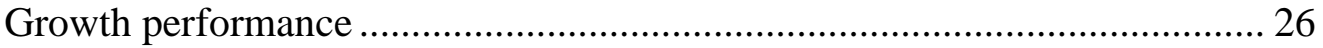

Carcass yield measurements ...................................................................... 26

Fresh meat measurements ......................................................................... 26

Fatty acid analysis .................................................................................... 27

Bacon yield and quality. ....................................................................... 28

Ground pork patty shelf-life analysis.......................................................... 28

DISCUSSION ...................................................................................................................................29

IMPLICATIONS ..................................................................................................................................30

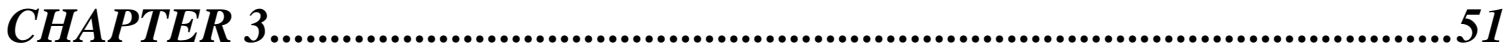

ABSTRACT ...............................................................................................................................51

INTRODUCTION .............................................................................................................................53

MATERIALS AND METHODS ....................................................................................54

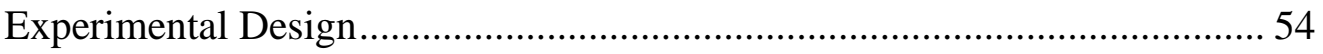

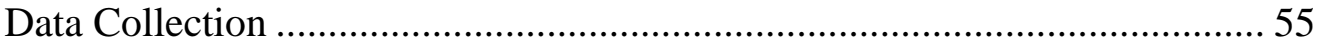




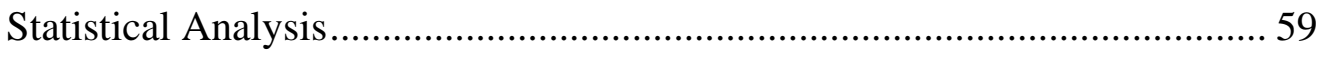

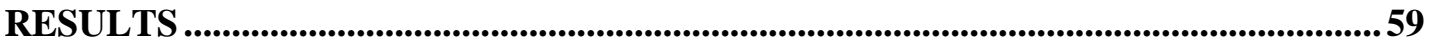

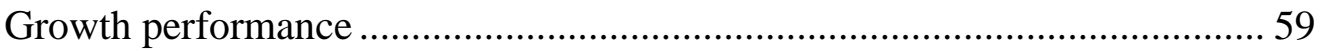

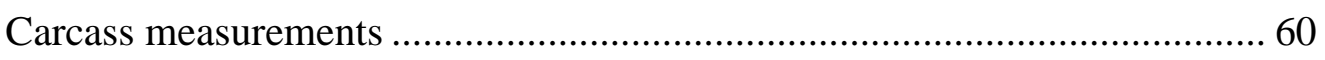

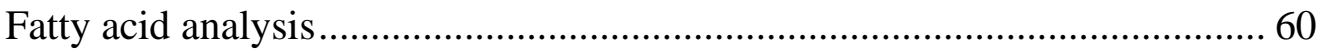

Further processed chicken bratwurst shelf-life........................................ 61

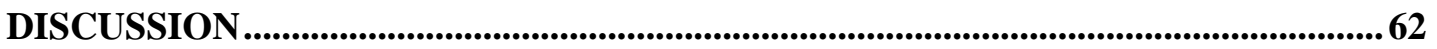

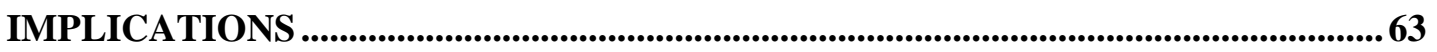

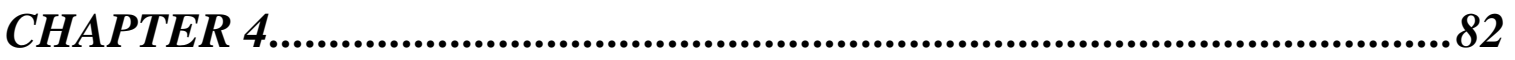

ABSTRACT

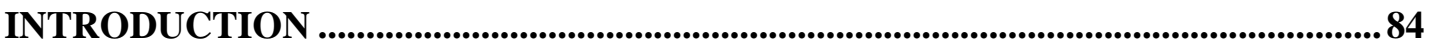

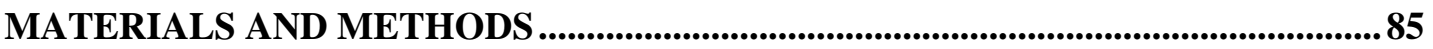

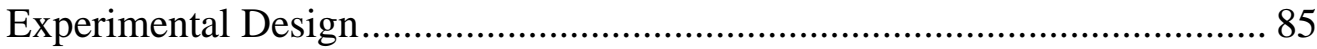

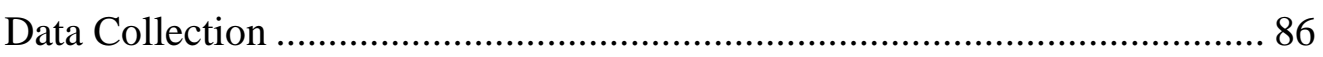

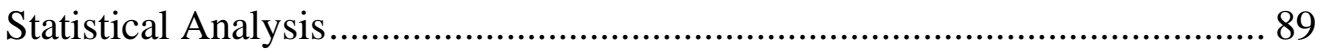

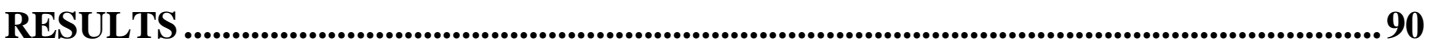

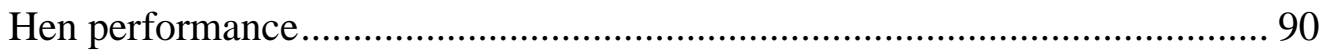

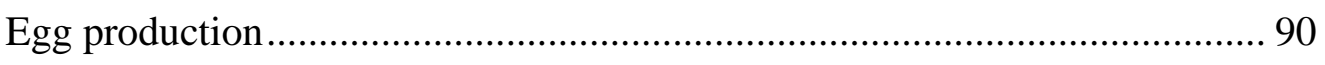

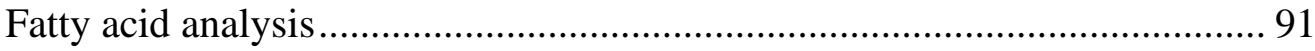

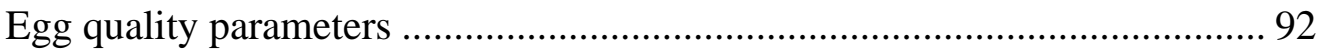

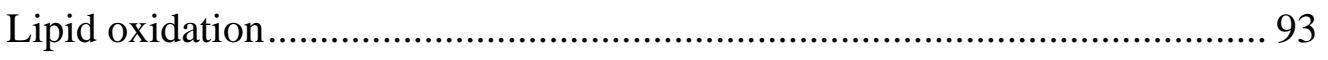

DISCUSSION ................................................................................................................................................93

IMPLICATIONS .....................................................................................................................................94

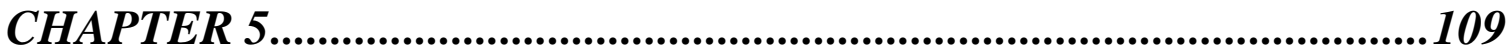

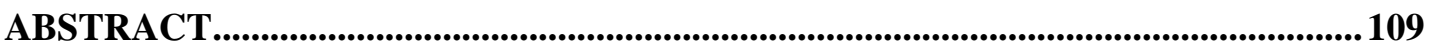

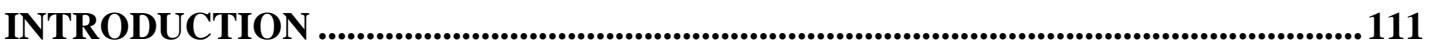

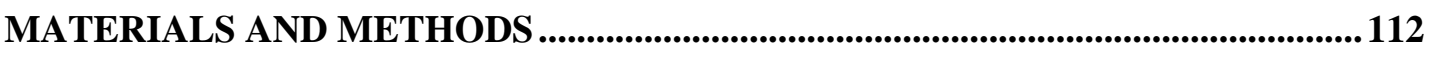

Experimental Design................................................................... 112 


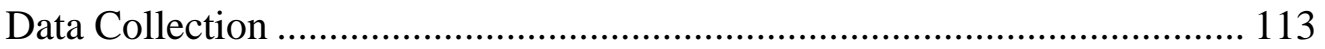

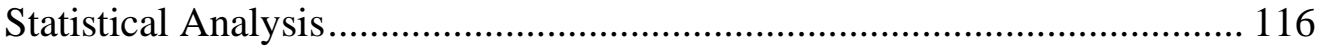

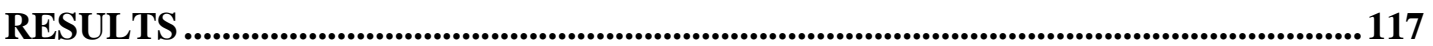

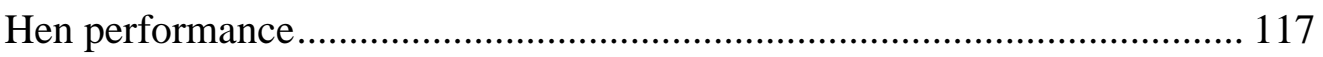

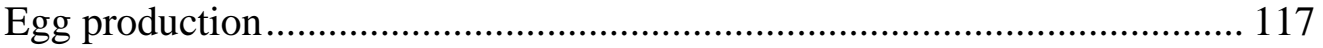

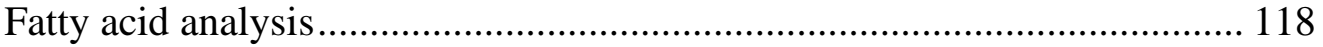

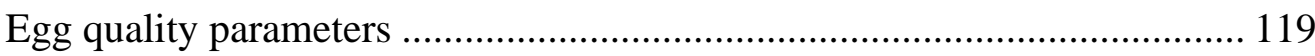

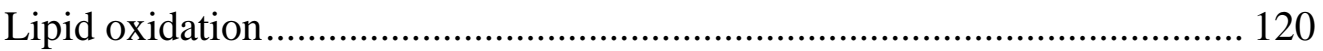

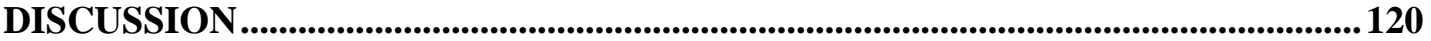

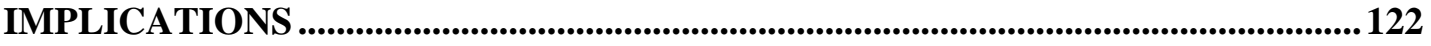

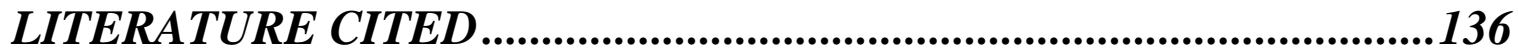




\section{LIST OF TABLES}

2.1. Composition of finisher treatment diets with high oleic soybean oil.

2.2. Fatty acid composition of finisher treatment diets with high oleic soybean oil. .......32

2.3. Amino acid profile of finisher treatment diets with high oleic soybean oil. .............33

2.4. Growth Performance least squares means of barrows fed high oleic soybean oil.....34

2.5. Carcass measurements least squares means of barrows fed high oleic soybean oil. .35

2.6. Fresh meat measurements least squares means of barrows fed high oleic soybean oil. .36

2.7. Moisture and fat percentages of loin chops from barrows fed high oleic soybean oil. 37

2.8. Fatty acid composition of subcutaneous layer 1 from barrows fed high oleic soybean oil. .38

2.9. Fatty acid composition of subcutaneous layer 2 from barrows fed high oleic soybean oil. 39

2.10. Fatty acid composition of jowl fat from barrows fed high oleic soybean oil. .40

2.11. Fatty acid composition of intramuscular fat from barrows fed high oleic soybean oil.

2.12. Bacon slice yield and quality of barrows fed high oleic soybean oil.

3.1. Composition of broiler starter treatment diets with varying inclusion levels of high oleic soybean oil. .65

3.2. Composition of broiler finisher treatment diets with varying inclusion levels of high oleic soybean oil. .66

3.3. Fatty acid composition of broiler starter treatment diets with varying inclusion levels of high oleic soybean oil.

3.4. Fatty acid composition of broiler finisher treatment diets with varying inclusion levels of high oleic soybean oil. 68 
3.5. Amino acid profiles of broiler starter treatment diets with varying inclusion levels of high oleic soybean oil.

3.6. Amino acid profiles of broiler finisher treatment diets with varying inclusion levels of

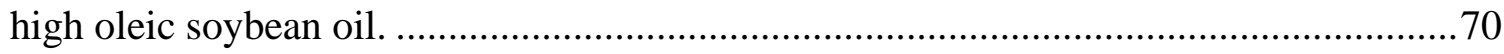

3.7. Growth Performance of broilers fed high oleic soybean oil......................................71

3.8. Carcass measurements of broilers fed high oleic soybean oil. ..................................72

3.9. Fatty acid composition of fat pads from broilers fed high oleic soybean oil.............73

3.10. Moisture and fat content of chicken bratwurst from broilers fed high oleic soybean oil.

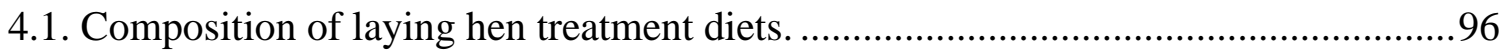

4.2. Fatty acid composition of laying hen treatment diets.............................................97

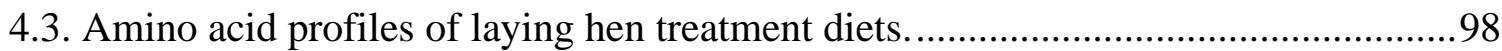

4.4. Growth Performance least squares means of laying hens fed high oleic soybean oil and commodity soybean oil..........................................................................................

4.5. Fatty acid profile of egg yolks from laying hens fed high oleic soybean oil and commodity soybean oil......................................................................................... 105

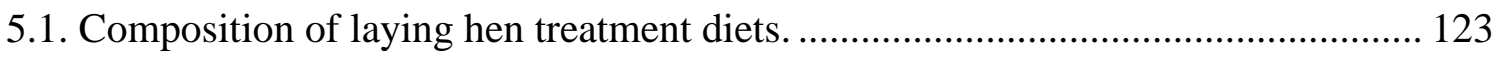

5.2. Amino acid profiles of laying hen treatment diets................................................ 124

5.3. Fatty acid composition of laying hen treatment diets......................................... 125

5.4. Growth Performance least squares means of laying hens fed high oleic soybean oil and commodity soybean oil..................................................................................... 126

5.5. Fatty acid profile of egg yolks from laying hens fed high oleic soybean oil and commodity soybean oil 130 


\section{LIST OF FIGURES}

Figure

2.1. L* values of ground pork patties during 5 days in retail display from barrows fed high oleic soybean oil.

2.2. $\mathrm{a}^{*}$ values of ground pork patties during 5 days in retail display from barrows fed high oleic soybean oil.

2.3. $b^{*}$ values of ground pork patties during 5 days in retail display from barrows fed high oleic soybean oil. 45

2.4. a/b values of ground pork patties during 5 days in retail display from barrows fed high oleic soybean oil. 46

2.5. Hue angle values of ground pork patties during 5 days in retail display from barrows fed high oleic soybean oil. 47

2.6. Metmyoglobin values of ground pork patties during 5 days in retail display from barrows fed high oleic soybean oil. .48

2.7. Dexoxymyoglobin values of ground pork patties during 5 days in retail display from barrows fed high oleic soybean oil.

2.8. Oxymyoglobin values of ground pork patties during 5 days in retail display from barrows fed high oleic soybean oil. .50

3.1. TBAR values of chicken bratwurst from broilers fed high oleic soybean oil. ..........74

3.2. $\mathrm{L}^{*}$ values of chicken bratwurst from broiler fed high oleic soybean oil. ..................75

3.3. $\mathrm{a}^{*}$ values of chicken bratwurst from broilers fed high oleic soybean oil. ................76

3.4. $b^{*}$ values of chicken bratwurst from broilers fed high oleic soybean oil. ................77

3.5. a:b ratio values of chicken bratwurst from broilers fed high oleic soybean oil.........78

3.6. Saturation index values of chicken bratwurst from broilers fed high oleic soybean oil.

.79

3.7. Hue angle values of chicken bratwurst from broilers fed high oleic soybean oil......80 
4.1 Average daily egg count of laying hens fed high oleic soybean oil and commodity soybean oil. 100

4.2 Average egg weight during laying cycle 1 of laying hens fed high oleic soybean oil and commodity soybean oil. 101

4.3 Average egg weight during laying cycle 2 of laying hens fed high oleic soybean oil and commodity soybean oil. 102

4.4. $\mathrm{L}^{*}$ values of egg yolks from laying hens fed high oleic and commodity soybean oil, over weeks in cold storage. 104

4.5. a* values of egg yolks from laying hens fed high oleic and commodity soybean oil, over weeks in cold storage. 105

4.6. $b^{*}$ values of egg yolks from laying hens fed high oleic and commodity soybean oil, over weeks in cold storage. 106

4.7. Roche color fan score values of egg yolks from laying hens fed high oleic and commodity soybean oil, over weeks in cold storage. 107

4.8. TBAR values of egg yolks from laying hens fed high oleic and commodity soybean oil. 108

5.1 Average daily egg count of laying hens fed high oleic soybean oil and commodity soybean oil. 127

5.2 Average egg weight during laying cycle 1 of laying hens fed high oleic soybean oil and commodity soybean oil. 128

5.3 Average egg weight during laying cycle 2 of laying hens fed high oleic soybean oil and commodity soybean oil. 129

5.4. L* values of egg yolks from laying hens fed high oleic and commodity soybean oil, over weeks in cold storage. 131

5.5. a* values of egg yolks from laying hens fed high oleic and commodity soybean oil, over weeks in cold storage. 132

5.6. $b^{*}$ values of egg yolks from laying hens fed high oleic and commodity soybean oil, over weeks in cold storage.

5.7. Roche color fan score values of egg yolks from laying hens fed high oleic and commodity soybean oil, over weeks in cold storage. 134 
5.8. TBAR values of egg yolks from laying hens fed high oleic and commodity soybean

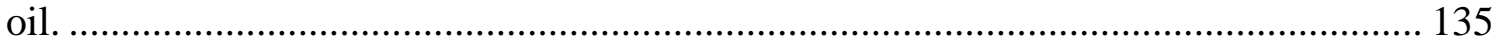




\title{
ASSESSMENT OF GROWTH, PERFORMANCE, AND END-PRODUCT \\ VALUE WHEN HIGH OLEIC SOYBEAN OIL IS FED TO MARKET \\ HOGS, BROILER CHICKENS AND LAYING HENS
}

Teagan Schnurbusch

Advisor: Dr. Bryon Wiegand

\begin{abstract}
For the past decade consumers have become more aware of the food they are eating and demand healthier animal products. The use of dietary oils has allowed the livestock industry to manipulate the fatty acid profiles of various animal products, allowing these products to provide consumers with healthier fats. Recent efforts have been placed on increasing monounsaturated fatty acids in human diets. Thus, research has been conducted by manipulating dietary oils to include higher levels of monounsaturated fats in the diet, in turn monogastric tissues alter their fatty acid profiles, providing a healthier product. Little to no research has been done thus far that includes the use of high oleic soybean oil and the effects it can have in the monogastric diet. Therefore, the objective of this project was to evaluate the effects of high oleic soybean oil on growth, performance, and end-product value of market hogs, broiler chickens and laying hens.
\end{abstract}

Barrows $(n=40)$ were individually housed in pens, stratified by body weight and randomly assigned to one of five treatments: $0 \%, 2 \%, 4 \%, 6 \%$, and $8 \%$ of added high oleic (HO) soybean oil. Pigs were fed ad libitum for $38 \mathrm{~d}$ prior to harvest $(94.3 \mathrm{~kg} \pm 15.38)$. Feed 
refusal and individual pig weights were collected every $7 \mathrm{~d}$ and used to calculate average daily gain (ADG), gain-to-feed (G:F), and average daily feed intake (ADFi). Following harvest, carcass quality was determined by loin objective color $\left(L^{*}, a^{*}\right.$ and $\left.b^{*}\right)$, fat composition and marbling percentages. Fat samples were removed from multiple fat depots (jowl, loin subcutaneous layer 1 and 2, and belly) and analyzed for fatty acid composition. Sample chops were removed between the $10^{\text {th }}$ and $11^{\text {th }}$ rib of the left side of each carcass and analyzed for fatty acid composition, moisture and fat content. Growth performance, carcass characteristics, and fatty acid composition were analyzed using GLM procedure of SAS. Significance was determined at $P$-value $<0.05$. No differences were detected for ADG across treatments $(P=0.3431)$. Barrows fed $0 \%$ added oil had a higher ADFi compared to barrows fed $4 \%$ added oil $(P=0.0251)$. Inclusion of dietary oil at 4,6 , and $8 \%$ increased feed efficiency compared to 0 and $2 \%(P=0.033)$. Dietary treatments did not impact carcass characteristics or carcass quality $(P>0.05)$. Dietary treatments did not impact total polyunsaturated fatty acids (PUFA) $(P>0.05)$. Increasing levels of $\mathrm{HO}$ oil lead to a linear decrease in total saturated fatty acids (SFA) $(P<0.05)$. There was a linear increase across dietary treatments for total monounsaturated fatty acids (MUFA) and iodine value (IV) for the five fat depots. For subcutaneous layer 1 and 2, the ratio of PUFA to SFA increased across dietary treatments; however, the ratio was not impacted in the jowl fat depot $(P>0.05)$.

Male Ross 308 broiler chicks $(\mathrm{n}=300)$ were sorted by weight and randomly assigned to one of five treatments containing five replicate pens with 12 broilers each. Treatment groups consisted of corn-soy mash diets that included $0 \%, 2 \%, 4 \%, 6 \%$, and $8 \%$ of added HO soybean oil. Broilers received, ad libitum, a two-phase diet consisting of a 
starter (d0-21) and a grower (d21-41) phase. Body weight (BW) and feed intake (FI) were recorded weekly and used to calculate feed to gain ratio (F:G). Broilers were slaughtered over a three day kill schedule on $\mathrm{d} 41, \mathrm{~d} 42, \mathrm{~d} 43$, after which carcasses were weighed and fabricated. Hot carcass weights were recorded to obtain dressing percentage (DP). Samples of abdominal fat pads were taken for fatty acid profile analysis. Thigh and boneless, skinless breast meat were removed, packaged by pen and frozen for further analysis. Approximately three pounds of thigh and boneless, skinless breast meat were ground, seasoned and linked into five, approximately 114-gram, bratwurst links. Bratwursts were placed on Styrofoam trays and overwrapped with polyvinyl chloride (PVC), then placed into retail display cases $\left(4^{\circ} \mathrm{C}\right)$ and used for collection of thiobarbituric acid reactive substances (TBARS) on day 0, 1, 3, 5, and 7 of storage. Data were analyzed using PROC GLM procedure in SAS, with level of significance set at $\mathrm{P} \leq 0.05$. ADFi significantly decreased across treatments as the percent of added $\mathrm{HO}$ oil increased ( $\mathrm{P}=0.0002)$. F:G ratio significantly decreased as the percent of added $\mathrm{HO}$ oil increased $(\mathrm{P}=0.0063)$. Abdominal fat pads significantly increased in weight as the percent of included $\mathrm{HO}$ oil increased $(\mathrm{P}<0.0001)$. Diet changed $(\mathrm{P}<0.001)$ the proportion of SFA, MUFA, and PUFA in abdominal fat pads. Percent of C18:0 was lower in broilers fed 0\% and 2\% compared to $4 \%, 6 \%$, and $8 \%$ added $\mathrm{HO}$ oil $(\mathrm{P}<0.0001)$. Total SFA decreased as the amount of added HO oil increased $(\mathrm{P}<0.0001)$. Percent of $\mathrm{C} 16: 1$ decreased as the level of $\mathrm{HO}$ oil added increased $(\mathrm{P}<0.0001)$. Percent of $\mathrm{C} 18: \ln 9$ increased significantly as the level of $\mathrm{HO}$ oil increased $(\mathrm{P}<0.0001)$. Broilers fed $0 \%$ and $2 \%$ added $\mathrm{HO}$ oil had higher amounts of C18:1n7 compared to broilers fed $4 \%, 6 \%$, and $8 \%$ added $\mathrm{HO}$ oil ( $\mathrm{P}=0.0003$ ). Total MUFA increased significantly as the amount of added $\mathrm{HO}$ oil increased $(\mathrm{P}<0.0001)$. Percent of 
C18:2n6 was higher in broilers fed $0 \%$ and $2 \%$ compared to $4 \%, 6 \%$, and $8 \%$ added $\mathrm{HO}$ oil $(\mathrm{P}<0.0001)$. Percent of $\mathrm{C} 18: 3 \mathrm{n} 3$ increased across treatments as level of added $\mathrm{HO}$ oil increased $(\mathrm{P}<0.0001)$. PUFA:SFA ratio increased as the level of added $\mathrm{HO}$ oil increased $(\mathrm{P}<0.0001)$. Results of lipid oxidation showed on day 7 of retail display bratwurst from broilers fed the $0 \%$ and $2 \%$ added $\mathrm{HO}$ oil had lower values of malonaldehyde formed compared to the higher fat diets $4 \%, 6 \%$, and $8 \%(\mathrm{P}<0.0001)$.

White Leghorn laying hens $(\mathrm{n}=192)$ were randomly sorted into 24 pens and randomly assigned to one of three treatments: $0.6 \%$ added conventional soybean oil $(\mathrm{CON}), 3 \%$ added high oleic soybean oil (HO), and 3\% conventional soybean oil (SOY). Hens were fed ad libitum access for 32-weeks, force molted and then returned to treatment for laying cycle two. Feed refusal and pen weights were collected monthly and used to calculate average hen body weight (BW) and feed intake (FI). Eggs were collected daily to calculate average lay rate per hen. Eggs were sampled weekly to measure egg weight size. Eggs were sampled monthly, placed into cold storage for 0,8 , or 12 weeks, and then analyzed for color and fatty acid composition. Data were analyzed using PROC GLM procedure of SAS and significance was set at P-value $<0.05$. Hens on the $\mathrm{HO}$ diet weighed more than hens on the CON and SOY $\operatorname{diet}(\mathrm{P}=0.0002)$. No differences were observed between treatments for feed intake $(\mathrm{P}=0.6941)$. Hens consuming the $\mathrm{HO}$ diet had a higher average daily lay rate compared to hens on the CON and SOY diets $(\mathrm{P}<0.0001)$. Egg weights were heavier for $\mathrm{HO}$ treatment compared to the $\mathrm{CON}$ and SOY treatments during the first laying cycle $(\mathrm{P}=0.0002)$. Diet changed the proportion of SFA, MUFA, and PUFA in egg yolk fat $(\mathrm{P}<0.001)$. The HO treatment decreased in total SFA, while the CON and SOY treatments resulted in no changes $(\mathrm{P}<0.0001)$. Total MUFA for HO treatment 
increased, while the SOY treatment decreased in total MUFA, and the CON treatment resulted in no change $(\mathrm{P}<0.0001)$. The HO treatment decreased in total PUFA, SOY treatment had a significant increase, and the CON treatment resulted in no change in total PUFA $(\mathrm{P}<0.0001)$. HO eggs had a significant increase in $\mathrm{C} 18: 1 \mathrm{n} 9(\mathrm{P}<0.0001)$. SOY eggs had a significant increase in $\mathrm{C} 18: 2 \mathrm{n} 6$ and $\mathrm{C} 18: 3 \mathrm{n} 3$ ( $\mathrm{P}<0.0001)$. Eggs from hens fed the HO diet resulted in higher $b^{*}$ values (more yellow) and higher $a^{*}$ values (more red) compared to eggs from SOY treatment $(\mathrm{P}<0.05)$. Subjective color measures recorded using the Roche yolk color fan found HO eggs had higher (more intense yellow-orange) Roche color fan scores compared to CON and SOY treatment eggs $(\mathrm{P}<0.0001)$ throughout time in cold storage.

Red Sex Link laying hens ( $\mathrm{n}=192)$ were randomly sorted into 24 pens and randomly assigned to one of three treatments: $0.6 \%$ added conventional soybean oil $(\mathrm{CON}), 3 \%$ added high oleic soybean oil (HO), and 3\% conventional soybean oil (SOY). Hens were fed ad libitum access for 34-weeks, force molted and then returned to treatment for laying cycle two. Feed refusal and pen weights were collected monthly and used to calculate average hen body weight (BW) and feed intake (FI). Eggs were collected daily to calculate average lay rate per hen. Eggs were sampled weekly to measure egg weight size. Eggs were sampled monthly, placed into cold storage for 0,8 , or 12 weeks, and then analyzed for color and fatty acid composition. Data were analyzed using PROC GLM procedure of SAS and significance was set at P-value $<0.05$. Hens on the SOY diet weighed more than hens on the $\mathrm{CON}$ diet $((\mathrm{P}=0.0481)$. Hens consuming the $\mathrm{HO}$ diet consumed a lower amount of feed compared to the CON and SOY treatments $(\mathrm{P}=0.0245)$. Hens consuming the HO diet had a lower average daily lay rate compared to hens on the CON and SOY diets $(\mathrm{P}=0.0325)$. 
No differences were detected in egg weight size between treatments during the first or second laying cycle $(\mathrm{P}=0.1377, \mathrm{P}=0.7826)$. Diet changed the proportion of SFA, MUFA, and PUFA in egg yolk fat $(\mathrm{P}<0.001)$. The HO treatment decreased in total SFA, while the CON and SOY treatments resulted in no changes $(\mathrm{P}<0.0001)$. Total MUFA for HO treatment increased, while the SOY treatment decreased in total MUFA, and the CON treatment resulted in no change $(\mathrm{P}<0.0001)$. The HO treatment decreased in total PUFA, SOY treatment resulted in a significant increase, and the CON treatment resulted in no change in total PUFA $(\mathrm{P}<0.0001)$. HO eggs had a significant increase in $\mathrm{C} 18: 1 \mathrm{n} 9(\mathrm{P}<$ 0.0001). SOY eggs had a significant increase in $\mathrm{C} 18: 2 \mathrm{n} 6$ and $\mathrm{C} 18: 3 \mathrm{n} 3(\mathrm{P}<0.0001)$. Objective egg color measures resulted in an effect of weeks in storage ( $\mathrm{P} \leq 0.05)$, but no treatment effects were observed. Subjective color measures recorded using the Roche Yolk color score fan found SOY eggs were a lighter yellow compared to CON and HO treatment eggs $(\mathrm{P}<0.0001)$ throughout time in cold storage. 


\section{CHAPTER 1}

\section{LITERATURE REVIEW}

\section{ANIMAL-DERIVED PROTEIN CONSUMPTION}

\section{Global Meat Consumption:}

Meat consumption can vary widely throughout the world, in developed countries such as the USA, meat counts as a significant portion of the diet, contributing to protein, energy, and fat intake (Daniel et al., 2010). Meat consumption has been increasing significantly since the 1980 s to today (Godfray et al., 2018, Gonzalez et al., 2020). A significant increase in meat consumption can be attributed to increases in population and individual incomes (Daniel et al., 2010, Godfray et al., 2018, Gonzalez et al., 2020). Specifically, there have been large increases in chicken and pork consumption globally (Godfray el al., 2018). Increases in chicken and pork consumption can be attributed to changes in consumer health concerns, prices, and livestock production technology (Guenther et al., 2005). As countries continue to develop, meat consumption can be expected to continue to rise, producers and processors should consider the above factors when developing products for consumers. 


\section{Global Chicken Egg Consumption:}

Chicken eggs provide a multitude of nutritious components including essential amino acids, B vitamins, A vitamin, iron, fatty acids and vitamin D, while maintaining a low-cost (Conrad et al., 2017, Feddern, et al., 2017). Chicken egg consumption has varied widely in the past due to health concerns associated with human cholesterol levels, cardiovascular diseases and type II diabetes (Geiker et al., 2017). However, in data collected from USDA in 2019, chicken egg consumption in the United States was 293.6 eggs per person, up from 287.5 in 2018.

\section{CONSUMER DEMAND OF ANIMAL DERIVED PROTEINS}

In recent decades, consumers have continued to grow conscious of meat quality, the perceived healthiness of their food, but also how that meat is produced and processed (Teixeira and Rodrigues, 2020; Lusk, 2018b). Consumer's perceptions of healthy meat now consider physical and chemical composition, nutritional quality, sensory properties, and sociodemographic aspects (Teixeira and Rodrigues, 2020). Producers and processors should consider the above factors when evaluating the production of animal derived protein products, further processing techniques, and marketing and branding of these products. 


\section{Consumer Demand for Pork:}

Consumer demand for pork is continuing to grow. Data from the United States Department of Agriculture Economic Research Service (USDA-ERS) showed February 2020 hog prices to be $\$ 53.93$ per hundredweight, almost 33 percent higher than a year earlier. Hog prices are expected to increase to $\$ 55.75$ per hundredweight in 2021 (USDAERS, 2021). Pork processing facilities currently do not pay premiums/enforce discounts based off quality (Lusk et al., 2018a). However, there has been much discussion on USDA implementing pork grading systems, also inviting public comments on grading changes being purposed (Federal Register, 2017). Consumers have continuously been demanding healthier pork products, producers and processors are still working towards ways to produce, process, and market healthier pork products.

\section{Consumer Demand for Broiler Meat:}

Chicken broiler meat continues to dominant the meat industry. According to USDA-ERS, broiler slaughter volume for January 2021 reached 37.3 million birds per day, equal with January 2020 numbers (USDA-ERS, 2021). Over the past few decades, broiler production has drastically reduced the time needed for broilers to reach market weight (Lusk, 2018b). This increase in efficiency now has consumers concerned with animal welfare practice related to the production of broiler meat (Lusk, 2018b). Consumers are certainly concerned with quality of their meat products, but there has been an over whelming increase in consumers concerns related to how the animal was raised and produced. 


\section{Consumer Demand for Chicken Eggs:}

Consumer demand for chicken eggs has been steady, but more recently consumers have raised concern with the egg production industry. Majority of the chicken eggs produced worldwide are coming from cage-based systems, consumers perceive this to be an animal welfare issue and have been urging for alternative production systems (Rondoni et al., 2020). While consumers have raised these concerns, chicken egg demand and prices are still holding steady. Chicken egg prices for 2021 are expected to reach 114.3 cents per dozen, a two percent increase from last year (USDA-ERS, 2021).

\section{LIPIDS}

Lipids play a vital role in meat quality, influencing shelf-life, nutritional value, and processing procedures (Wood, 2003). Lipids also serve in many other roles in the body, as an energy source for the body, transporter for lipid-soluble vitamins, and other cellular membrane structures and functions (Nelson and Cox, 2013). Triglycerides are composed of a glycerol backbone with three fatty acids attached (Aberle et al., 2012). Fatty acids are carboxylic acids that include hydrocarbon chains ranging from four to thirty-six carbons in length (Nelson and Cox, 2013). Each fatty acid has different physical and chemical properties that can affect meat quality. Fatty acids are subdivided into three groups: saturated fatty acids (SFA), monounsaturated fatty acids (MUFA), and polyunsaturated fatty acids (PUFA). Saturated fatty acids are saturated in hydrogens, including no double bonds, MUFA include one double bond on their carbon chain, and PUFA include two or 
more double bonds in their carbon chain. Fat and fatty acids are crucial to the nutritional value and meat quality of meat products (Wood, 2008).

\section{Fat quality:}

Quality fat is important for carcass quality, and in terms of meat processing and consumer acceptability (Maw et al., 2003). Fatty acid make-up of fats influences the quality of meat through firmness, color, and lipid oxidative stability of the specific fatty acids (Wood et al., 2003). Individual fatty acids and ratios of saturated vs. unsaturated and MUFA vs. PUFA are used to predict fat quality (Hugo and Roodt, 2007). Firmness is affected by fatty acids through the different melting points for each type of fatty acid. With a higher degree of unsaturation comes a decrease in melting point, for example stearic acid (C18:0) melts at $69.6^{\circ} \mathrm{C}$, oleic acid $(\mathrm{C} 18: 1)$ melts at $13.4^{\circ} \mathrm{C}$, and linoleic acid (C18:2) melts at $-5^{\circ} \mathrm{C}$ (Wood et al., 2003). Soft fat will lead to difficulty during processing, oxidative rancidity, and an undesirable appearance (Maw et al., 2003). Iodine value is a measurement of the degree of unsaturation in lipids, it can be measured from the fatty acid profile or direct titration of the lipid source (Kellner, 2014). Iodine binds to double bonds in fatty acids, leading to higher iodine values implicating a higher amount of unsaturated fatty acids (Benz et al., 2011). Fat cells that contain solidified fat with higher melting points lead to whiter, more desirable fat compared to those with liquid fat with lower melting points (Wood et al., 2003). Fat quality also plays a key role in shelf-life stability of meat products, as unsaturated fatty acids are more prone to oxidation compared to saturated fatty acids, leading to rancidity (Wood et al., 2003). Thus, saturated fatty acids play a key role in stabilizing oxidative stability in meat products. 


\section{LIPID METABOLISM}

\section{Digestion:}

Lipids are insoluble in water, certain chemical and physical events must occur to make these molecules capable of being absorbed in the digestive tract (Johnson, 2007). In the stomach, digesta is mixed with pepsin, small portions of digesta are then passed through into the duodenum. Once passed into the duodenum, cholecystokinin (CCK) is activated which is a signaling molecule that stimulates the pancreas and gallbladder to release secretions for digestion (Johnson, 2007). Bile salts are released from the gallbladder into the duodenum with the primary function being emulsification of fat droplets. Emulsification refers to the suspension of fat droplets held apart by lecithin, bile salts, and other emulsifying agents (Johnson, 2007). The pancreas is stimulated simultaneously as the gallbladder, releasing pancreatic lipase and phospholipase $\mathrm{A}_{2}$ (Johnson, 2007). Pancreatic lipases are secreted in excess and rapidly hydrolyze triglycerides, until their inactivation by bile salts.

\section{Absorption:}

Once lipids are properly digested, absorption begins in the small intestine. Triglycerides which were broken-down into monoglycerides and free fatty acids from pancreatic lipase, form the hydrophobic center of micelles. Phospholipids and bile salts form mixed micelles. Micelle formation increases the amount of lipid molecules that are accessible to water-soluble lipases in the intestine (Nelson and Cox, 2013). The structure

of a micelle is formed as having a hydrophobic core and hydrophilic outer surface. Micelle 
formation is key to the absorption of lipids, the structure of micelles allow the molecule to be water-soluble. The formed micelle will then diffuse across the unstirred water layer bringing several fatty acids and monoglycerides into the enterocyte (Johnson, 2007).

Once absorbed by the enterocyte, monoglycerides and free fatty acids are resynthesized into triglycerides. The newly formed triglycerides are packaged with proteins to form chylomicrons (Nelson and Cox, 2013). Chylomicrons are lipoprotein particles responsible for transporting triglycerides from the intestines to other parts of the body (Johnson, 2007 and Nelson and Cox, 2013).

\section{EFFECTS OF DIETARY FAT ALTERATIONS ON PIG PERFORMANCE, PORK CARCASS COMPOSITION AND PORK QUALITY}

\section{Pig performance:}

As previously stated, consumer trends have led to the manipulation of fat sources in animal diets, to achieve healthier meat products. When manipulating the animal's diet, consideration needs to be given to the effects it can have on animal performance. Altering the fatty acid profile in diets has shown to have no effect on animal performance in terms of average daily gain, feed intake, and gain to feed ratio (Tartrakoon et al, 2016, Mitchaothai et al., 2007). Moreover, results from Benz et al., showed no differences in ADFI or G:F from barrows fed soybean oil or choice white grease.

However, inclusion level of added fat in the diet has shown to increase animal performance. Stephenson et al., showed that pigs fed diets with $4 \%$ added fat had increased 
average daily gain and improved gain to feed ratios compared to pigs fed diets with no added fat. Furthermore, gilts fed a fat blend (beef tallow, sunflower oil and linseed oil) added into the diet had improved feed:gain ratios compared to gilts fed a diet with no added fat (Realini et al., 2010). Pigs fed 6\% added fat, regardless of being choice white grease or poultry fat, saw reduced ADFI and improved gain:feed ratios compared to other treatments including no added fat, $2 \%$ or $4 \%$ added fat (Engel, et al., 2001).

\section{Pork carcass composition:}

Pork carcasses are sold and marketed based off lean yield production. Consideration should be given to potential effects on carcass composition before manipulating dietary fat composition and inclusion level. Treatment diets with three percent oil, formulated to achieve unsaturated fatty acid to saturated fatty acid ratios of 2.5:1 and 5:1, had no impact on hot carcass weight, carcass yield, back fat thickness or carcass length (Tartrakoon et al., 2016). No differences were observed in pigs fed beef tallow or sunflower oil for hot carcass weight, fat to lean ratio or back fat thickness (Mitchaothai et al., 2007). Regardless of fat source, ten percent added fat did not have an affect on hot carcass weight, backfat thickness, or estimated lean percentage compared to pigs fed a diet with no added fat (Realini et al., 2010). Increasing levels of either choice white grease or poultry fat did not impact carcass characteristics, including dressing percentage, carcass length, backfat thickness, longissimuss muscle area or calculated percentages of lean (Engel et al., 2001). 


\section{Pork meat quality:}

Arguably the most important factor to consider when manipulating the diet, is the effect it will have on meat quality. Meat quality, or eating quality, encompass several factors including color, flavor, tenderness, odor and juiciness, all of which are affected by chemical properties of the meat including $\mathrm{pH}$, shear force, water holding capacity, and intermuscular fat content (Alonso et al., 2012). Understanding how dietary changes affect the above factors is crucial when producing pork.

Tartrakoon and others, found diets including three percent added oil (coconut and canola oil) to achieve an unsaturated to saturated fatty acid ratio of 2.5:1 and 5:1, had no influence on longissimus dorsi muscle $\mathrm{pH}$, water holding capacity, shear force, or $\mathrm{a}^{*}$ values (redness) (Tartrakoon et al., 2016). Furthermore, when feeding choice white grease and poultry fat at two, four, or six percent inclusion into the diet, no differences were detected in meat quality parameters which included visual or instrumental color, drip loss, waterbinding capacity, cook loss or shear-force values (Engel et al., 2001). Flavor precursors, instrumental color values, drip loss, and $\mathrm{pH}$ values of the longissimus dorsi saw no differences in pigs fed diets containing either three percent palm oil or three percent rapeseed oil (Tikk et al., 2007).

As mentioned previously consumers are driving for healthier pork products, which can be accomplished in two ways: 1 . Reduce the amount of fat on the pork carcass 2 . Alter the fatty acid profile of the pork. Altering the fatty acid profile can lead to improved benefits for the consumer but can also lead to difficulties for the meat processor. Alonso and others found lipid oxidation values from pigs fed one percent animal fat were higher compared to pigs fed one percent soybean oil and one percent calcium soaps of palm oil 
(Alonso et al., 2012). Iodine value (IV) is a measure of double bonds present, the higher the IV the more double bonds present (Kellner et al., 2014). A high IV results in soft fat and increased susceptibility for lipid oxidation. Kellner and others, feed tallow, choice white grease, and corn oil at either three or six percent of the diet to barrows and gilts. They found that corn oil increased IV, followed by choice white grease and finally tallow barrows having the lowest IV value (Kellner et al., 2014). Identifying that varying fatty acid types can lead to lipid oxidation differences, which can impact overall storage shelf life and rancidity of the product.

\section{EFFECTS OF DIETARY FAT ALTERATIONS ON BROILER PERFORMANCE, BROILER CARCASS COMPOSITION AND BROILER MEAT QUALITY}

\section{Broiler performance:}

Alterations in dietary fatty acids can lead to changes in broiler growth performance. From days 21 to 41, broilers fed six percent beef tallow had higher daily weight gain compared to broilers fed six percent soybean oil or six percent poultry grease (Azman et al., 2005). However, this increase in body weight gain came at the price of these broilers consuming more feed, thus there were no differences observed between treatments for their feed conversion ratio or final body weight (Azman et al., 2005). Broilers fed a diet consisting of high levels of saturated fatty acids resulted in a larger feed to gain ratio compared to animals fed diets high in unsaturated fatty acids, animals fed this diet required 
more feed to gain (Zollitsch et al., 1997). Broilers fed diets containing animal fat blends or sunflower oil did not see any differences in weight gain, final weight, or feed to gain ratios (Sanz et al., 1999). However, Sanz and others also compared inclusion level on broiler growth performance, and regardless of fat type, as inclusion level increased the final body weight and weight gain increased and feed to gain ratio decreased (Sanz et al., 1999). Furthermore, broilers fed high oleic sunflower oil and conventional sunflower oil saw no differences in growth performance (Ortiz et al., 2006).

\section{Broiler carcass composition:}

Broiler production over the past several years has led to mass production of heavy weight birds in a much shorter time (Mir et al., 2017). With the demand of chicken continuing to rise, attention needs to be put one how dietary manipulation can affect the chicken carcass. Birds fed a diet containing sunflower oil had a significant decrease in abdominal fat pad weight compared to birds fed tallow or lard (Sanz et al., 1999). Toomer and others found that broilers fed high oleic peanuts had reduced average live weights, hot carcass weights, and breast size (Toomer et al., 2020). Furthermore, birds fed oxidized oil had lower carcass weights compared to birds fed diets containing fresh oil, no differences were observed for dressing percentage or breast yield (Tavarez et al., 2011).

\section{Broiler meat quality:}

Important components of broiler meat quality include appearance, juiciness, firmness, texture, and tenderness, overall quality influences a consumer's decision in 
purchasing chicken products (Mir et al., 2017). Quantifiable properties including cook loss, $\mathrm{pH}$, shelf life, drip loss, shear force and water holding capacity influence the quality factors listed above and the consumers decision in making a repeat purchase (Mir et al., 2017). There are many factors that can play into broiler meat quality, nutrition, management, slaughter and processing techniques, all work in tandem to influence meat quality.

Worldwide, poultry grading is done on an appearance base, looking at attributes including color, carcass defects, bruising, and skin tares (Mir et al., 2017). Appearance of meat is the first trait noticed by consumers purchasing meat and arguably the most crucial meat quality attribute for this reason (Aberle et al., 2012, Mancini and Hunt, 2005). Consumers associate color of raw or cooked poultry meat with product freshness, ultimately using this to determine whether to purchase a product (Mir et al., 2017). Panelists indicated no differences in fresh meat color of broiler chicken breasts from broilers fed high oleic peanuts or oleic acid (Toomer et al., 2019a).

Palatability drives consumers to make repeat purchases of meat products (Aberle et al., 2012, Maltin et al., 2003). The term palatability encompasses the consumers perception of tenderness, juiciness and flavor (Aberle et al., 2012, Mir et al., 2017, Wood et al., 1999). Breed, genotype, growth rate, nutrition, fiber type and composition play a role in determining tenderness (Maltin et al., 2003). Sensory analysis of cooked poultry meat from broilers fed lard, sunflower oil, or olive oil resulted in no differences in tenderness and juiciness (Ruiz et al., 2001). Moreover, shear force values of chicken breasts from broilers fed high oleic peanuts and oleic acid were not different (Toomer et al., 2019a). Bou and others conducted a sensory panel using trained panelist to determine acceptability of dark leg meat from broilers fed one of four fat sources (beef tallow, sunflower oil, 
oxidized sunflower oil and linseed oil), significant differences were observed in acceptability of leg meat (Bou et al., 2001). However, Toomer and others reported similar sensory scores (color, texture, flavor, and moistness) on chicken breast meat from birds fed diets consisting of high oleic peanuts or oleic acid (Toomer et al., 2019a).

Dietary fatty acid profiles are known to be expressed in monogastric animal tissues (Andersen et al., 2005 and Hugo et al., 2009). This could allow the manipulation of fatty acid profiles to provide certain fatty acids for human consumption, it would also allow for changes in fatty acid profiles that could increase lipid oxidation stability. Increased levels of polyunsaturated fatty acids can lead to a decrease in lipid oxidation stability (Hugo et al., 2009). TBARS values for thigh and breast samples from birds fed fish oil were higher compared to birds fed a diet including tallow, high-oleic sunflower oil or sunflower oil (Hugo et al., 2009). However, diets high in monounsaturated fatty acids have little effect on oxidative stability (Ortiz et al., 2005).

\section{Effects of Dietary Fat Alterations on Laying Hen Performance and Egg Quality}

\section{Hen performance:}

Dietary fatty acid manipulation in the laying hen occurs in hopes of altering the fatty acid composition of the egg. Consideration should be placed on the effects that occur to hen performance. Hens fed animal fat or soybean oil had greater body weight gain 
compared to hens fed a control no added fat diet combined, interestingly, with increased feed intake (Kim et al., 2019). On contrary, Celebi and Macit saw reduced feed intake and improved feed conversion ratio when fed diets containing two percent tallow, one percent tallow + one percent flaxseed oil, two percent sunflower oil, or two percent flaxseed oil (Celebi and Macit, 2008). Hens fed one of six treatments including cottonseed oil, soybean oil, lard, sunflower oil and canola oil saw no difference in hen performance (Filardi et al., 2005). Toomer and others found no differences in hen performance from layers fed high oleic peanuts or soybean meal diet (Toomer et al., 2019b).

\section{Egg quality:}

Quality of eggs is determined by chemical, physical, organoleptic and microbiological factors (Ledvinka et al., 2012). Eggs provide an excellent food source not only for their nutrient components, but also for their long and stable shelf life. Changes to the chemical composition, specifically fatty acids, can lead to alterations in the quality of eggs.

Eggs from hens supplemented with either four percent animal fat or four percent soybean oil, saw a decrease in egg yolk yellowness compared to eggs from hens supplemented with no added fat, two percent animal fat, or two percent soybean oil (Kim et al., 2019). Celebi and Macit found no differences in egg quality parameters from hens supplemented with tallow, sunflower oil, or flaxseed oil (Celebi and Macit, 2008). Eggs from hens fed with soybean oil, recycled soy oil, or acidulated soy oil saw no difference in Roche egg yolk color fan score (Irandoust et al., 2012). However, eggs from hens fed high 
oleic peanuts had higher Roche value scores (more intense yellow orange) compared to eggs from hens feed soybean meal (Toomer et al., 2019b).

Manipulations to egg yolk fatty acids has the potential to effect shelf-life stability of eggs. Eggs from hens fed soybean meal or sunflower seeds resulted in higher TBARS value at 0 days in storage compared to hens fed soybean oil. After 60 days in cold storage eggs from hens fed the soybean oil had significantly higher TBARS values compared to hens fed soybean meal or sunflower seed treatments (Pereira et al., 2011). Soybean oil contains higher values of polyunsaturated fatty acids, which increase lipid oxidation. Furthermore, diets supplemented with flax seed increased egg TBARS values over time in cold storage compared to a basal control diet (Hayat et al., 2010).

\section{HIGH OLEIC SOYBEAN OIL}

High oleic soybean oil has grown in popularity over recent years. According to the United States Soy group, high oleic soybean oil has proposed benefits to food service operators, food manufacturers, human health and environmental impacts. Research has shown high-oleic soybean oil performs longer than standard vegetable oils in hightemperature frying (Qualisoy). The extended use from the high oleic soybean oil comes from the oils improved oxidative stability. Food manufacturers can benefit from using high oleic soybean oil as it can extend shelf life for products and provides a neutral flavor profile which does not interact with other ingredients (Qualisoy). Furthermore, Huth and others,

concluded that consuming high oleic soybean oil in place of oils high in saturated fats and 
trans fat would favorably affect plasma lipids and the risk of coronary heart disease (Huth et al., 2015). 


\title{
CHAPTER 2
}

\section{INCLUSION OF DIETARY HIGH OLEIC SOYBEAN OIL IMPROVES FEED EFFICIENCY AND ALTERS FATTY ACID COMPOSITION IN MULTIPLE FAT DEPOTS IN PORK CARCASSES}

\begin{abstract}
The objective of this study was to determine the effects of dietary high oleic (HO) soybean oil inclusion on the growth performance, carcass quality and fatty acid composition of finishing barrows. Barrows $(n=40)$ were individually housed in pens, stratified by body weight and randomly assigned to one of five treatments: $0 \%, 2 \%, 4 \%$, $6 \%$, and $8 \%$ of added $\mathrm{HO}$ soybean oil. Pigs were fed ad libitum for $38 \mathrm{~d}$ prior to harvest (94.3 $\mathrm{kg} \pm 15.38)$. Feed refusal and individual pig weights were collected every $7 \mathrm{~d}$ and used to calculate average daily gain (ADG), gain-to-feed (G:F), and average daily feed intake (ADFi). Following harvest, carcass quality was determined by loin objective color $\left(L^{*}, a^{*}\right.$ and $\left.b^{*}\right)$, fat composition and marbling scores. Fat samples were removed from multiple fat depots (jowl, subcutaneous layer 1 and 2, and belly) and analyzed for fatty acid composition. Sample chops were removed between the $10^{\text {th }}$ and $11^{\text {th }}$ rib of the left side of each carcass and analyzed for fatty acid composition, moisture and fat content. Growth performance, carcass characteristics, and fatty acid composition were analyzed using GLM
\end{abstract}


procedure of SAS. Significance was determined at $P$-value $<0.05$. No differences were detected for ADG across treatments $(P=0.3431)$. Barrows fed $0 \%$ added oil had a higher ADFi compared to barrows fed $4 \%$ added oil $(P=0.0251)$. Inclusion of dietary oil at 4,6 , and $8 \%$ increased feed efficiency compared to 0 and $2 \%(P=0.033)$. Dietary treatments did not impact carcass characteristics or carcass quality $(P>0.05)$. Dietary treatments did not impact total polyunsaturated fatty acids (PUFA) $(P>0.05)$. Increasing levels of $\mathrm{HO}$ oil lead to a linear decrease in total saturated fatty acids (SFA) $(P<0.05)$. There was a linear increase across dietary treatments for total monounsaturated fatty acids (MUFA) and iodine value (IV) for the five fat depots. For loin subcutaneous layer 1 and 2, the ratio of PUFA to SFA increased across dietary treatments; however, the ratio was not impacted in the jowl fat depot $(P>0.05)$. 


\section{INTRODUCTION}

Over the past decade consumers have changed the pork industry by demanding healthier pork products. Consumption of saturated fatty acids have been shown to impact multiple human health diseases, including coronary heart disease (Mas et al., 2011). Typically, the fatty acid profile of pork contains high concentrations of saturated fatty acids (Aberle et al., 2012; Rentfrow et al., 2003). The drive for healthier pork products has drove the pork industry to manipulate dietary oil sources, to in turn alter the fatty acid profile of pork meat and fat tissues. Different fat sources have shown to have varying impacts on pig performance and pork meat quality (Kellner et al., 2014; Realini et al., 2010; Tartrakoon et al., 2016). There has been previous research utilizing high oleic corn and its effects on fatty acid profiles and further processed bellies (Rentfrow et al., 2003). Others have evaluated the effects of high oleic sunflower oil on pork meat (Cardenia et al., 2011; Boselli et al., 2008). However, there has been minimal research done utilizing high oleic soybean oil in pig diets. Therefore, the purpose of this study was to feed high oleic soybean oil at various inclusion levels and determine the effects on pig performance, carcass and fresh meat quality, and further processed pork products. 


\section{MATERIALS AND METHODS}

The University of Missouri Animal Care and Use Committee approved animal care and experimental protocols prior to initiation of this experiment (\#EX-10094).

\section{Experimental Design}

Single-sired Duroc crossbred barrows $(n=40)$, were selected from half or full sibling sows from Illinois State University Swine Farm.. Barrows were stratified by weight and randomly assigned to one of five treatments containing 8 replicates per treatment. Pigs were housed individually in the Double L Building at the MU Swine Teaching Farm and under the same environmental conditions. Treatments consisted of $0 \%, 2 \%, 4 \%, 6 \%$, and $8 \%$ of added HO soybean oil. Pigs were provided ad libitum access to feed and water for the 38 days of the experiment, until the time of slaughter. Pig weights and quantity of feed consumed by each animal were recorded weekly to determine average daily gain (ADG), average daily feed intake (ADFi), and gain to feed ratio (G:F). On day 38, pigs were slaughtered under USDA inspection at an average finish weight of $120.6 \mathrm{~kg}$ (265.2 pounds). Carcasses were weighed, then chilled for 24 hours. Carcass measurements were recorded at 24 hours postmortem. Carcasses were then fabricated to obtain samples as the methods outline below.

\section{Data Collection}

Growth performance. Feed refusal and individual body weights of pigs were recorded weekly from the start of the study until harvest. Feed consumption was calculated 
from recorded weights of feed given and residual feed. Feed consumption and individual body weights were used to calculate ADG, ADFi, and G:F.

Carcass measurements. Hot carcass weights (HCW) were recorded immediately after slaughter, used in conjunction with final live weight to calculate dressing percentage for each animal. 24 hours postmortem the left side of the carcasses were ribbed between the $10^{\text {th }}$ and $11^{\text {th }}$ rib, loin eye area, backfat thickness at the tenth rib and fat thickness at the last rib were taken. Loin eye area was measured in square inches using a grid (Iowa State University, Ames, IA) and fat thickness was measured in tenths of an inch utilizing a probe (Nasco, Wisconsin). Tenth rib fat was measured $3 / 4$ around the loin eye from the backbone and last rib fat thickness was taken adjacent to the split surface of the backbone next to the last rib.

Fresh meat measurements. A portable $\mathrm{pH}$ meter (Meat Probes, Inc., Topeka, KS, USA) was utilized to determine the $\mathrm{pH}$ of the loin muscle between the $10^{\text {th }}$ and $11^{\text {th }}$ rib. Subjective marbling and color scores were analyzed using the exposed loin eye surface at the $10^{\text {th }}$ and $11^{\text {th }}$ ribs. Subjective marbling scores were recorded using the National Pork Board marbling standards, 1.0 is considered devoid and 10.0 is considered abundant amounts of marbling. Subjective color scores were recorded using the National Pork Board color standards, 1.0 is considered pale pinkish gray to white and a 6.0 is considered dark purplish red. Objective color was measured by the CIE system L* (lightness), a* (redness), and $b^{*}$ (yellowness) using a HunterLab MiniScan Spectrocolorimeter (MiniScan XE; Hunter and Assoc., Reston, VA) with a $2.5 \mathrm{~cm}$ port and glass cover calibrated against a white tile. Instrumental color readings were utilized to calculate $\mathrm{a} / \mathrm{b}$ ration, saturation index (SI), and hue angle (HA) values. 
Myoglobin concentration. Myoglobin concentrations, deoxymyoglobin (Dmb), oxymyoglobin $(\mathrm{Omb})$ and metmyoglobin $(\mathrm{MMb})$ were determined on the surface of the longissimus dorsi (AMSA, 2012). Reflectance was measured at wavelengths of 470, 530, 570, and $700 \mathrm{~nm}$ which were determine by a HunterLab MiniScan Spectrocolorimeter (MiniScan XE; Hunter and Assoc., Reston, VA). Objective color readings were obtained in triplicate. The reflectance (R) was converted to reflex attenuance (A) using Equation 1. The A-values were then inserted into Equation 2 to calculate $\mathrm{MMb}$ and into Equation 3 to calculate Deoxymyoglobin (DMb). Oxymyoglobin was then calculated using Equation 4:

Equation 1: $\mathrm{A}=\log (1 / \mathrm{R})$

Equation $2: \% \mathrm{MMb}=\{1.395-[(\mathrm{A} 570-\mathrm{A} 700) /(\mathrm{A} 530-\mathrm{A} 700)]\} \times 100$

Equation 3: \% DMb $=\{2.375 x-[1-(\mathrm{A} 470-\mathrm{A} 700) /(\mathrm{A} 525-\mathrm{A} 700)]\} \times 100$

Equation $4: \% \mathrm{OMb}=100-(\% \mathrm{MMb}+\% \mathrm{DMb})$

Moisture and fat content analysis. Determination of fat percentage was performed in triplicate utilizing microwave drying and nuclear magnetic resonance (NMR) as described in Dow et al. (2011) with a CEM SMART Trac rapid fat analysis system 5 (CEM Corp., Matthews, NC, USA). Briefly, two CEM sample pads were heated and dried before 3.75 - $4.5 \mathrm{~g}$ of minced sample was smeared across one pad and topped with the remaining pad. Samples were dried using the CEM Moisture/Solids Analyzer, and moisture was determined on a dry weight basis. Following determination of moisture, sample pads were wrapped in TRAC paper, inserted into a CEM TRAC tube and was placed into the CEM Rapid Fat Analyzer. Fat percentage of samples was then determined on a dry basis using 
NMR and was ultimately converted to a wet basis. Triplicate values were averaged to determine overall moisture and fat percentages for each sample.

Fatty acid analysis. Fatty acid profiles of fat depots (loin subcutaneous layer 1, loin subcutaneous layer 2, jowl, intramuscular) were analyzed according to modified methodologies by Folch et al, (1957) and Morrison and Smith (1964). Approximately 100 mg of sample was homogenized in chloroform:methanol $\left(\mathrm{CHCl}_{3}: \mathrm{CH}_{3} \mathrm{OH}, 2: 1, \mathrm{v} / \mathrm{v}\right)$ in a glass tube to extract lipids. Dehydrated samples were filtered through a sintered glass funnel fitted with a Whatman $2.4 \mathrm{~cm} \mathrm{GF/C} \mathrm{filter.}$

A volume of $8 \mathrm{ml}$ of $0.74 \%$ potassium chloride $(\mathrm{KCl})$ was added to each sample and after two hours, two distinct layers formed. The upper phased was removed and discarded while the lower phase was evaporated to dryness with nitrogen in a water bath. At the point of dryness, $1 \mathrm{ml}$ of $0.5 \mathrm{~N}$ potassium hydroxide $(\mathrm{KOH})$ was added to each tube and heated for 10 minutes in a $70^{\circ} \mathrm{C}$ water bath. The addition of $\mathrm{KOH}$ initiates the saponification reaction, which hydrolyzes fatty acids from a triglyceride molecule. Following this, $1 \mathrm{ml}$ of $14 \% \mathrm{BF} 3$ in $\mathrm{MeOH}$ was added, samples were flushed with nitrogen and heated in the water bath for 30 minutes. Boron trifluoride is highly volatile and acts as an acid catalyst in the transesterification reaction that methylates the acid group on free fatty acids removing the net negative charge. The remaining molecule is known as a fatty acid methyl ester (FAME).

Fatty acid methyl esters are liquefied by adding $2 \mathrm{ml}$ of HPLC grade hexane and 2 $\mathrm{ml}$ of $\mathrm{NaCl}$. Two distinct layers are formed; the upper layer is removed and added to $\sim 800$ $\mathrm{mg}$ of $\mathrm{Na} 2 \mathrm{SO} 4$ to remove any moisture in the sample. At this point, 2 more $\mathrm{ml}$ of hexane was added to the tube containing $\mathrm{NaCl}$ and once more, the upper layer was removed and 
added to the tube containing $\mathrm{Na} 2 \mathrm{SO} 4$. The hexane potion was removed from the salt and added to a labeled scintillation vial. The salt was rinsed once more with $1 \mathrm{ml}$ of hexane and the liquid was added to the vial. Samples were evaporated to dryness in a water bath at $70^{\circ} \mathrm{C}$ under nitrogen flow. Lastly, samples were reconstituted with $1 \mathrm{ml}$ HPLC grade hexane and transferred to gas chromatograph vials.

The stable FAMEs were loaded into a Varian 3,800 gas chromatographer (Varios, Pala Alto, CA) to determine fatty acid profiles. The column utilized was a fused silica capillary column (SPTM-2,560; $100 \mathrm{~m}$ x $0.25 \mathrm{~mm}$ x $0.2 \mu \mathrm{m}$ film thickness; Supelco, Bellefonte, PA). Temperature of the injector was held constant at $240^{\circ} \mathrm{C}$ and temperature of the flame-ionizer detector was held at $260^{\circ} \mathrm{C}$. The oven operated at $140^{\circ} \mathrm{C}$ for 5 minutes (temperature programmed $2.5^{\circ} \mathrm{C} /$ minute to $240^{\circ} \mathrm{C}$ and held for 16 minutes). Helium, the carries gas, was maintained at a constant pressure of 37 psi. Individual fatty acids were expressed as a percentage of the total area under the peaks.

Total saturated fatty acid (SFA), monounsaturated fatty acids (MUFA) and polyunsaturated fatty acid (PUFA) contents were calculated according to the following equations: $\mathrm{SFA}=(\mathrm{C} 12: 0+\mathrm{C} 14: 0+\mathrm{C} 15: 0+\mathrm{C} 16: 0+\mathrm{C} 17: 0+\mathrm{C} 18: 0) ; \mathrm{MUFA}=(\mathrm{C} 16: 1+$ $\mathrm{C} 18: 1 \mathrm{n} 9 \mathrm{c}) ; \mathrm{PUFA}=(\mathrm{C} 18: 2 \mathrm{n} 6 \mathrm{t}+\mathrm{C} 18: 2 \mathrm{n} 6 \mathrm{c})$.

Bacon yield and quality. All slab bacons were further processed at Paradise Meat Locker, Trimble, $\mathrm{MO}$ and cooled at $2^{\circ} \mathrm{C}$. Ten slices were removed from each end and discarded to avoid damaged slices from processing. Slices were individually removed from packaging and arranged in order from shoulder to flank end. Number 1 slices were 
established based on uniformity and desirable lean-to fat ratio of 50:50. Furthermore, number 2 slices were determined by the irregular shape and a higher lean-to fat ration of 60:40 (60 percent lean: 40 percent fat). Lastly, defective slices were categorized as irregular slices, evidence of cartilage and a higher lean-to fat ratio of 80:20 (80 percent lean:20 percent fat). Percent of number 1 , number 2 and defective slices were calculated and recorded.

$$
\begin{aligned}
& \% \text { of Number } 1 \text { Slices }=\# \text { Number } 1 / \text { Total Slices } \\
& \% \text { of Number } 2 \text { Slices }=\# \text { Number } 2 / \text { Total Slices } \\
& \% \text { of Defective Slices }=\# \text { Defective/Total Slices }
\end{aligned}
$$

Ground pork patty shelf-life. Picnic shoulders from barrows were trimmed out, trim was ground through a $0.35 \mathrm{HP}$ meat grinder (Harrison, Ohio, USA), the mixture was ground through a kidney plate and then a $10 \mathrm{~mm}$ grinding plate. Four patties, approximately 114 grams, were created for each sample. Patties were placed on Styrofoam trays individually and overwrapped with polyvinyl chloride (PVC), then placed into retail display cases at $4{ }^{\circ} \mathrm{C}$. One patty from each barrow was removed to be measured on day 0 , 1,3 , and 5 of the shelf-life study. Objective color measures were taken in triplicate as mentioned above using a HunterLab MiniScan Spectrocolorimeter (MiniScan XE; Hunter and Assoc., Reston, VA).

\section{Statistical Analysis}

Collected data was analyzed using SAS 9.4. The least squares mean and standard error were determined for variable according to treatment. An analysis of variance of least 
squares means of treatments for pre-established variable was conducted using PROC GLM to determine if there was an effect of treatment, within each group. A pairwise comparison used to detect potential differences between treatments. Level of significance was set at $\mathrm{P}$ $\leq 0.05$.

\section{RESULTS}

\section{Growth performance}

Results for growth performance are outlined in Table 2.4. No differences were observed for initial body weight $(\mathrm{P}=0.8912)$, final body weight $(\mathrm{P}=0.4337)$, and average daily gain ( $\mathrm{P}=0.3431)$ amoung treatments. Barrows fed $0 \%$ added oil had a higher ADFi compared to barrows fed $4 \%$ added oil $(P=0.0251)$. Treatments $4 \%, 6 \%$, and $8 \%$ had higher G:F ratios compared to $0 \%$ and $2 \%$ treatments $(\mathrm{P}=0.0336)$.

\section{Carcass yield measurements}

Results for carcass measurements are outline in Table 2.5. Inclusion level of dietary high oleic soybean oil had no impact on carcass measurements when looking at $\mathrm{HCW}$ ( $\mathrm{P}=0.3428), \mathrm{DP} \%(\mathrm{P}=0.2364)$, last rib fat $(\mathrm{P}=0.6696), 10^{\text {th }}$ rib fat $(\mathrm{P}=0.9145)$ and loin eye area $(\mathrm{P}=0.4738)$.

\section{Fresh meat measurements}

Results of fresh meat parameters are displayed in Table 2.6. Inclusion level of dietary high oleic soybean oil did not impact fresh meat parameters. No differences were 
observed for subjective marbling score $(\mathrm{P}=0.8859)$, loin $\mathrm{pH}(\mathrm{P}=3774)$, subjective color score $(\mathrm{P}=0.5199)$, or objective color measures $(\mathrm{P}>0.05)$.

\section{Myoglobin concentration}

Table 2.6 includes results of myoglobin concentrations determined utilizing a HunterLab MiniScan Spectrocolorimeter. No differences were observed for Mmb \% $(\mathrm{P}=0.9760), \mathrm{Dmb} \%(\mathrm{P}=0.9415)$, or Omb \% $(\mathrm{P}=0.8816)$.

\section{Moisture and fat content analysis.}

Results for loin moisture and fat analysis is presented in Table 2.7. Dietary high oleic soybean oil level did not impact loin moisture $(\mathrm{P}=0.9104)$ or loin fat percentage $(\mathrm{P}=0.7793)$.

\section{Fatty acid analysis}

Fatty acid compositions of subcutaneous layer 1 (SubQ1) and 2 (SubQ2), jowl, and intramuscular fat are presented in Table 2.8-2.11. SubQ1, SubQ2 and jowl fat followed similar patterns for fatty acid profile analysis. As level of added HO oil increased there was a decrease in 16:0, 16:1 and 18:0 $(\mathrm{P}<0.05)$ for SubQ1, SubQ2, and jowl fat samples. As level of added HO oil increased there was a significant increase in 18:1n9 $(\mathrm{P}<0.05)$. There were no differences observed for 18:2n6 (P>0.05). Total SFA decreased as level of added HO oil increased $(\mathrm{P}<0.05)$. Total MUFA increased as level of added HO oil increased $(\mathrm{P}<0.05)$. Total PUFA saw no differences as level of added HO oil increased $(\mathrm{P}>0.05)$. Iodine values (IV) increased as level of added $\mathrm{HO}$ oil increased $(\mathrm{P}<0.05)$. 
Intramuscular fat samples saw the following results. A decrease in 16:1 as level of added $\mathrm{HO}$ oil increased $(\mathrm{P}=0.0284) .8 \%$ added $\mathrm{HO}$ oil saw a higher percentage of $18: 1 \mathrm{n} 9$ compared to other treatments $(\mathrm{P}<0.05) .6 \%$ added $\mathrm{HO}$ oil saw a higher percentage of 18:2n6 compared to other treatments $(\mathrm{P}<0.05)$. No differences were observed for 16:0 $(\mathrm{P}=0.9999)$ and 18:0 $(\mathrm{P}=0.5659)$ in intramuscular fat. Total SFA decreased as level of added HO oil increased $(\mathrm{P}=0.0032)$. No difference was observed in total MUFA $(\mathrm{P}=0.7630)$. Total PUFA increased as level of added $\mathrm{HO}$ oil increased $(\mathrm{P}<0.05) .0 \%$ and $2 \%$ added $\mathrm{HO}$ oil had lower IV compared to $4 \%, 6 \%$, and $8 \%$ added $\mathrm{HO}$ oil ( $\mathrm{P}=0.0032)$.

\section{Bacon yield and quality.}

Bacon yield and quality data is represented in Table 2.12. Treatment did not impact bacon yield and quality parameters when looking at moisture \% ( $\mathrm{P}=0.7401)$, fat \% $(\mathrm{P}=0.7930)$, total slices $(\mathrm{P}=0.2865), \%$ number 1 slices $(\mathrm{P}=) 0.7880$, \% number 2 slices $(\mathrm{P}=0.6947)$, or \% defect slices $(\mathrm{P}=0.9001)$.

\section{Ground pork patty shelf-life analysis.}

Results for the ground pork patty shelf-life study are presented in Figures 2.1-2.8. Dietary inclusion level of HO soybean oil did not impact color measures in ground pork patty display over five days in retail. 


\section{DISCUSSION}

The results for growth performance are to be expected from barrows consuming diets with varying energy amounts. As energy levels in the diet increases, we expect to see those animals perform better in terms of G:F ratios. This is supported in other studies that looked at varying levels of fat and its effects on pig performance (Liu et al., 2018).

Inclusion level of $\mathrm{HO}$ oil showed no effect on carcass composition and fresh meat quality. This supports that inclusion of dietary HO oil does not negatively impact the fresh pork supply chain. Bacon yield and quality analysis and the ground pork patty shelf-life study showed no significant differences between varying inclusion levels of $\mathrm{HO}$ oil. These results strengthen the argument that inclusion of $\mathrm{HO}$ soybean oil will not negatively impact further processed pork products.

Fatty acid analysis of pork subcutaneous, jowl, and intramuscular fat from barrows fed varying inclusion levels of $\mathrm{HO}$ soybean oil showed the impact dietary lipids have on monogastric animals. Fat tissues had an increase in total MUFA concentration, largely impart due to the increase in oleic acid $(\mathrm{C} 18: 1 \mathrm{n} 9 \mathrm{c})$ and a decrease in SFA and PUFA. Pigs are among those monogastric animals that are susceptible to alterations in fatty acid composition of fat and muscle tissues due to diets containing different oils (Wood et al. 2008). Intramuscular fat samples had less dietary effects partly due to the idea that intramuscular fat deposition is considered to be the last location for fat to be deposited, as a result of its increase metabolic activity (Wiegand et al., 2011; Shircliff, 2016). 


\section{IMPLICATIONS}

Overall, results from this experiment highlight previous conclusions regarding pig growth and carcass composition, with HO soybean oil strengthening the idea that increased levels of fat in the diet cause more efficient pigs, but do not change overall carcass and fresh meat parameters. The study along with others in this report showed the effect that dietary fatty acid compositions have on monogastric species. The fat tissue samples, carried through the fatty acid composition that was present in the diet. Further processed bacon and ground pork patties showed no negative effects of adding HO soybean oil, indicating pork from barrows fed HO soybean oil would market well in further processed situations. 
Table 2.1. Composition of finisher treatment diets with high oleic soybean oil.

\begin{tabular}{lccccc}
\hline & \multicolumn{5}{c}{ Treatment Diets $^{1}$} \\
\cline { 2 - 6 } Ingredient (kg) & $0 \%$ & $2 \%$ & $4 \%$ & $6 \%$ & $8 \%$ \\
\hline Corn & 711.23 & 693.05 & 674.86 & 656.68 & 638.50 \\
SBM 48 & 172.73 & 172.73 & 172.73 & 172.73 & 172.73 \\
High Oleic Soybean Oil & - & 18.18 & 36.36 & 54.55 & 72.73 \\
Dical Phosphate & 5.91 & 5.91 & 5.91 & 5.91 & 5.91 \\
Limestone & 7.50 & 7.50 & 7.50 & 7.50 & 7.50 \\
Salt & 4.55 & 4.55 & 4.55 & 4.55 & 4.55 \\
L-Lysine & 3.18 & 3.18 & 3.18 & 3.18 & 3.18 \\
Methionine & 0.57 & 0.57 & 0.57 & 0.57 & 0.57 \\
L-Threonine & 1.16 & 1.16 & 1.16 & 1.16 & 1.16 \\
Vitamin Premix & 1.36 & 1.36 & 1.36 & 1.36 & 1.36 \\
Mineral Premix & 0.91 & 0.91 & 0.91 & 0.91 & 0.91 \\
\cline { 2 - 6 } & 909.09 & 909.09 & 909.09 & 909.09 & 909.09 \\
& & & & & \\
Crude Protein, \% & 15.63 & 15.47 & 15.18 & 16.59 & 15.08 \\
Crude Fat, \% & 3.28 & 5.31 & 6.66 & 7.80 & 9.87 \\
Crude Fiber, \% & 1.99 & 2.05 & 2.06 & 2.20 & 1.95 \\
Moisture, \% & 12.21 & 11.88 & 11.58 & 12.19 & 11.45 \\
Ash, \% & 4.26 & 4.51 & 4.93 & 3.34 & 4.09 \\
\hline Treatment
\end{tabular}

${ }^{1}$ Treatment percentages indicate amount of added High Oleic Soybean Oil 
Table 2.2. Fatty acid composition of finisher treatment diets with high oleic soybean oil.

\begin{tabular}{lccccc}
\hline & \multicolumn{5}{c}{ Treatment Diets } \\
\cline { 2 - 6 } Fatty acid, \% & $0 \%$ & $2 \%$ & $4 \%$ & $6 \%$ & $8 \%$ \\
\hline Palmitic Acid (16:0) & 18.00 & 11.89 & 10.33 & 9.66 & 9.02 \\
Palmitoleic Acid (16:1) & - & 0.50 & 0.92 & 0.92 & 0.78 \\
Margaric acid (17:0) & - & - & 0.46 & 0.74 & 0.78 \\
Stearic Acid (18:0) & 2.71 & 2.68 & 2.98 & 3.16 & 3.14 \\
Oleic Acid (18:1n9c) & 27.86 & 46.83 & 54.37 & 55.80 & 60.78 \\
Linoleic Acid (18:2n6c) & 51.44 & 38.11 & 30.93 & 29.71 & 25.49 \\
\hline
\end{tabular}

${ }^{1}$ Treatment percentages indicate amount of added High Oleic Soybean Oil 
Table 2.3. Amino acid profile of finisher treatment diets with high oleic soybean oil.

\begin{tabular}{lccccc}
\hline & \multicolumn{5}{c}{ Treatment Diets $^{1}$} \\
Item, g & 0 & 2 & 4 & 6 & 8 \\
\hline Taurine & 0.15 & 0.15 & 0.15 & 0.14 & 0.15 \\
Hydroxyproline & 0.06 & 0.07 & 0.03 & 0.06 & 0.06 \\
Aspartic Acid & 1.56 & 1.41 & 1.37 & 1.38 & 1.41 \\
Threonine & 0.68 & 0.76 & 0.65 & 0.62 & 0.72 \\
Serine & 0.70 & 0.66 & 0.65 & 0.64 & 0.65 \\
Glutamic Acid & 3.05 & 2.84 & 2.76 & 2.68 & 2.74 \\
Proline & 1.05 & 1.03 & 1.03 & 0.98 & 1.00 \\
Lanthionine & 0.02 & 0.02 & 0.02 & 0.02 & 0.02 \\
Glycine & 0.68 & 0.64 & 0.61 & 0.62 & 0.61 \\
Alanine & 0.92 & 0.89 & 0.85 & 0.84 & 0.85 \\
Cysteine & 0.32 & 0.30 & 0.27 & 0.27 & 0.26 \\
Valine & 0.82 & 0.75 & 0.72 & 0.73 & 0.72 \\
Methionine & 0.34 & 0.33 & 0.28 & 0.27 & 0.29 \\
Isoleucine & 0.73 & 0.67 & 0.64 & 0.63 & 0.64 \\
Leucine & 1.56 & 1.50 & 1.46 & 1.40 & 1.43 \\
Tyrosine & 0.58 & 0.55 & 0.55 & 0.53 & 0.54 \\
Phenylalanine & 0.86 & 0.80 & 0.78 & 0.77 & 0.77 \\
Hydroxylysine & 0.03 & 0.03 & 0.04 & 0.04 & 0.03 \\
Ornithine & 0.01 & 0.01 & 0.01 & 0.01 & 0.01 \\
Lysine & 1.06 & 1.05 & 0.99 & 0.98 & 1.03 \\
Histidine & 0.44 & 0.41 & 0.40 & 0.40 & 0.40 \\
Arginine & 1.04 & 0.95 & 0.92 & 0.95 & 0.93 \\
Tryptophan & 0.18 & 0.18 & 0.20 & 0.18 & 0.19 \\
& 16.84 & 16.00 & 15.38 & 15.17 & 15.45 \\
\hline Treatment petal & 0.95 &
\end{tabular}

${ }^{1}$ Treatment percentages indicate amount of added High Oleic Soybean Oil 


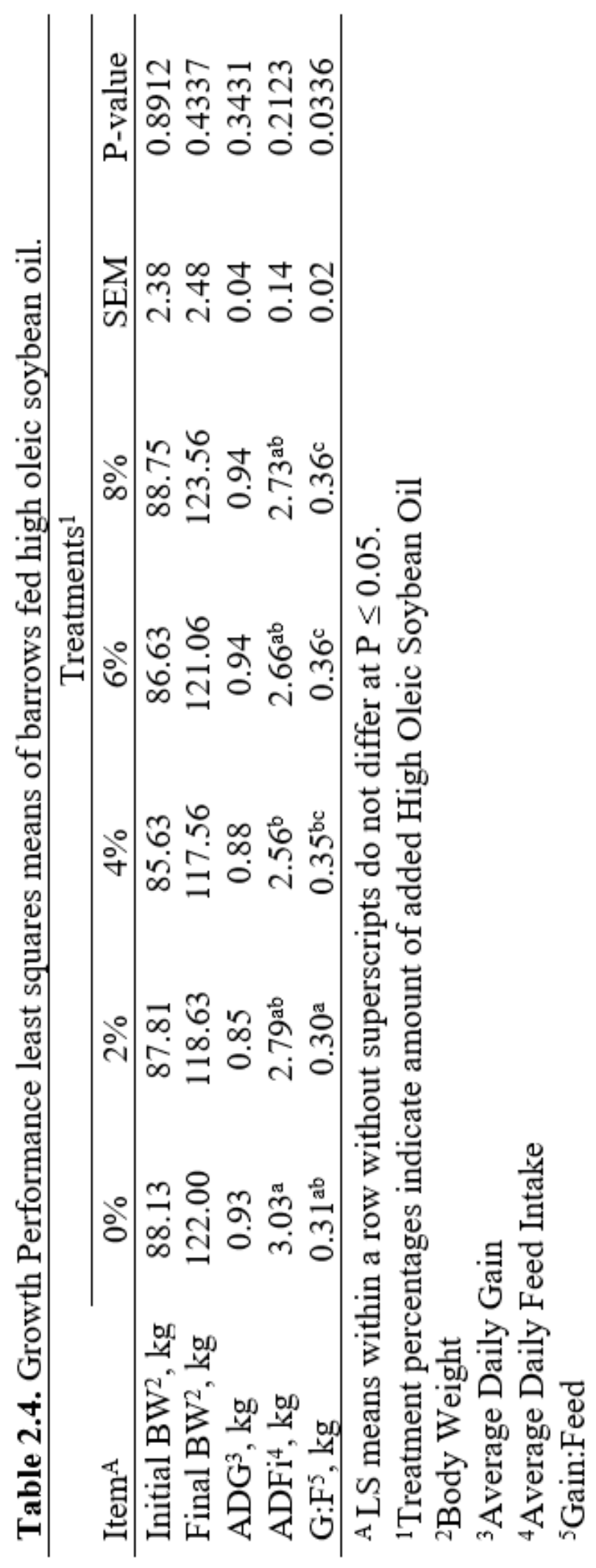




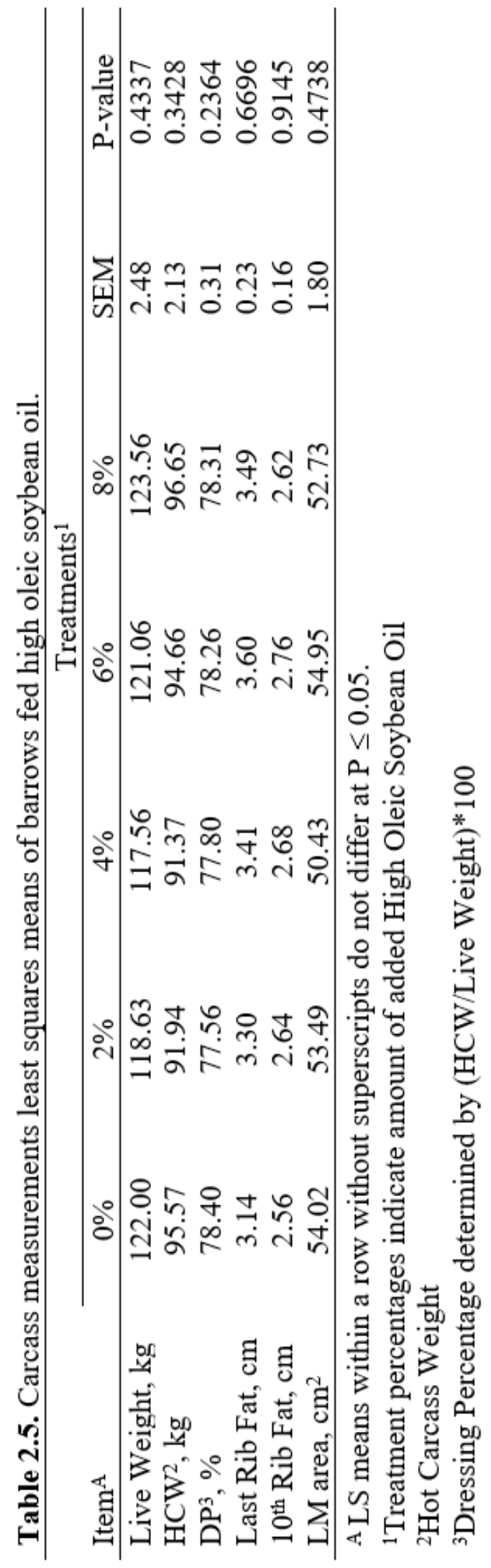




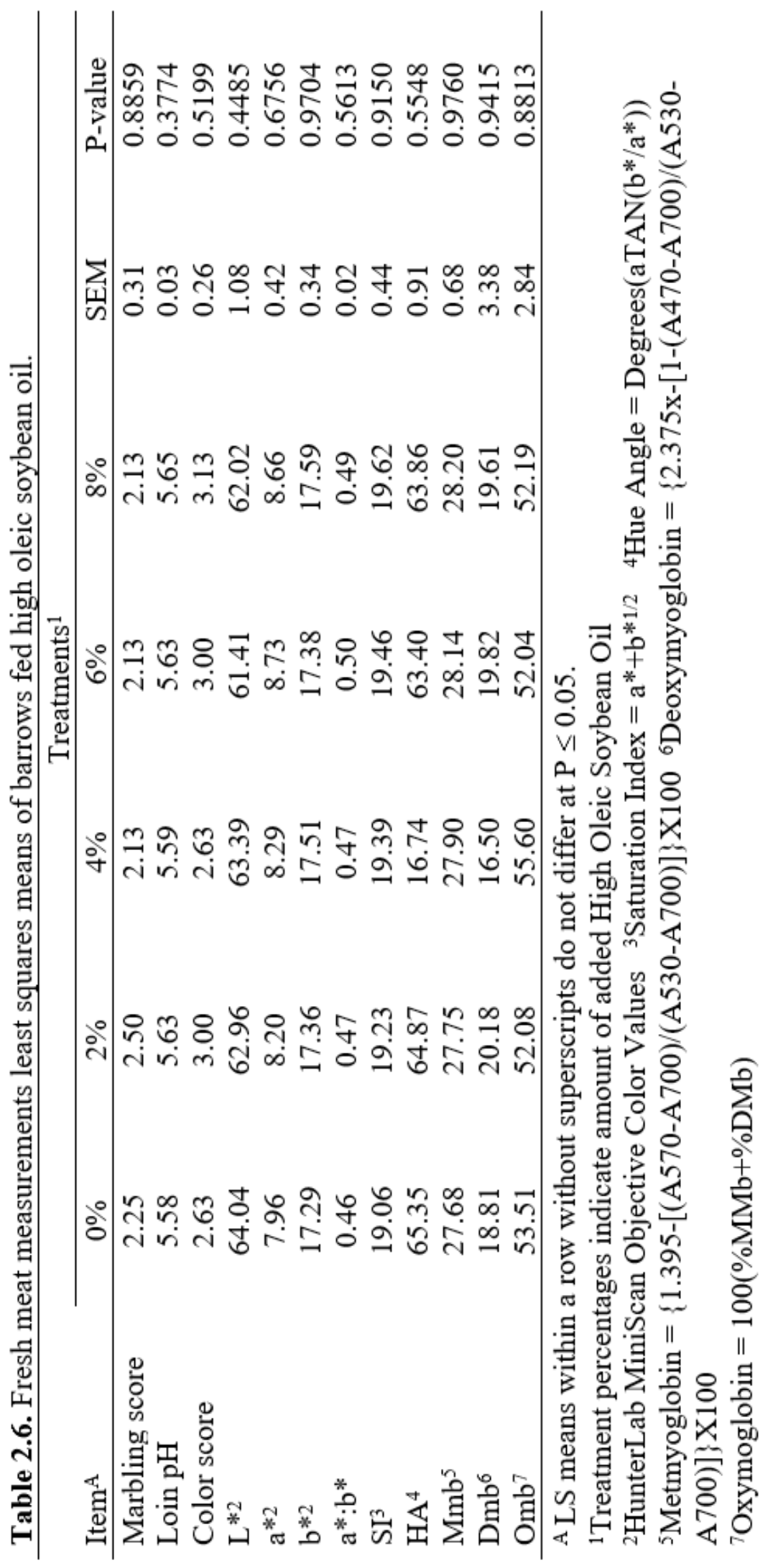




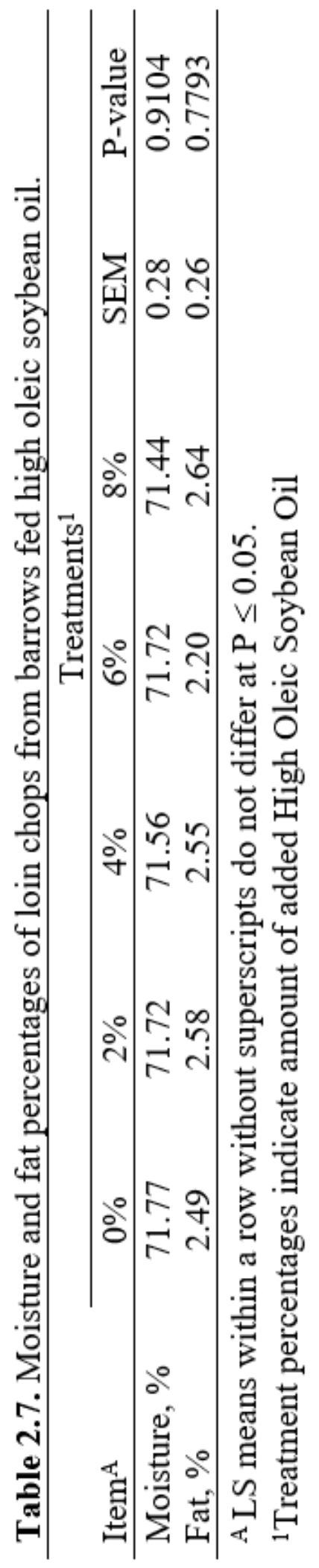




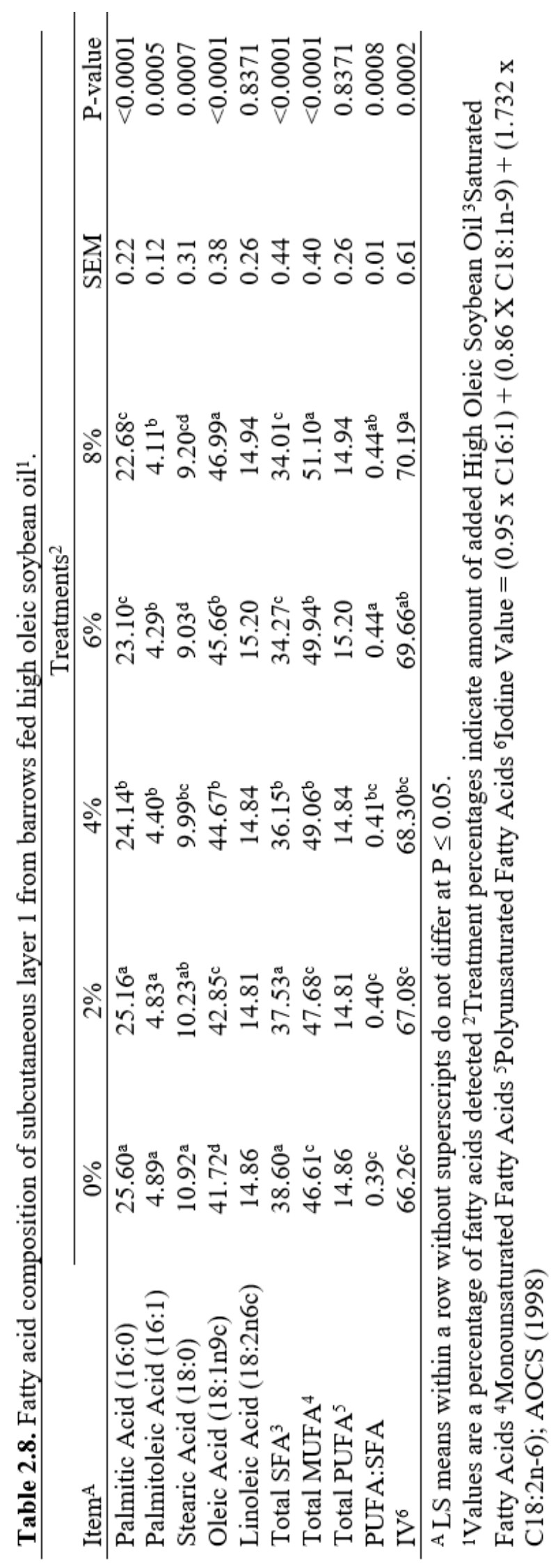




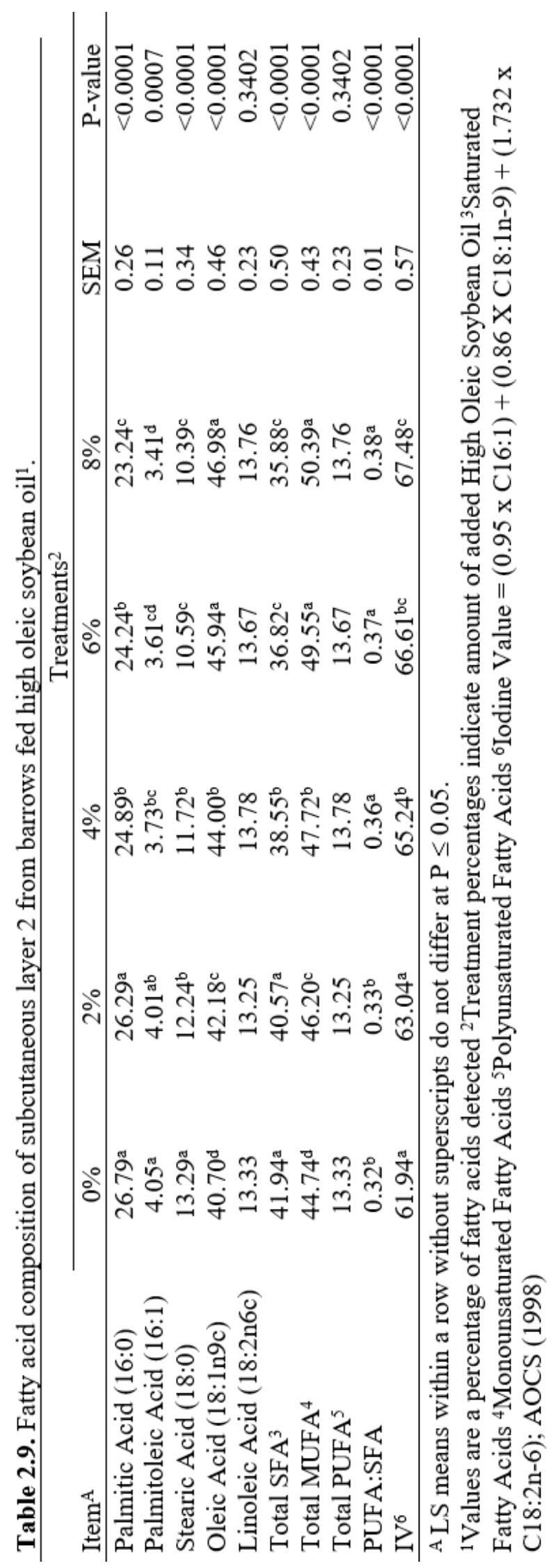




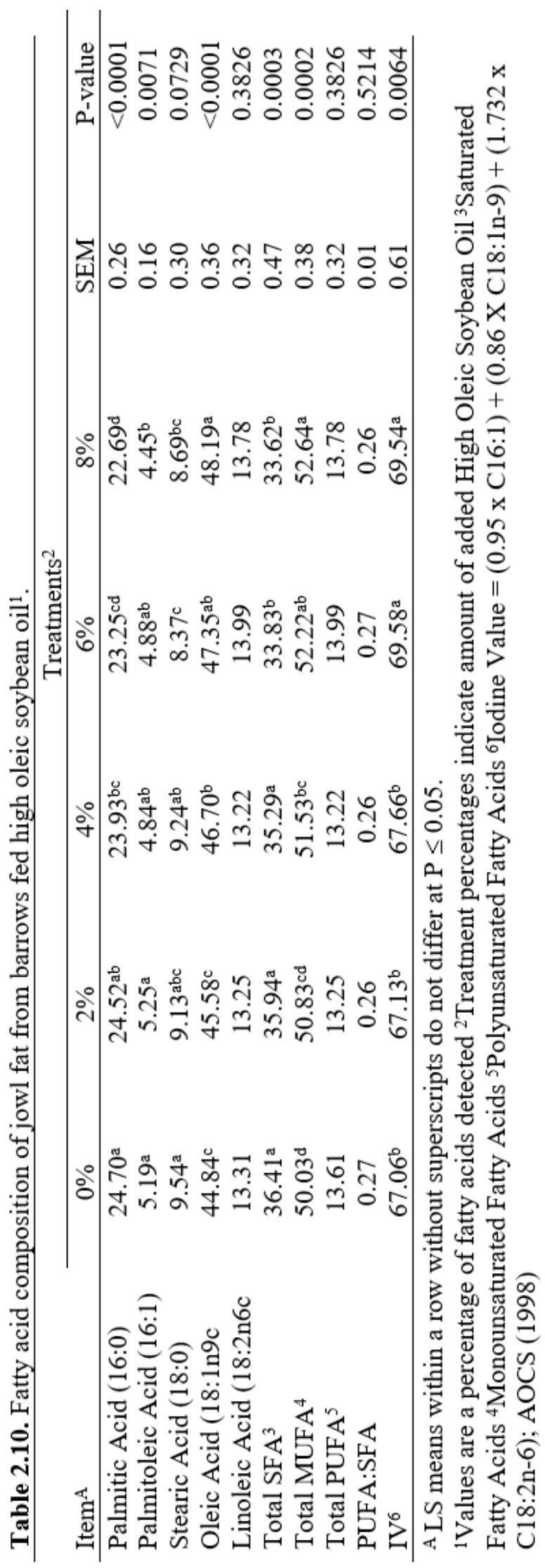




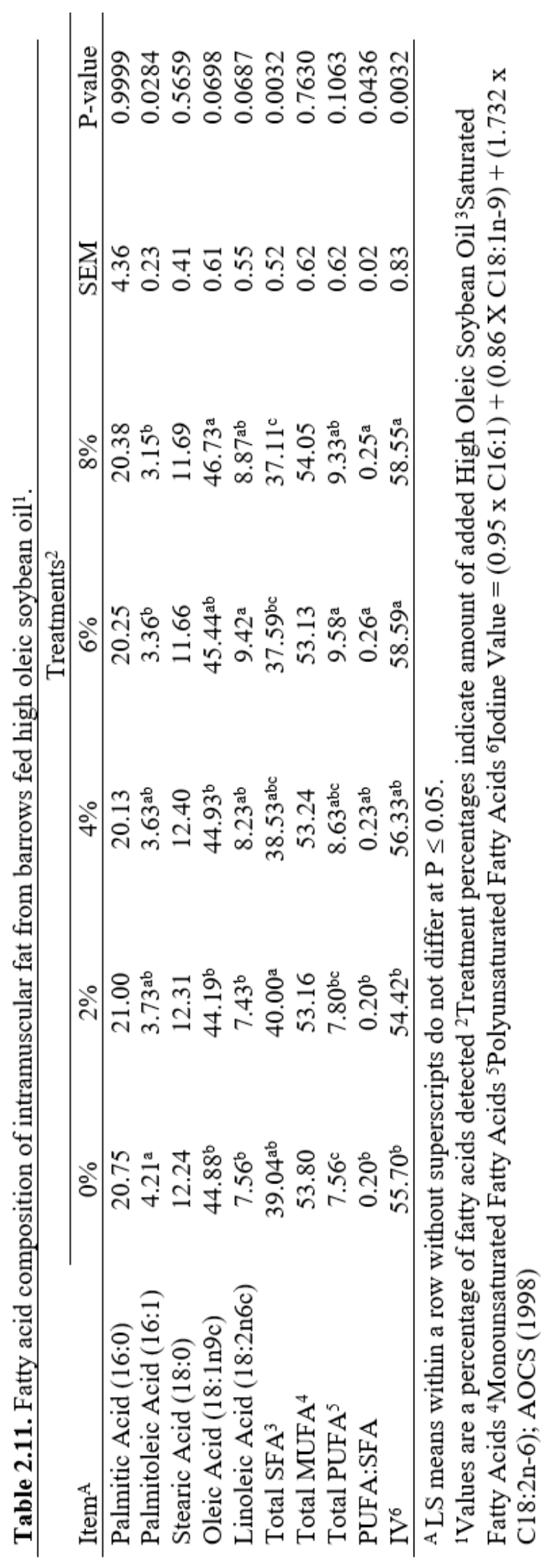




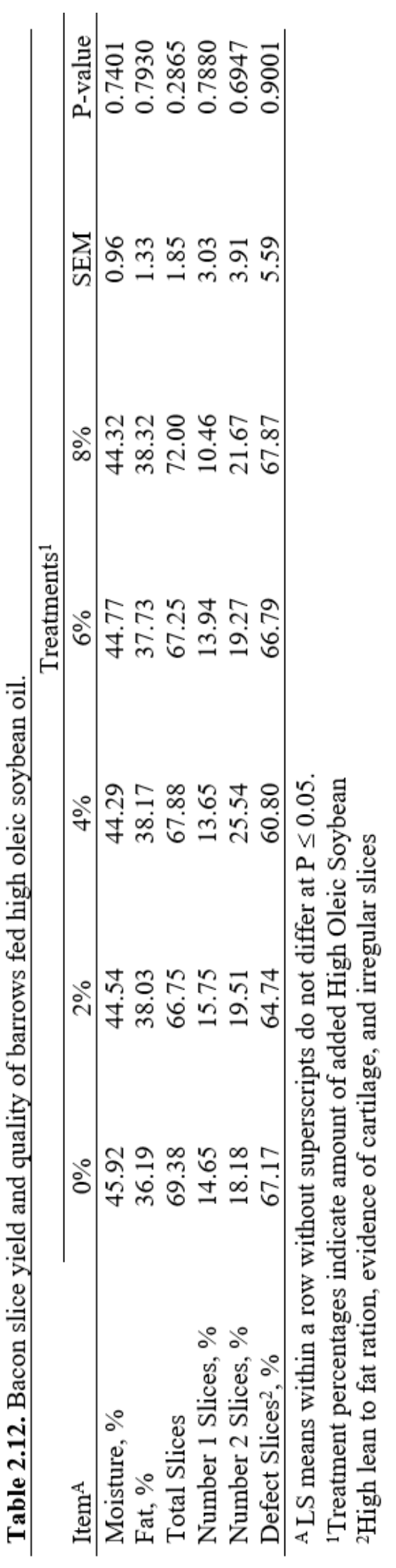


Figure 2.1. $L^{*}$ values of ground pork patties during 5 days in retail display from barrows fed high oleic soybean oil.

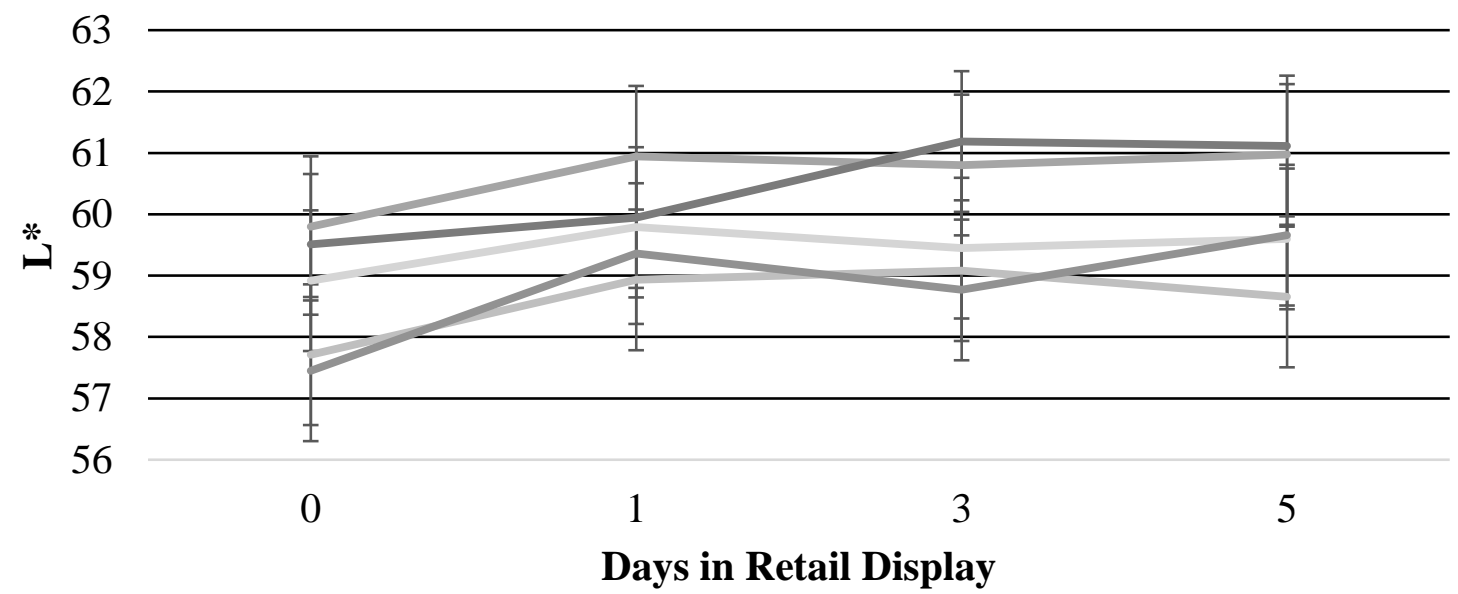

$-0-2-4-6-8$

Treatment $x$ Day: $\mathrm{P}=0.6456 \quad \mathrm{SEM}=1.146$ 
Figure 2.2. $a^{*}$ values of ground pork patties during 5 days in retail display from barrows fed high oleic soybean oil.

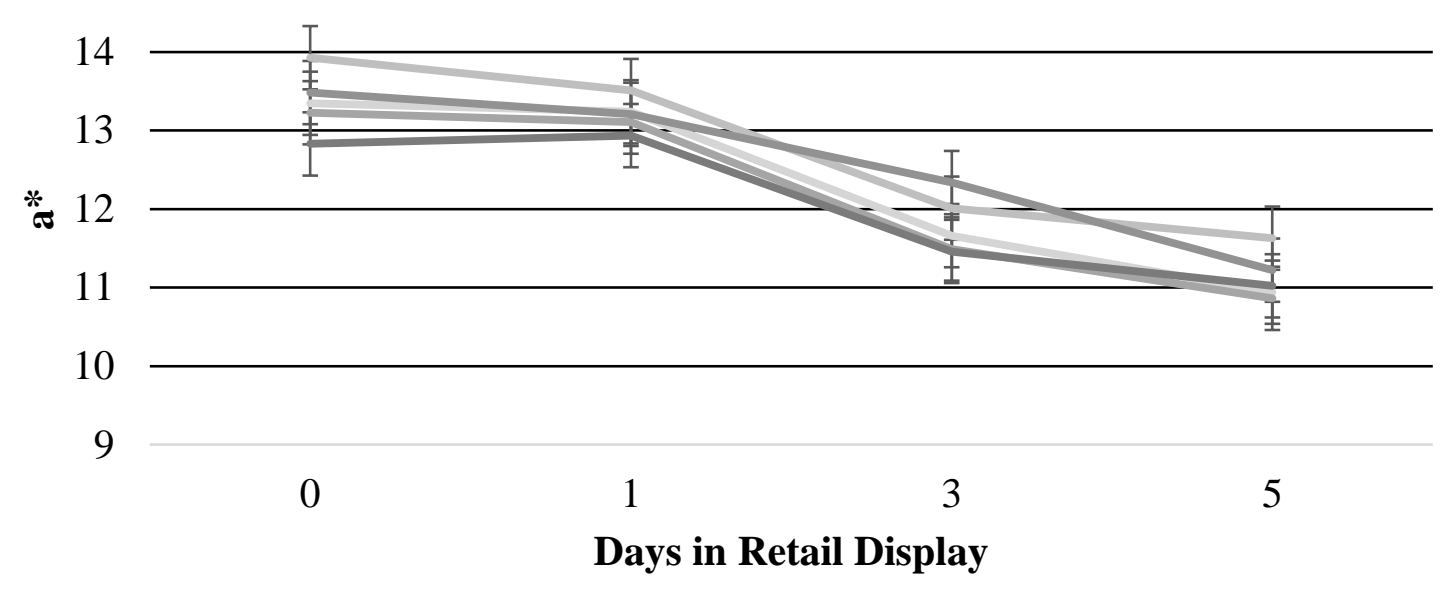

\begin{tabular}{ll} 
& $0 \longleftarrow 2-4-6-8$ \\
\hline Treatment $x$ Day: $\mathrm{P}<0.0001 \quad \mathrm{SEM}=0.403$
\end{tabular}


Figure 2.3. $b^{*}$ values of ground pork patties during 5 days in retail display from barrows fed high oleic soybean oil.

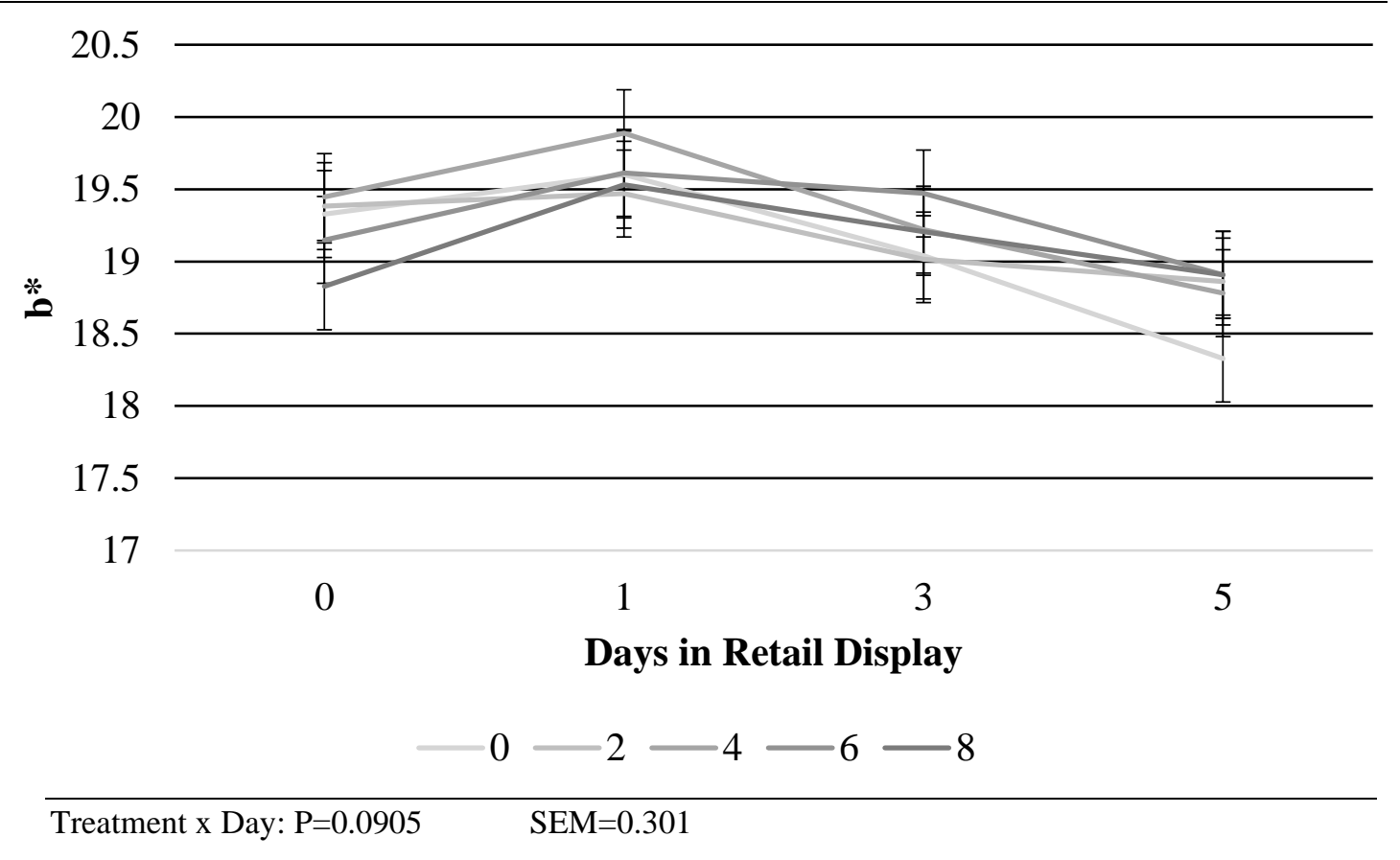


Figure 2.4. a/b values of ground pork patties during 5 days in retail display from barrows fed high oleic soybean oil.

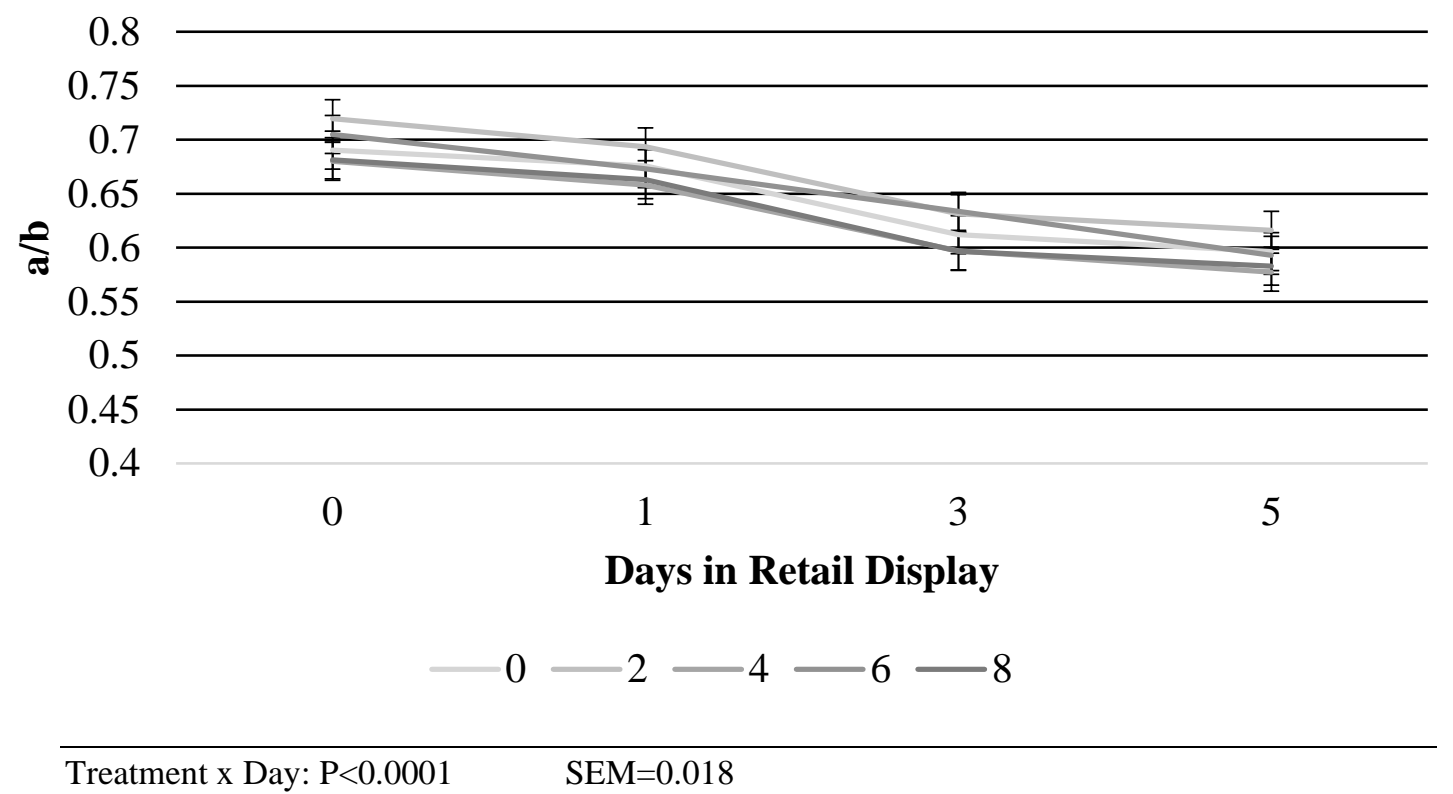


Figure 2.5. Hue angle values of ground pork patties during 5 days in retail display from barrows fed high oleic soybean oil.

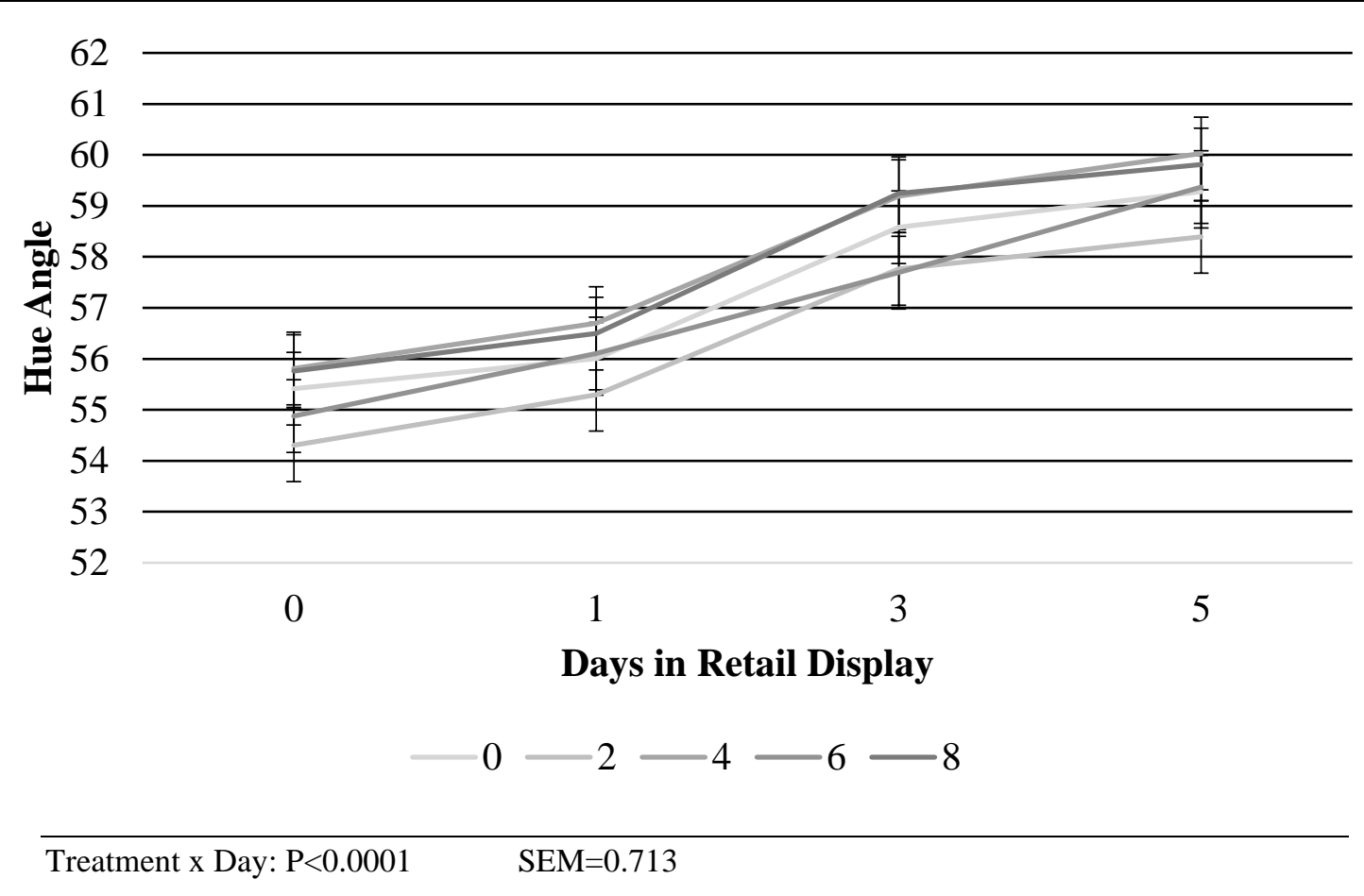


Figure 2.6. Metmyoglobin values of ground pork patties during 5 days in retail display from barrows fed high oleic soybean oil.

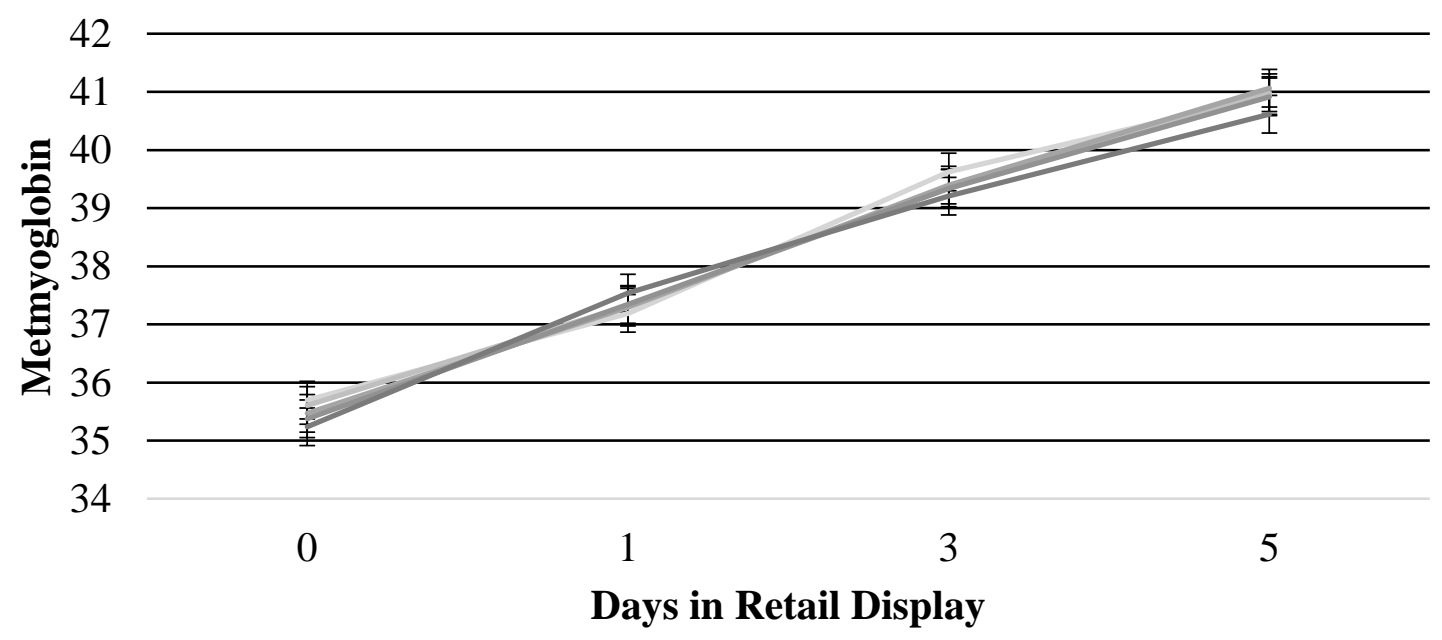

$\begin{array}{ll} & 0-2 \longleftarrow-4-6-8 \\ \text { Treatment } x \text { Day: } \mathrm{P}<0.0001 \quad \mathrm{SEM}=0.323\end{array}$


Figure 2.7. Dexoxymyoglobin values of ground pork patties during 5 days in retail display from barrows fed high oleic soybean oil.

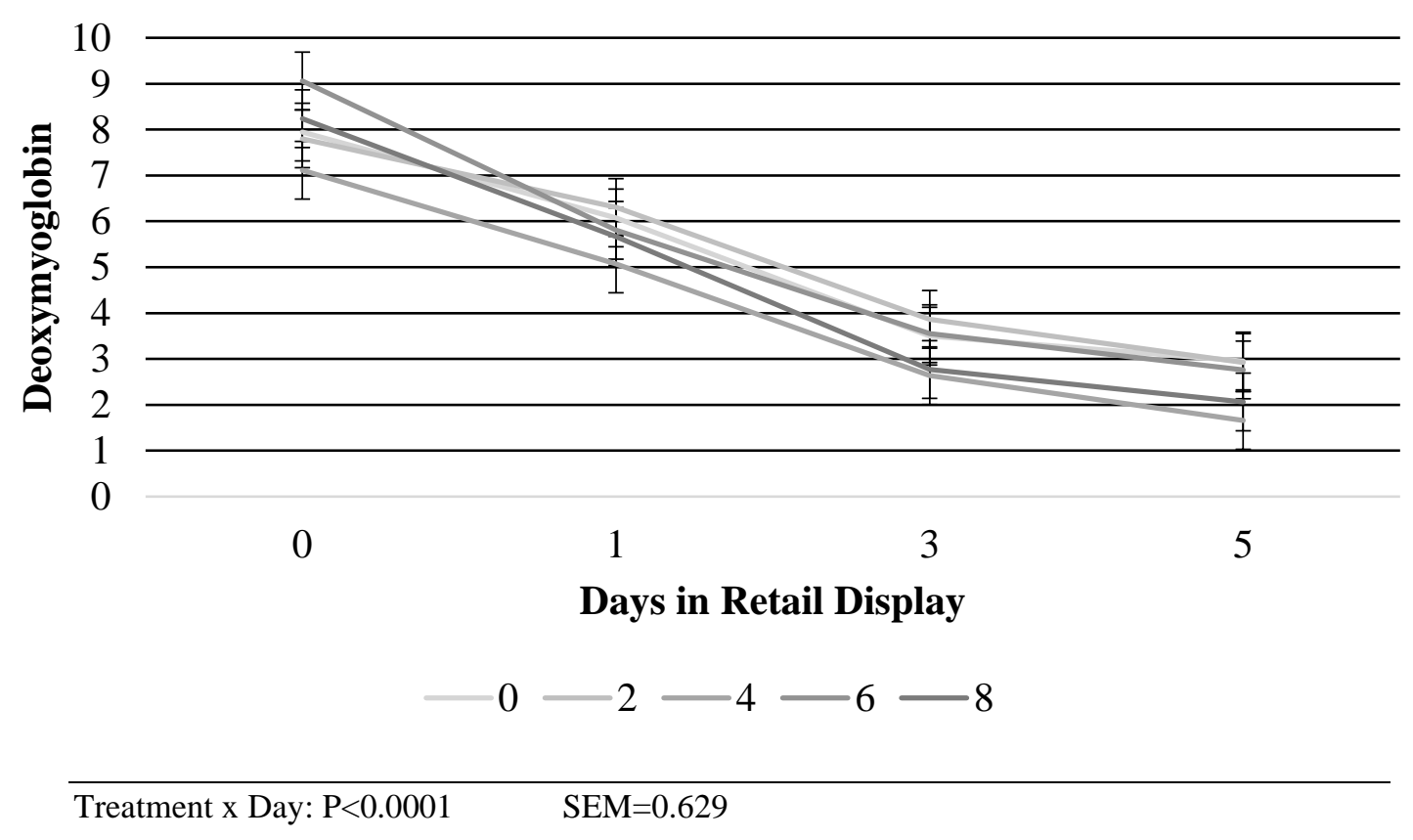


Figure 2.8. Oxymyoglobin values of ground pork patties during 5 days in retail display from barrows fed high oleic soybean oil.

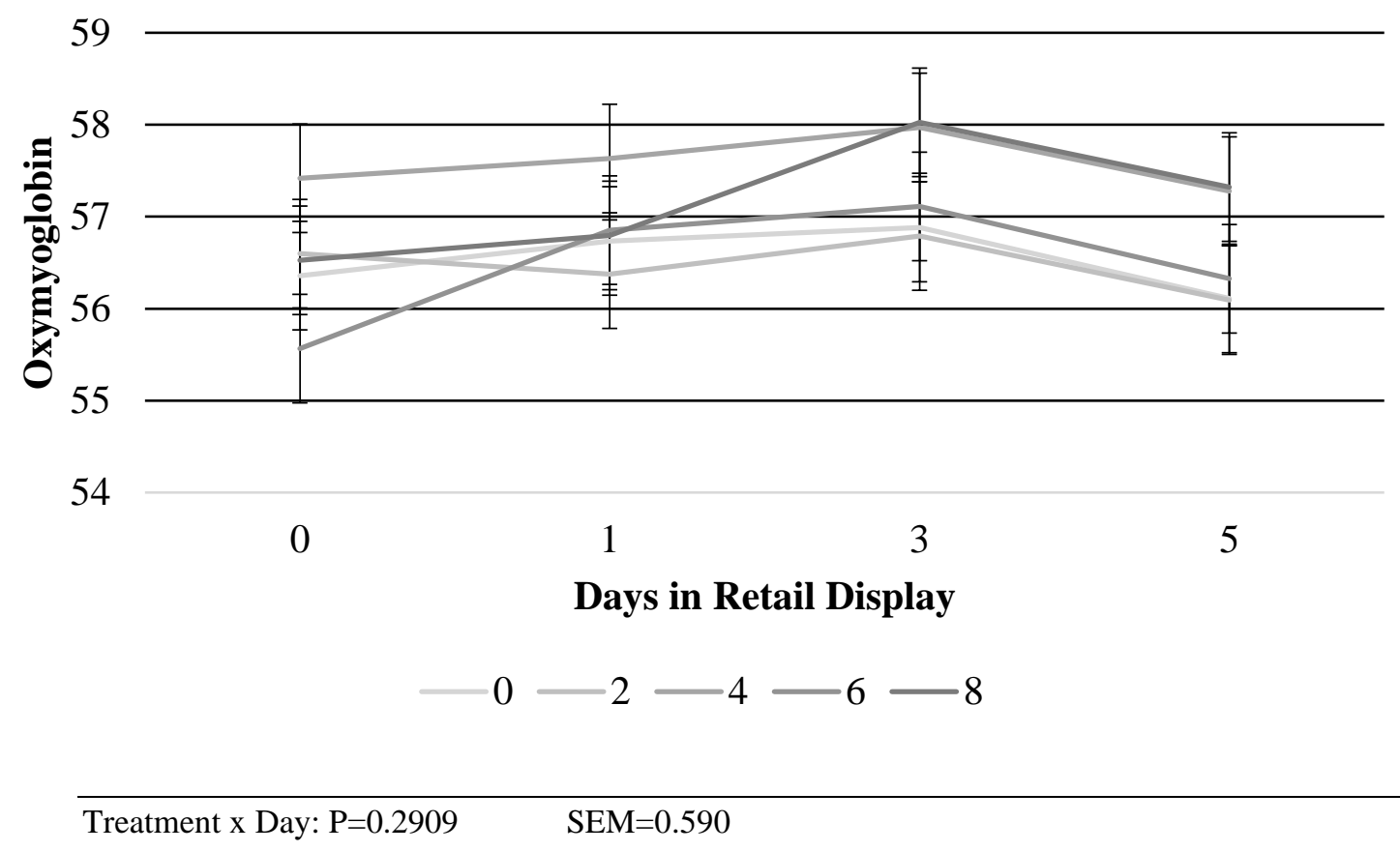




\title{
CHAPTER 3
}

\section{EFFECT OF DIETARY INCULSION OF PLENISH HIGH OLEIC SOYBEAN OIL ON BROILER PERFORMANCE AND FATTY ACID PROFILES}

\begin{abstract}
The objective of this experiment was to evaluate the effect of dietary high oleic soybean oil and inclusion level on broiler performance and lipid quality of broiler meat. Male Ross 308 broiler chicks ( $\mathrm{n}=300$ ) were sorted by weight and randomly assigned to one of five treatments containing five replicate pens with 12 broilers each. Treatment groups consisted of corn-soy diets that included $0 \%, 2 \%, 4 \%, 6 \%$, and $8 \%$ of added HO soybean oil. Broilers received, ad libitum, a two-phase diet consisting of a starter (d0-21) and a grower (d21-41) phase. Body weight (BW) and feed intake (FI) were recorded weekly and used to calculate gain to feed ratio $(\mathrm{G}: \mathrm{F})$. Broilers were slaughtered over a three day kill schedule on d41, d42, d43, after which carcasses were weighed and fabricated. Carcass weights were recorded to obtain dressing percentage (DP). Samples of abdominal fat pads were taken for fatty acid profile analysis. Thigh and boneless, skinless breast meat were removed, packaged by pen and frozen for further analysis. Approximately three pounds of thigh and boneless, skinless breast meat were ground, seasoned and linked into five, approximately 114-gram, bratwurst links. Bratwursts were placed on Styrofoam trays and overwrapped with polyvinyl chloride (PVC), then placed into retail display cases $\left(4^{\circ} \mathrm{C}\right)$ and
\end{abstract}


used for collection of thiobarbituric acid reactive substances (TBARS) on day $0,1,3,5$, and 7 of storage. Data were analyzed using PROC GLM procedure in SAS, with level of significance set at $\mathrm{P} \leq 0.05$. ADFi significantly decreased across treatments as the percent of added $\mathrm{HO}$ oil increased $(\mathrm{P}=0.0002)$. F:G ratio significantly decreased as the percent of added $\mathrm{HO}$ oil increased $(\mathrm{P}=0.0063)$. Abdominal fat pad significantly increased in weight as the percent of included HO oil increased $(\mathrm{P}<0.0001)$. Diet changed $(\mathrm{P}<0.001)$ the proportion of SFA, MUFA, and PUFA in abdominal fat pads. Percent of 18:0 was lower in broilers fed $0 \%$ and $2 \%$ compared to $4 \%, 6 \%$, and $8 \%$ added $\mathrm{HO}$ oil $(\mathrm{P}<0.0001)$. Total SFA decreased as the amount of added HO oil increased $(\mathrm{P}<0.0001)$. Percent of 16:1 decreased as the level of $\mathrm{HO}$ oil added increased $(\mathrm{P}<0.0001)$. Percent of 18:1n9 increased significantly as the level of $\mathrm{HO}$ oil increased $(\mathrm{P}<0.0001)$. Broilers fed $0 \%$ and $2 \%$ added HO oil had higher amounts of 18:1n7 compared to broilers fed $4 \%, 6 \%$, and $8 \%$ added $\mathrm{HO}$ oil $(\mathrm{P}=0.0003)$. Total MUFA increased significantly as the amount of added HO oil increased $(\mathrm{P}<0.0001)$. Percent of 18:2n6 was higher in broilers fed $0 \%$ and $2 \%$ compared to $4 \%, 6 \%$, and $8 \%$ added $\mathrm{HO}$ oil $(\mathrm{P}<0.0001)$. Percent of $18: 3 \mathrm{n} 3$ increased across treatments as level of added $\mathrm{HO}$ oil increased $(\mathrm{P}<0.0001)$. PUFA:SFA ratio increased as the level of added HO oil increased $(\mathrm{P}<0.0001)$. Results of lipid oxidation showed on day 7 of retail display bratwurst from broilers fed the $0 \%$ and $2 \%$ added $\mathrm{HO}$ oil had lower values of malonaldehyde formed compared to the higher fat diets $4 \%, 6 \%$, and $8 \%$ $(\mathrm{P}<0.0001)$ 


\section{INTRODUCTION}

Broiler tissue fatty acid profiles are known to be manipulated by oil sources added into the diet. However, different oil sources and inclusion levels have shown to have varying effects on broiler performance, carcass quality and further processed products (Azman et al., 2005; Bou et al., 2001; Sanz et al., 1999). Traditionally, broiler meat is thought to be higher in PUFA concentrations, which can lead to negative effects on lipid oxidation in poultry products (Aberle et al., 2012; Mir et al., 2017). The use of oil sources to alter fatty acid profiles and improve lipid oxidation is of much concern to provide processors optimal meat quality for broiler meat. There has been work done utilizing high oleic peanuts in broilers (Toomer et al., 2019a; Toomer et al., 2019b) and high oleic sunflower oil (Viveros et al., 2009), however, little to nothing is known how high oleic soybean oil will affect broiler performance, carcass quality and further processed products. Therefore, the purpose of this study was to evaluate the effect of dietary inclusion level of high oleic soybean oil on broiler performance, carcass quality and further processed chicken bratwurst. 


\section{MATERIALS AND METHODS}

The University of Missouri Animal Care and Use Committee approved animal care and experimental protocols prior to initiation of this experiment (\#EX-10094).

\section{Experimental Design}

Male Ross 308 broiler chicks $(n=300)$ were sorted by weight and then randomly assigned to one of five treatment groups, 5 replicate pens with 12 broilers in each. Broilers were housed in a climate-controlled facility, that allowed for the temperature to be adjusted to meet bird requirements throughout the growing period.

Treatments consisted of $0 \%, 2 \%, 4 \%, 6 \%$, and $8 \%$ of added $\mathrm{HO}$ soybean oil. Broilers received a two-stage diet consisting of a starter diet (d0-21) and a grower diet (d21-42). All diets were formulated and balanced to meet NRC energy requirements. Birds were provided feed and water ad libitum until harvest. Feed was added as needed; total weight of added feed was recorded to calculate total feed consumption (feed given residual). Broilers were humanely slaughtered over a three day kill schedule, after being fed for 41, 42, or 43 days. Treatments were equalized over the three day kill schedule. 


\section{Data Collection}

Growth performance. Pen weight and feed consumption was recorded weekly from the start of the study until broilers were processed. Pen weights and feed weight were used to calculate average broiler body weight $(\mathrm{BW})$, average daily gain (ADG), average daily feed intake (ADFi), and feed to gain ratio $(\mathrm{F}: \mathrm{G})$. Bird mortality records were used to adjust feed intake based on calculating bird days on feed.

Carcass measurements. Broilers were individually weighed prior to slaughter (final live weight), used in conjunction with hot carcass weight (HCW) to determine dressing percentage (DP). Dressing percentage was calculated by dividing the HCW by the live weight and multiplying the value by 100 . Carcasses were chilled after slaughter for one hour, then carcasses were fabricated. Thighs and boneless, skinless breasts were removed from carcasses, thighs and boneless, skinless breasts were packaged as pens and frozen.

Fatty acid analysis. Fatty acid profiles of abdominal fat pads were determined according to modified methodologies by Folch et al. (1957) and Morrison and Smith (1964). Approximately $100 \mathrm{mg}$ of tissue was homogenized in chloroform:methanol (CHCl3:CH3OH, 2:1, v/v) in a glass tube to extract lipids. Dehydrated samples were filtered through a sintered glass funnel fitted with a Whatman $2.4 \mathrm{~cm} \mathrm{GF/C} \mathrm{filter.}$

A volume of $8 \mathrm{ml}$ of $0.74 \% \mathrm{KCl}$ was added to each sample and after two hours, two distinct layers formed. The upper phase was removed and discarded while the lower phase was evaporated to dryness with nitrogen in a water bath. At the point of dryness, $1 \mathrm{ml}$ of $0.5 \mathrm{~N} \mathrm{KOH}$ was added to each tube and heated for $10 \mathrm{~min}$. in a $70^{\circ} \mathrm{C}$ water bath. The 
addition of $\mathrm{KOH}$ initiates the saponification reaction, which hydrolyzes fatty acids from a triglyceride molecule. Following this, $1 \mathrm{ml}$ of $14 \% \mathrm{BF} 3$ in $\mathrm{MeOH}$ was added, samples were flushed with nitrogen and heated in the water bath for $30 \mathrm{~min}$. Boron trifluoride is highly volatile and acts as an acid catalyst in the transesterification reaction that methylates the acid group on free fatty acids removing the net negative charge. The remaining molecule is known as a fatty acid methyl ester (FAME).

FAMEs are liquefied by adding $2 \mathrm{ml}$ of HPLC grade hexane and $2 \mathrm{ml}$ of $\mathrm{NaCl}$. Two distinct layers are formed; the upper layer is removed and added to $\sim 800 \mathrm{mg}$ of $\mathrm{Na} 2 \mathrm{SO} 4$ to remove any moisture in the sample. At this point, 2 more $\mathrm{ml}$ of hexane was added to the tube containing $\mathrm{NaCl}$ and once more, the upper layer was removed and added to the tube containing Na2SO4. The hexane portion was removed from the salt and added to a labeled scintillation vial. The salt was rinsed once more with $1 \mathrm{ml}$ of hexane and the liquid was added to the vial. Samples were evaporated to dryness in a water bath at $70^{\circ} \mathrm{C}$ under nitrogen flow. Lastly, samples were reconstituted with $1 \mathrm{ml}$ HPLC grade hexane and transferred to gas chromatograph vials.

The stable FAMEs were loaded into a Varian 3,800 gas chromatographer (Varion, Pala Alto, CA) to determine fatty acid profiles. The column utilized was a fused silica capillary column (SPTM - 2,560; $100 \mathrm{~m}$ x $0.25 \mathrm{~mm}$ x $0.2 \mu \mathrm{m}$ film thickness; Supelco, Bellefonte, PA). Temperature of the injector was held constant at $240^{\circ} \mathrm{C}$ and temperature of the flame-ionizer detector was held at $260^{\circ} \mathrm{C}$. The oven operated at $140^{\circ} \mathrm{C}$ for $5 \mathrm{~min}$ (temperature programmed $2.5^{\circ} \mathrm{C} / \mathrm{min}$ to $240^{\circ} \mathrm{C}$ and held for $16 \mathrm{~min}$ ). Helium, the carrier gas, was maintained at a constant pressure of $37 \mathrm{psi}$. Individual fatty acids were expressed as a percentage of the total area under the peaks. 
Total saturated fatty acid (SFA), monounsaturated fatty acids (MUFA) and polyunsaturated fatty acid (PUFA) contents were calculated according to the following equations: $\mathrm{SFA}=(\mathrm{C} 10: 0+\mathrm{C} 12: 0+\mathrm{C} 14: 0+\mathrm{C} 15: 0+\mathrm{C} 16: 0+\mathrm{C} 17: 0+\mathrm{C} 18: 0+\mathrm{C} 20: 0+$ $\mathrm{C} 22: 0+\mathrm{C} 23: 0) ; \mathrm{MUFA}=(\mathrm{C} 14: 1+\mathrm{C} 15: 1+\mathrm{C} 16: 1+\mathrm{C} 17: 1+\mathrm{C} 18: 1 \mathrm{n} 9 \mathrm{t}+\mathrm{C} 18: 1 \mathrm{n} 9 \mathrm{c}+$ $\mathrm{C} 18: 1 \mathrm{n} 7+\mathrm{C} 20: 1+\mathrm{C} 22: 1 \mathrm{n} 9+\mathrm{C} 24: 1) ; \mathrm{PUFA}=(\mathrm{C} 18: 2 \mathrm{n} 6 \mathrm{t}+\mathrm{C} 18: 2 \mathrm{n} 6 \mathrm{c}+\mathrm{C} 18: 3 \mathrm{n} 6+$ $\mathrm{C} 18: 3 \mathrm{n} 3+\mathrm{C} 18: 9 \mathrm{c} 11 \mathrm{t}+\mathrm{C} 18: 10 \mathrm{t} 12 \mathrm{c}+\mathrm{C} 18: 9 \mathrm{c} 11 \mathrm{c}+\mathrm{C} 18: 9 \mathrm{t} 11 \mathrm{t}+\mathrm{C} 20: 2+\mathrm{C} 20: 3 \mathrm{n} 6+$ $\mathrm{C} 20: 3 \mathrm{n} 3+\mathrm{C} 20: 4 \mathrm{n} 6+\mathrm{C} 22: 5 \mathrm{n} 3+\mathrm{C} 22: 6 \mathrm{n} 3)$. The ratio between PUFAs and SFAs was calculated using the equation: $[(\mathrm{C} 18: 2 \mathrm{n} 6 \mathrm{c})+(\mathrm{C} 18: 3 \mathrm{n} 3)] /[(\mathrm{C} 14: 0+\mathrm{C} 16: 0+\mathrm{C} 18: 0)]$. The following equations were used to calculated total omega 3 and omega 6 fatty acid content: total omega $3=\mathrm{C} 18: 3 \mathrm{n} 3+\mathrm{C} 20: 3 \mathrm{n} 3+\mathrm{C} 22: 5 \mathrm{n} 3+\mathrm{C} 22: 6 \mathrm{n} 3) ;$ total omega $6=(\mathrm{C} 18: 3 \mathrm{n} 6+$ $\mathrm{C} 20: 3 \mathrm{n} 6+\mathrm{C} 20: 4 \mathrm{n} 6)$.

Further processed chicken bratwurst shelf-life. Boneless, skinless breasts and thighs were removed from cold storage and approximately $1.5 \mathrm{lbs}$ of each was weighed and added together. The 3 pounds of whole muscle product was ground through a LEM 0.35 HP meat grinder (Harrison, Ohio, USA), the mixture was ground through a kidney plate and then a $10 \mathrm{~mm}$ grinding plate. Original Blue Ribbon Bratwurst Seasoning (Walton's Inc.) was added to the ground meat mixture prior to stuffing. The ground bratwurst mixture was placed into a $11 \mathrm{lb}$. capacity Walton's hand crank stuffer and stuffed into a natural pork casing. Five, approximately 114-gram, bratwurst links were created per pen and placed on Styrofoam trays and overwrapped with polyvinyl chloride (PVC), then placed into retail display cases. Bratwursts were removed on day $0,1,3,5$, and 7 for lipid oxidation and color measurements. 
Lipid oxidation (TBARS). Duplicate 5-gram samples from each bratwurst were blended for 2 minutes with $25 \mathrm{~mL}$ of distilled water using a Hamilton Beach hand blender. Following homogenization, the $50 \mathrm{~mL}$ tube with sample was rinsed with an additional $25 \mathrm{ml}$ of distilled water and transferred into a Kjeldahl flask. $2.5 \mathrm{ml}$ of $\mathrm{HCl}$ was added to the flask to balance the $\mathrm{pH}$ between 1.5 and 1.6 along with two drops of antifoam solution. $25 \mathrm{ml}$ of each sample was distilled through a water-cooled distillation apparatus. Following distillation, $5 \mathrm{ml}$ of each sample was pipetted into a glass tube followed by $5 \mathrm{ml}$ of TBA ( $0.02 \mathrm{M}$ thiobarbituric acid in $90 \%$ acetic acid) reagent. Samples were then placed in a boiling water bath for 35 minutes and then immediately transferred to an ice bath for 10 minutes to stop the chemical reaction. Color absorbance was measured at $538 \mathrm{~nm}$ using a Spectronic 20 (Bausch \& Lomb, Rochester, NY) spectrophotometer. Values of each reading were recorded and averaged for further calculation. Lipid oxidation was expressed in $\mathrm{mg} / \mathrm{kg}$ of malonaldehyde recovered and calculated using the recorded spectrophotometer averages and the given equation below.

$\mathrm{mg} / \mathrm{kg}$ of malonaldehyde $=7.8 *$ spectrophotometer reading

Objective color measure. Bratwurst were cut lengthwise and butterflied open. Objective color was measured by CIE system L* (lightness), a* (redness), and $b^{*}$ (yellowness) using a HunterLab MiniScan Spectrocolorimeter (MiniScan XE; Hunter and Assoc., Reston, VA) with a $2.5 \mathrm{~cm}$ port and glass cover calibrated against a white tile. Color scans were taken in triplicate and averages were recorded. Instrumental color readings were utilized to calculate a/b ration, saturation index (SI), and hue angle (HA) values. 
Fat and moisture content analysis. Fat and moisture content analysis was performed according to Keeton et al. (2003). A CEM Moisture/Solids Analyzer and Smart Trac Rapid Fat Analysis system (CEM Corp., Matthews, NC, U.S.A.) was used to analyze the samples. Briefly, the moisture percentage was determined by weight using the CEM moisture/solids analyzer and the fat percentage was determined on dry basis using nuclear magnetic resonance and converted to wet basis. Each sample for analysis was performed in triplicate as described by Dow et al. (2011).

\section{Statistical Analysis}

Collected data was analyzed using SAS 9.4. The least squares mean and standard error were determined for variable according to treatment. An analysis of variance of least squares means of treatments for pre-established variable was conducted using PROC GLM to determine if there was an effect of treatment, within each group. A pairwise comparison used to detect potential differences between treatments. Level of significance was set at P $\leq 0.05$

\section{RESULTS}

\section{Growth performance}

Growth performance results are presented in Table 3.7. Broilers fed the $4 \%$ added $\mathrm{HO}$ oil were smaller at time of slaughter compared to broilers fed $0 \%$ added $\mathrm{HO}$ oil $(\mathrm{P}=$ 0.0359). No other differences were observed in final live weight of broilers. Broilers fed 
the $4 \% \mathrm{HO}$ oil diet had a lower ADG compared to broilers fed the 0\% ( $\mathrm{P}=0.0400)$ and $2 \%$ $\mathrm{HO}$ oil ( $\mathrm{P}=0.0541)$. ADFi significantly decreased across treatments as the percent of added $\mathrm{HO}$ oil increased $(\mathrm{P}=0.0002)$. $\mathrm{F}: \mathrm{G}$ ratio significantly decreased as the percent of added $\mathrm{HO}$ oil increased $(\mathrm{P}=0.0063)$.

\section{Carcass measurements}

Results for carcasses measurements are outlined in Table 3.8. HCW tended to decrease as the percent of $\mathrm{HO}$ oil increased in the diet $(\mathrm{P}=0.0658)$. DP tended to decrease as the percent of $\mathrm{HO}$ oil increased in the $\operatorname{diet}(\mathrm{P}=0.1042)$. Liver weights from broilers fed $0 \% \mathrm{HO}$ oil weighed more compared to liver weights from broilers fed $6 \%$ and $8 \% \mathrm{HO}$ oil $(\mathrm{P}=0.0377$ and $\mathrm{P}=0.0127)$. Liver weights tended to decrease as the level of $\mathrm{HO}$ oil increased $(\mathrm{P}=0.0911)$. Fat pad weights significantly increased in weight as the percent of included HO oil increased $(\mathrm{P}<0.0001)$.

\section{Fatty acid analysis}

Abdominal fat pad fatty acid compositions are presented in Table 3.9. Percent of 18:0 was lower in broilers fed $0 \%$ and $2 \%$ compared to $4 \%, 6 \%$, and $8 \%$ added $\mathrm{HO}$ oil $(\mathrm{P}<0.0001)$. No differences were observed in 16:0 between treatments $(\mathrm{P}=0.9606)$. Total SFA decreased as the amount of added $\mathrm{HO}$ oil increased $(\mathrm{P}<0.0001)$.

Percent of 16:1 decreased as the level of $\mathrm{HO}$ oil added increased $(\mathrm{P}<0.0001)$. Percent of 18:1n9 increased significantly as the level of $\mathrm{HO}$ oil increased $(\mathrm{P}<0.0001)$. 
Broilers fed $0 \%$ and $2 \%$ added $\mathrm{HO}$ oil had higher amounts of 18:1n7 compared to broilers fed $4 \%, 6 \%$, and $8 \%$ added $\mathrm{HO}$ oil ( $\mathrm{P}=0.0003)$. Total MUFA increased significantly as the amount of added $\mathrm{HO}$ oil increased $(\mathrm{P}<0.0001)$.

Percent of 18:2n6 was higher in broilers fed $0 \%$ and $2 \%$ compared to $4 \%, 6 \%$, and $8 \%$ added $\mathrm{HO}$ oil $(\mathrm{P}<0.0001)$. Percent of $18: 3 \mathrm{n} 3$ increased across treatments as level of added HO oil increased $(\mathrm{P}<0.0001)$. No differences were observed in $22: 4 \mathrm{n} 6$ between treatments $(\mathrm{P}=0.9869)$. Broilers fed 0\% added oil had higher total PUFA, followed by broilers fed $2 \%$ added $\mathrm{HO}$, then broilers fed 4\%, 6\%, and 8\% added oil $(\mathrm{P}<0.0001)$. PUFA:SFA ratio increased as the level of added $\mathrm{HO}$ oil increased $(\mathrm{P}<0.0001)$.

\section{Further processed chicken bratwurst shelf-life.}

Lipid oxidation. Results from the retail shelf-life study for lipid oxidation is presented in Figure 3.1. During days 0, 1, 3, and 5 of retail display, there were no differences seen in $\mathrm{mg}$ of malonaldehyde formed between treatments $(\mathrm{P}>0.05)$. However, on day 7 of retail display bratwurst from broilers fed the $0 \%$ and $2 \%$ added $\mathrm{HO}$ oil had lower values of malonaldehyde formed compared to the higher fat diets $4 \%, 6 \%$, and $8 \%$ $(\mathrm{P}<0.0001)$.

Objective color measurements. Color measurement data is presented in Figures 3.2-3.7. Lower fat diets, $0 \%$ and $2 \%$ added oil had lower $\mathrm{L}^{*}$ values compared to higher fat diets, $4 \%, 6 \%, 8 \%$ added $\mathrm{HO}$ oil, while in retail storage $(\mathrm{P}<0.0001)$. Over 7 days in retail, all treatments saw a reduction in a* value. On day 3 in retail $0 \%$ and $2 \%$ diets had lower $\mathrm{a}^{*}$ values compared to other treatments. No differences were observed between treatments 
on days $0,1,5$, and $7(\mathrm{P}>0.05)$. Over 7 days in retail storage all treatments saw a decrease in $b^{*}$ values. The $0 \%$ diet saw a lower $b^{*}$ value each day compared to all other treatments over 7 days in retail storage $(\mathrm{P}<0.0001)$. No differences were observed in $\mathrm{a} / \mathrm{b}$ ratio for treatments during any sampling periods $(\mathrm{P}>0.05)$. Bratwurst from broilers fed $0 \%$ added $\mathrm{HO}$ oil had lower saturation values compared to other treatments during day $0,1,3$, and 7 of retail display. No differences were observed for hue angle between treatments over the sampling periods $(\mathrm{P}>0.05)$.

Fat and moisture content analysis. Fat and moisture content analysis is presented in Table 3.10. Fat percentage of bratwurst increased as the percent of added $\mathrm{HO}$ oil fed to broilers increased $(\mathrm{P}<0.0001)$. Moisture percentage of bratwurst decreased as the percent of added $\mathrm{HO}$ oil fed to broilers increased $(\mathrm{P}=0.0089)$.

\section{DISCUSSION}

Higher levels of dietary HO soybean oil in the diet made broilers more efficient by reducing their feed intake while also converting better with a lower F:G ratio. Sanz et al. (2010) found that dietary energy concentrations lowered feed intake and F:G ratio similar to the results presented here. However, there was a tendency for the higher inclusion rates to have smaller HCW and DP compared to the lower inclusion rates. Suggesting that producers may benefit more from feeding a middle level inclusion rate, to gain the feed intake and F:G benefits, without losing out on carcass parameters.

Fatty acid analysis of fat pads from broilers fed varying inclusion levels of HO soybean oil showed the impact dietary lipids have on monogastric animals. Fat pad 
profiles had an increase in total MUFA concentration, specifically due to increased levels of oleic acid $(\mathrm{C} 18: \ln 9 \mathrm{c})$ and decreased concentrations in SFA and PUFA. This is in line with work done using high oleic sunflower hulls, which also saw a shift in fatty acid profiles that were in line with the dietary fatty acid profile (Viveros et al., 2009). An increase in oleic acid is beneficial for a few reasons; increased MUFA concentrations have been the target of health-conscious individuals wanting low levels of SFA, high oleic oil contains high levels of tocopherols, naturally occurring antioxidants (Sangkaew et al., 2017).

Further processed chicken products are on the rise as individuals become more health conscious. Results from the chicken bratwurst study, suggest that including HO soybean oil at some level will not negatively impact product quality. Diets with $4 \%$, $6 \%$, and $8 \%$ added $\mathrm{HO}$ oil were brighter and redder during various sampling periods in the retail display study. The results also suggest that further processed chicken brats from broilers fed $\mathrm{HO}$ soybean oil does not negatively impact grams of malonaldehyde formed up to five days in retail display.

\section{IMPLICATIONS}

The inclusion of $\mathrm{HO}$ soybean oil in the broiler diet can give the producer benefits of lower feed intake, reducing feed costs, while still maintaining a better F:G conversion, making the animals more efficient. Producers may benefit more from feeding a mid-level inclusion of $\mathrm{HO}$ soybean oil to reap benefits of improved efficiency while also avoiding 
any loss due to carcass size. Including HO soybean oil will shift the proportion of fatty acids in the abdominal fat pad tissue, to include higher levels of beneficial monounsaturated fatty acids and decrease the amounts of saturated fatty acids. Previous research done in Dr. Bryon Wiegand's lab has shown that broiler breast and thigh meat from chickens fed high oleic soybean oil pick up the dietary fatty acid profile of the feed. Therefore, feeding high oleic soybean oil to broilers will impart a more beneficial fatty acid profile for the consumer. 
Table 3.1. Composition of broiler starter treatment diets with varying inclusion levels of high oleic soybean oil.

\begin{tabular}{lccccc}
\hline & \multicolumn{5}{c}{ Treatment Diets $^{1}$} \\
\cline { 2 - 6 } Ingredient (kg) & $0 \%$ & $2 \%$ & $4 \%$ & $6 \%$ & $8 \%$ \\
\hline Corn & 248.25 & 239.45 & 230.65 & 221.85 & 213.05 \\
SBM 48 & 133.65 & 133.65 & 133.65 & 133.65 & 133.65 \\
Corn Distillers Solubles & 44.00 & 44.00 & 44.00 & 44.00 & 44.00 \\
Plenish HO Oil & - & 8.80 & 17.60 & 26.40 & 35.20 \\
Limestone & 5.05 & 5.05 & 5.05 & 5.05 & 5.05 \\
Dical Phosphate & 4.84 & 4.84 & 4.84 & 4.84 & 4.84 \\
Salt & 1.54 & 1.54 & 1.54 & 1.54 & 1.54 \\
Vitamin/Mineral Premix & 1.10 & 1.10 & 1.10 & 1.10 & 1.10 \\
Methionine & 0.72 & 0.72 & 0.72 & 0.72 & 0.72 \\
Lysine HCL & 0.62 & 0.62 & 0.62 & 0.62 & 0.62 \\
Coban & 0.22 & 0.22 & 0.22 & 0.22 & 0.22 \\
\cline { 2 - 6 } & 440.00 & 440.00 & 440.00 & 440.00 & 440.00 \\
& & & & & \\
Crude Protein, \% & 22.49 & 22.24 & 21.89 & 19.72 & 20.77 \\
Crude Fat, \% & 3.56 & 5.24 & 7.26 & 9.02 & 10.78 \\
Crude Fiber, \% & 2.56 & 2.85 & 2.72 & 2.54 & 2.73 \\
Moisture, \% & 10.05 & 9.60 & 9.85 & 9.73 & 8.90 \\
Ash, \% & 5.77 & 5.53 & 5.94 & 5.57 & 5.50 \\
\hline
\end{tabular}

${ }^{1}$ Treatment percentages indicate amount of added High Oleic Soybean Oil 
Table 3.2. Composition of broiler finisher treatment diets with varying inclusion levels of high oleic soybean oil.

\begin{tabular}{lccccc}
\hline & \multicolumn{5}{c}{ Treatment Diets $^{1}$} \\
\cline { 2 - 6 } Ingredient (kg) & $0 \%$ & $2 \%$ & $4 \%$ & $6 \%$ & $8 \%$ \\
\hline Corn & 563.88 & 546.28 & 528.68 & 511.08 & 493.48 \\
SBM 48 & 204.92 & 204.92 & 204.92 & 204.92 & 204.92 \\
Corn Distillers Solubles & 88.00 & 88.00 & 88.00 & 88.00 & 88.00 \\
Plenish HO Oil & - & 17.60 & 35.20 & 52.80 & 70.40 \\
Limestone & 9.05 & 9.05 & 9.05 & 9.05 & 9.05 \\
Dical Phosphate & 6.89 & 6.89 & 6.89 & 6.89 & 6.89 \\
Salt & 3.08 & 3.08 & 3.08 & 3.08 & 3.08 \\
Vitamin/Mineral Premix & 2.20 & 2.20 & 2.20 & 2.20 & 2.20 \\
Methionine & 0.99 & 0.99 & 0.99 & 0.99 & 0.99 \\
Lysine HCL & 0.56 & 0.56 & 0.56 & 0.56 & 0.56 \\
Coban & 0.44 & 0.44 & 0.44 & 0.44 & 0.44 \\
\cline { 2 - 6 } & 880.00 & 880.00 & 880.00 & 880.00 & 880.00 \\
Crude Protein, \% & & & & & \\
Crude Fat, \% & 18.25 & 16.97 & 19.59 & 17.18 & 18.10 \\
Crude Fiber, \% & 3.98 & 5.39 & 7.26 & 9.23 & 10.87 \\
Moisture, \% & 2.46 & 2.65 & 2.45 & 2.49 & 2.50 \\
Ash, \% & 10.07 & 10.06 & 9.10 & 9.61 & 9.00 \\
\hline
\end{tabular}

${ }^{1}$ Treatment percentages indicate amount of added High Oleic Soybean Oil 
Table 3.3. Fatty acid composition of broiler starter treatment diets with varying inclusion levels of high oleic soybean oil.

\begin{tabular}{lccccc}
\hline & \multicolumn{5}{c}{ Treatment Diets $^{1}$} \\
\cline { 2 - 6 } Fatty acid, \% & $0 \%$ & $2 \%$ & $4 \%$ & $6 \%$ & $8 \%$ \\
\hline Palmitic Acid (16:0) & 14.21 & 10.34 & 9.34 & 8.59 & 8.51 \\
Palmitoleic Acid (16:1) & - & 0.80 & 0.47 & 0.60 & 0.75 \\
Margaric acid (17:0) & - & 0.87 & 0.94 & 1.02 & 1.12 \\
Stearic Acid (18:0) & 2.48 & 3.47 & 3.50 & 3.70 & 3.70 \\
Oleic Acid (18:1n9c) & 26.53 & 46.6 & 55.15 & 58.83 & 60.56 \\
Vaccenic Acid (18:1n7) & 1.24 & 0.87 & 0.94 & 1.02 & 1.12 \\
Linoleic Acid (18:2n6c) & 53.06 & 34.49 & 26.16 & 22.55 & 20.72 \\
Arachidic acid (20:0) & - & - & 0.47 & 0.42 & 0.37 \\
Gondoic acid (20:1) & - & - & 0.45 & 0.42 & 0.37 \\
Alpha-Linolenic acid & 2.48 & 2.60 & 2.34 & 2.45 & 2.41 \\
(18:3n3) & & & & & \\
Adrenic Acid (22:4n6) & - & - & 0.47 & 0.42 & 0.37 \\
\hline
\end{tabular}

${ }^{1}$ Treatment percentages indicate amount of added High Oleic Soybean Oil 
Table 3.4. Fatty acid composition of broiler finisher treatment diets with varying inclusion levels of high oleic soybean oil.

\begin{tabular}{lccccc}
\hline & \multicolumn{5}{c}{ Treatment Diets $^{1}$} \\
\cline { 2 - 6 } Fatty acid, \% & $0 \%$ & $2 \%$ & $4 \%$ & $6 \%$ & $8 \%$ \\
\hline Palmitic Acid (16:0) & 13.30 & 10.42 & 8.96 & 8.51 & 8.28 \\
Palmitoleic Acid (16:1) & - & 0.92 & 0.43 & 0.61 & 0.58 \\
Margaric acid (17:0) & - & 0.79 & 0.86 & 0.93 & 1.01 \\
Stearic Acid (18:0) & 2.64 & 3.17 & 3.62 & 3.65 & 3.64 \\
Oleic Acid (18:1n9c) & 27.66 & 48.02 & 55.65 & 59.12 & 61.05 \\
Vaccenic Acid (18:1n7) & 1.07 & 0.92 & 1.06 & 1.22 & 1.17 \\
Linoleic Acid (18:2n6c) & 53.20 & 33.91 & 25.80 & 22.65 & 20.92 \\
Arachidic acid (20:0) & - & - & 0.43 & 0.30 & 0.29 \\
Gondoic acid (20:1) & - & - & 0.43 & 0.30 & 0.29 \\
Alpha-Linolenic acid & 2.13 & 2.24 & 2.34 & 2.43 & 2.47 \\
(18:3n3) & & & & & \\
Adrenic Acid (22:4n6) & - & - & 0.43 & 0.30 & 0.29 \\
\hline
\end{tabular}

${ }^{1}$ Treatment percentages indicate amount of added High Oleic Soybean Oil 
Table 3.5. Amino acid profiles of broiler starter treatment diets with varying inclusion levels of high oleic soybean oil.

\begin{tabular}{|c|c|c|c|c|c|c|}
\hline \multirow{2}{*}{ Item, g } & & \multicolumn{5}{|c|}{ Treatment Diets $^{1}$} \\
\hline & & 0 & 2 & 4 & 6 & 8 \\
\hline Taurine & & 0.15 & 0.15 & 0.14 & 0.14 & 0.14 \\
\hline Hydroxyproline & & 0.05 & 0.03 & 0.05 & 0.04 & 0.04 \\
\hline Aspartic Acid & & 2.19 & 2.07 & 2.16 & 2.01 & 2.02 \\
\hline Threonine & & 0.82 & 0.78 & 0.82 & 0.77 & 0.77 \\
\hline Serine & & 0.91 & 0.88 & 0.91 & 0.86 & 0.86 \\
\hline Glutamic Acid & & 3.98 & 3.80 & 3.92 & 3.64 & 3.64 \\
\hline Proline & & 1.36 & 1.30 & 1.36 & 1.26 & 1.25 \\
\hline Lanthionine & & 0.00 & 0.00 & 0.00 & 0.00 & 0.00 \\
\hline Glycine & & 0.93 & 0.87 & 0.92 & 0.86 & 0.88 \\
\hline Alanine & & 1.16 & 1.11 & 1.15 & 1.09 & 1.09 \\
\hline Cysteine & & 0.41 & 0.35 & 0.38 & 0.35 & 0.35 \\
\hline Valine & & 1.11 & 1.04 & 1.11 & 1.03 & 1.04 \\
\hline Methionine & & 0.54 & 0.47 & 0.53 & 0.47 & 0.47 \\
\hline Isoleucine & & 1.02 & 0.97 & 1.01 & 0.94 & 0.94 \\
\hline Leucine & & 1.99 & 1.91 & 1.97 & 1.86 & 1.86 \\
\hline Tyrosine & & 0.71 & 0.71 & 0.75 & 0.70 & 0.70 \\
\hline Phenylalanine & & 1.13 & 1.07 & 1.12 & 1.04 & 1.04 \\
\hline Hydroxylysine & & 0.03 & 0.03 & 0.03 & 0.03 & 0.03 \\
\hline Ornithine & & 0.02 & 0.02 & 0.02 & 0.02 & 0.02 \\
\hline Lysine & & 1.29 & 1.25 & 1.34 & 1.23 & 1.23 \\
\hline Histidine & & 0.59 & 0.56 & 0.59 & 0.55 & 0.55 \\
\hline Arginine & & 1.42 & 1.33 & 1.43 & 1.32 & 1.32 \\
\hline \multirow[t]{2}{*}{ Tryptophan } & & 0.50 & 0.26 & 0.27 & 0.22 & 0.25 \\
\hline & Total & 22.31 & 20.96 & 21.96 & 20.43 & 20.46 \\
\hline
\end{tabular}

${ }^{1}$ Treatment percentages indicate amount of added High Oleic Soybean Oil 
Table 3.6. Amino acid profiles of broiler finisher treatment diets with varying inclusion levels of high oleic soybean oil.

\begin{tabular}{|c|c|c|c|c|c|c|}
\hline \multirow[b]{2}{*}{ Item, $\mathrm{g}$} & & \multicolumn{5}{|c|}{ Treatment Diets $^{1}$} \\
\hline & & 0 & 2 & 4 & 6 & 8 \\
\hline Taurine & & 0.16 & 0.15 & 0.15 & 0.15 & 0.14 \\
\hline Hydroxyproline & & 0.04 & 0.04 & 0.06 & 0.04 & 0.05 \\
\hline Aspartic Acid & & 1.76 & 1.87 & 1.65 & 1.67 & 1.70 \\
\hline Threonine & & 0.69 & 0.73 & 0.67 & 0.67 & 0.66 \\
\hline Serine & & 0.76 & 0.83 & 0.77 & 0.79 & 0.74 \\
\hline Glutamic Acid & & 3.31 & 3.47 & 3.18 & 3.20 & 3.23 \\
\hline Proline & & 1.21 & 1.23 & 1.18 & 1.17 & 1.14 \\
\hline Lanthionine & & 0.00 & 0.00 & 0.00 & 0.00 & 0.00 \\
\hline Glycine & & 0.78 & 0.81 & 0.75 & 0.75 & 0.76 \\
\hline Alanine & & 1.05 & 1.05 & 1.01 & 1.00 & 0.99 \\
\hline Cysteine & & 0.32 & 0.38 & 0.31 & 0.31 & 0.33 \\
\hline Valine & & 0.92 & 0.96 & 0.87 & 0.88 & 0.92 \\
\hline Methionine & & 0.37 & 0.47 & 0.40 & 0.39 & 0.42 \\
\hline Isoleucine & & 0.82 & 0.86 & 0.77 & 0.79 & 0.82 \\
\hline Leucine & & 1.76 & 1.77 & 1.68 & 1.69 & 1.67 \\
\hline Tyrosine & & 0.64 & 0.66 & 0.60 & 0.62 & 0.61 \\
\hline Phenylalanine & & 0.96 & 0.98 & 0.90 & 0.91 & 0.92 \\
\hline Hydroxylysine & & 0.03 & 0.03 & 0.03 & 0.03 & 0.03 \\
\hline Ornithine & & 0.01 & 0.01 & 0.01 & 0.01 & 0.02 \\
\hline Lysine & & 1.00 & 1.07 & 0.95 & 0.98 & 1.02 \\
\hline Histidine & & 0.50 & 0.52 & 0.48 & 0.48 & 0.49 \\
\hline Arginine & & 1.15 & 1.24 & 1.10 & 1.11 & 1.15 \\
\hline \multirow[t]{2}{*}{ Tryptophan } & & 0.21 & 0.20 & 0.22 & 0.22 & 0.23 \\
\hline & Total & 18.47 & 19.33 & 17.74 & 17.86 & 18.04 \\
\hline
\end{tabular}

${ }^{1}$ Treatment percentages indicate amount of added High Oleic Soybean Oil 


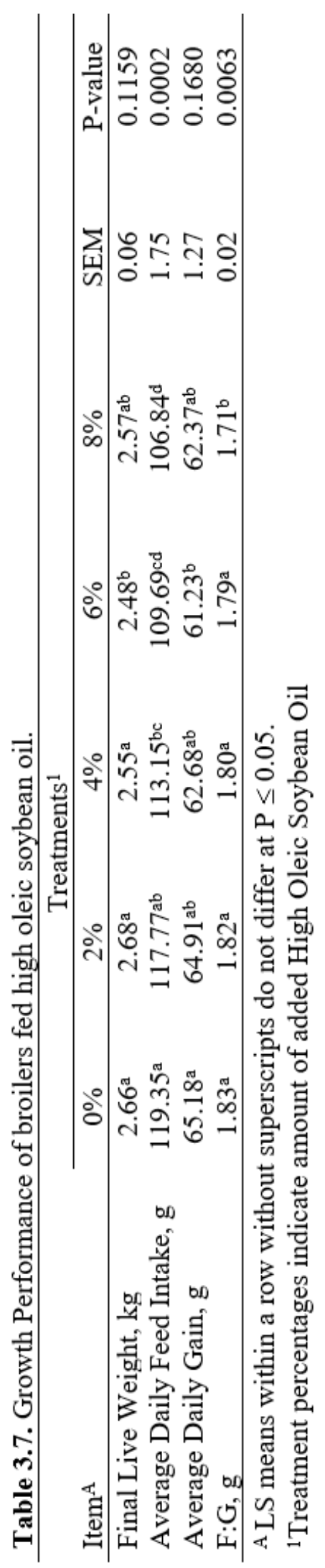




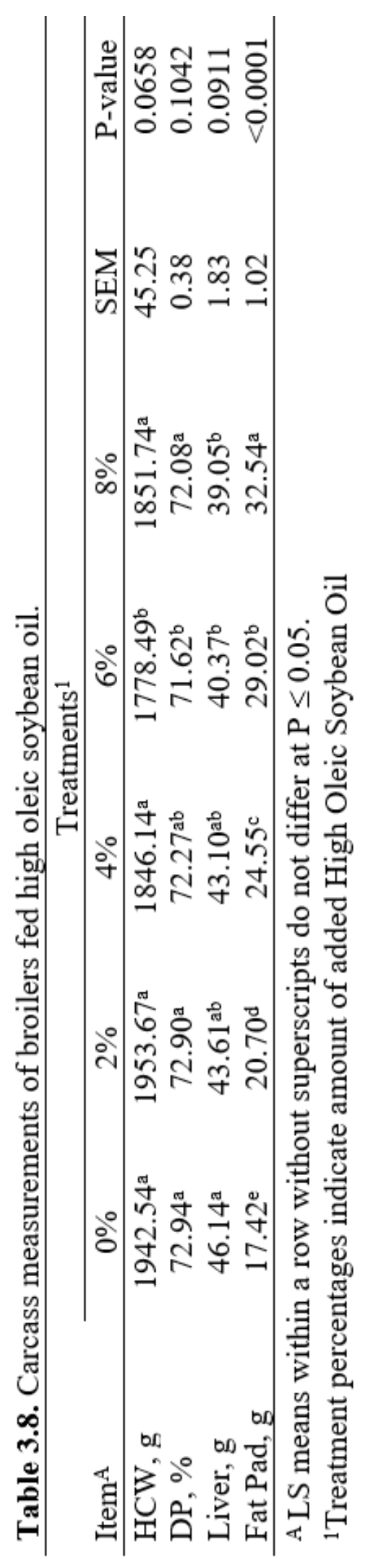




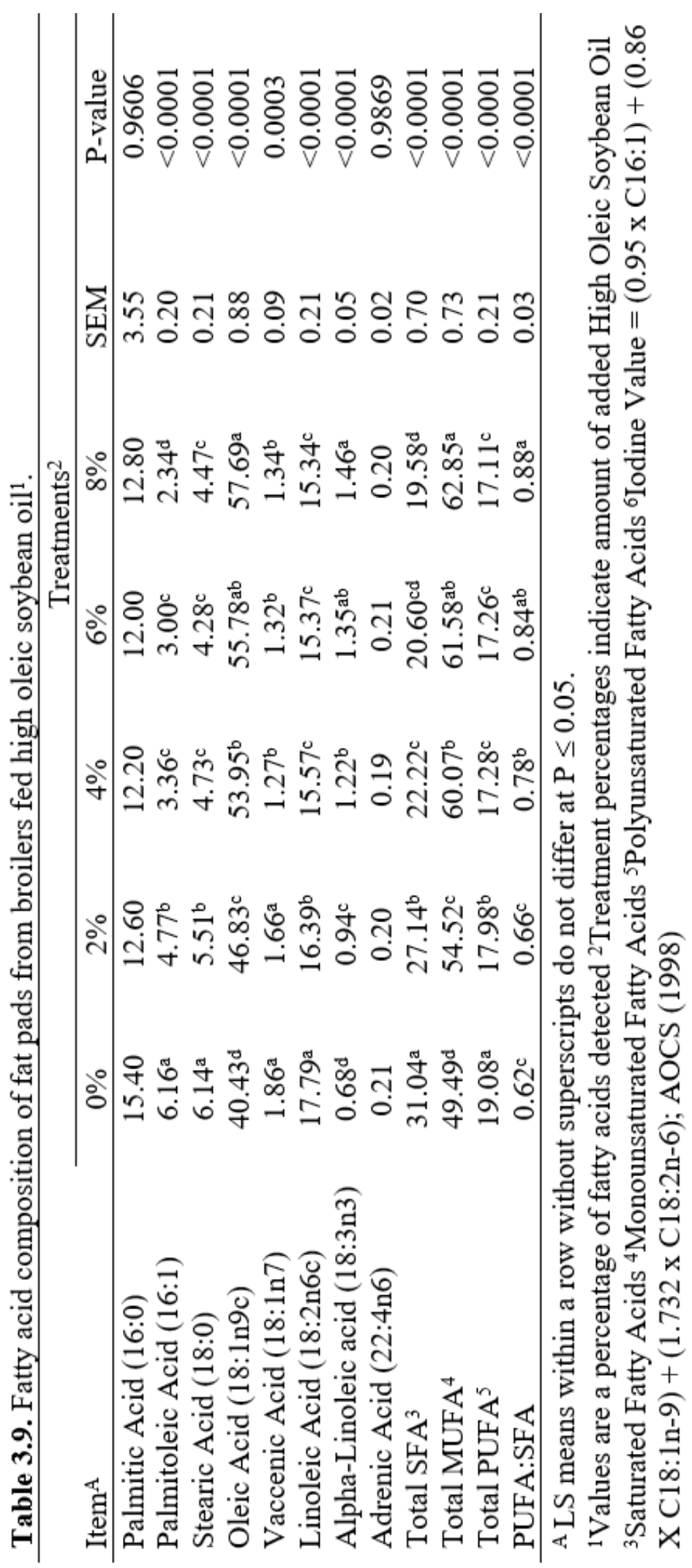


Figure 3.1. TBAR values of chicken bratwurst from broilers fed high oleic soybean oil.

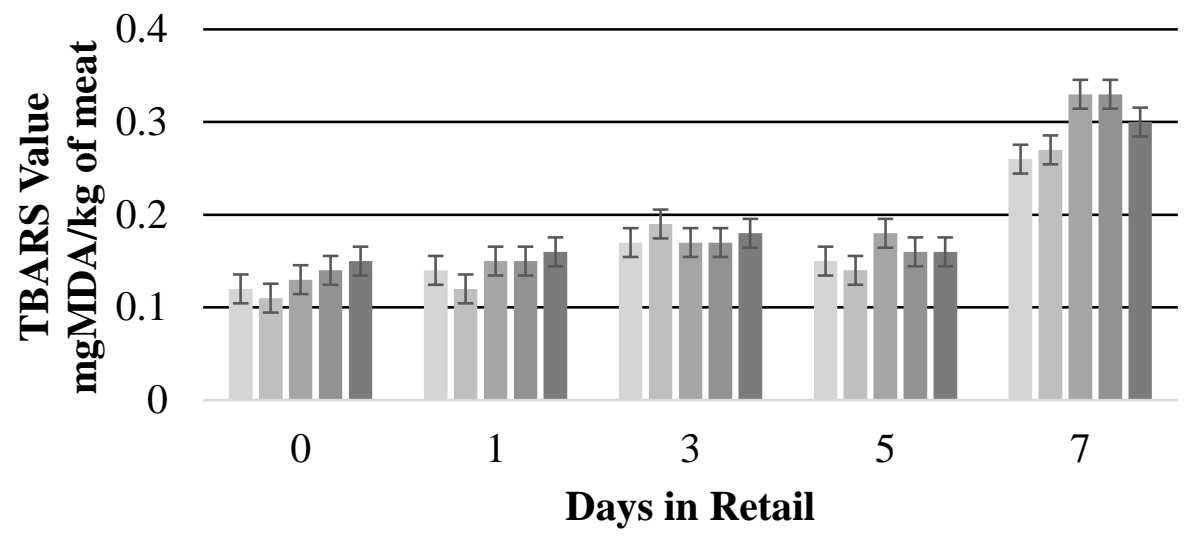

$\begin{array}{cc} & 0 \square 2 \square 4 \square 6 \square 8 \\ \text { Treatment } x \text { Day: } \mathrm{P}<0.0001 \quad \mathrm{SEM}=0.016\end{array}$


Figure 3.2. L* values of chicken bratwurst from broiler fed high oleic soybean oil.

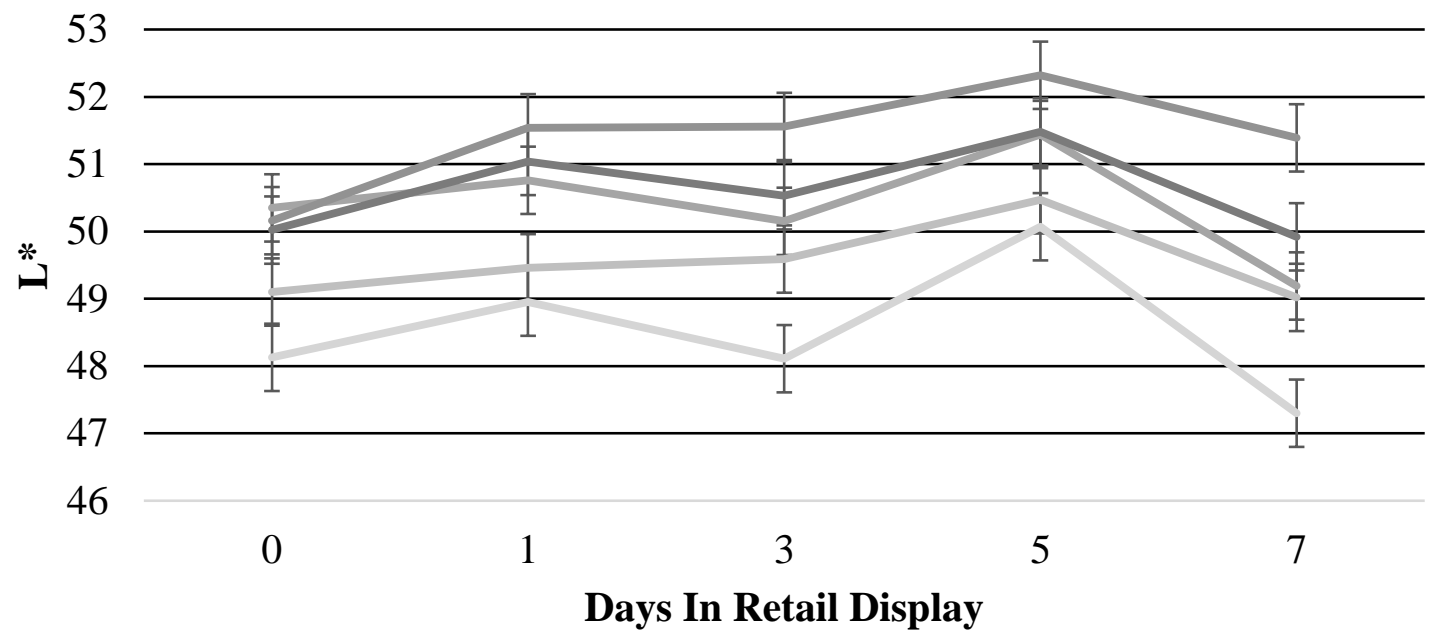

$\begin{array}{ll} & 0 \\ \text { Treatment } x \text { Day: } \mathrm{P}<0.0001 & \mathrm{SEM}=0.496\end{array}$


Figure 3.3. $a^{*}$ values of chicken bratwurst from broilers fed high oleic soybean oil.

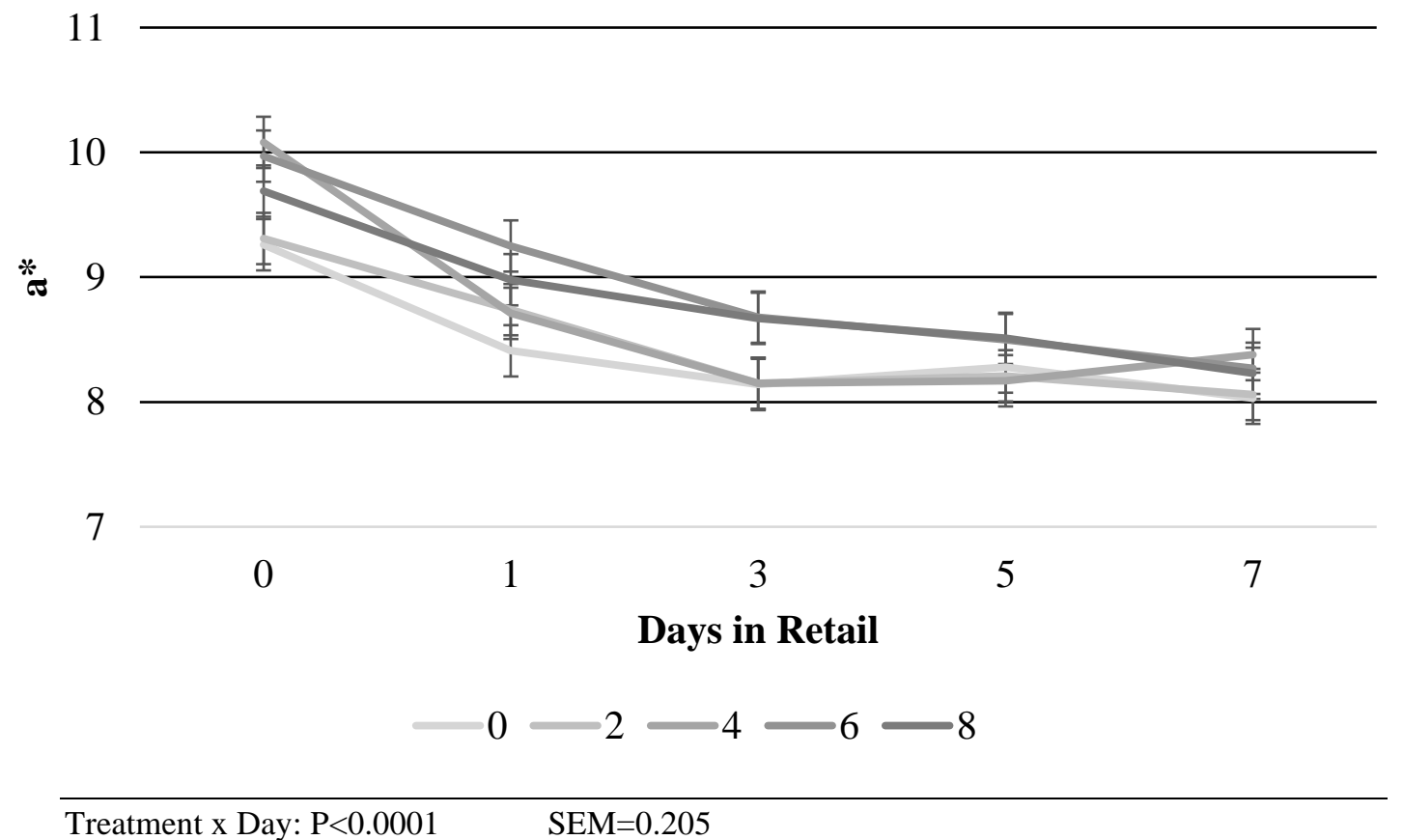

Treatment $x$ Day: $\mathrm{P}<0.0001 \quad$ SEM $=0.205$ 
Figure 3.4. $b^{*}$ values of chicken bratwurst from broilers fed high oleic soybean oil.

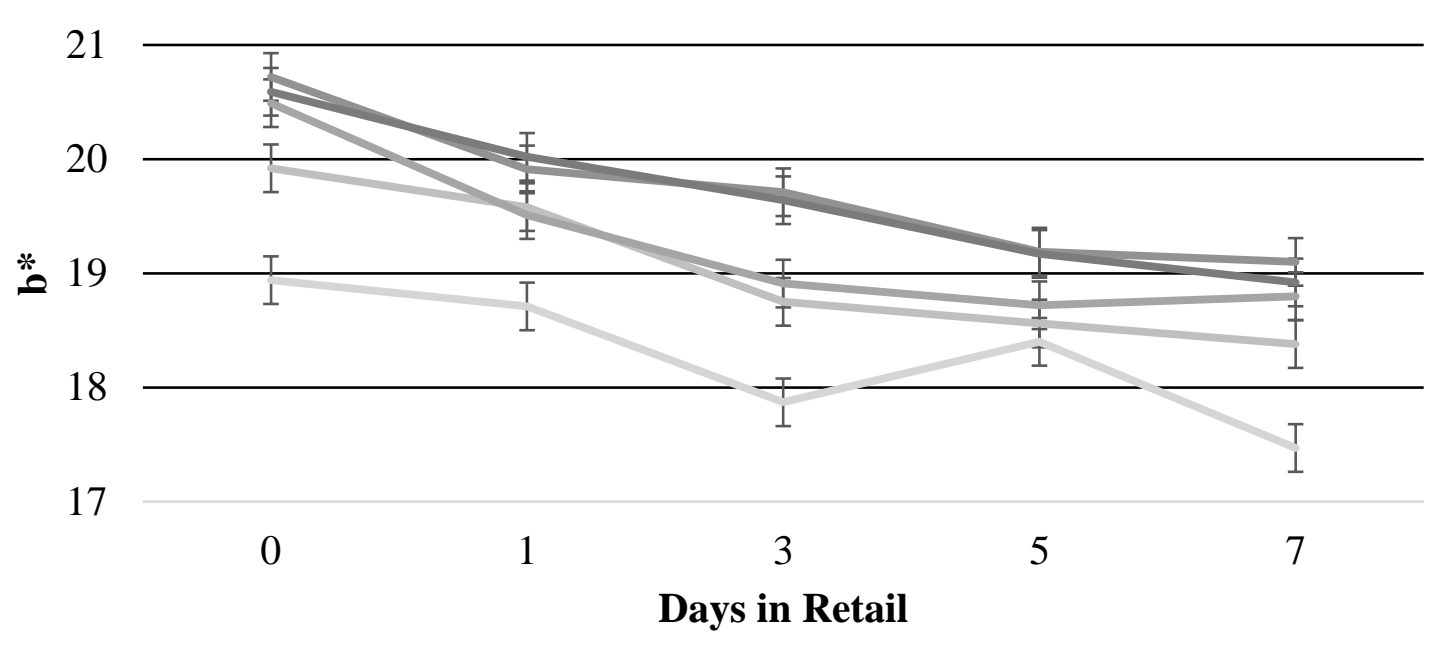

$\begin{array}{ll} & \\ & \\ \text { Treatment } x \text { Day: } \mathrm{P}<0.0001 & \mathrm{SEM}=0.209\end{array}$


Figure 3.5. a:b ratio values of chicken bratwurst from broilers fed high oleic soybean oil.

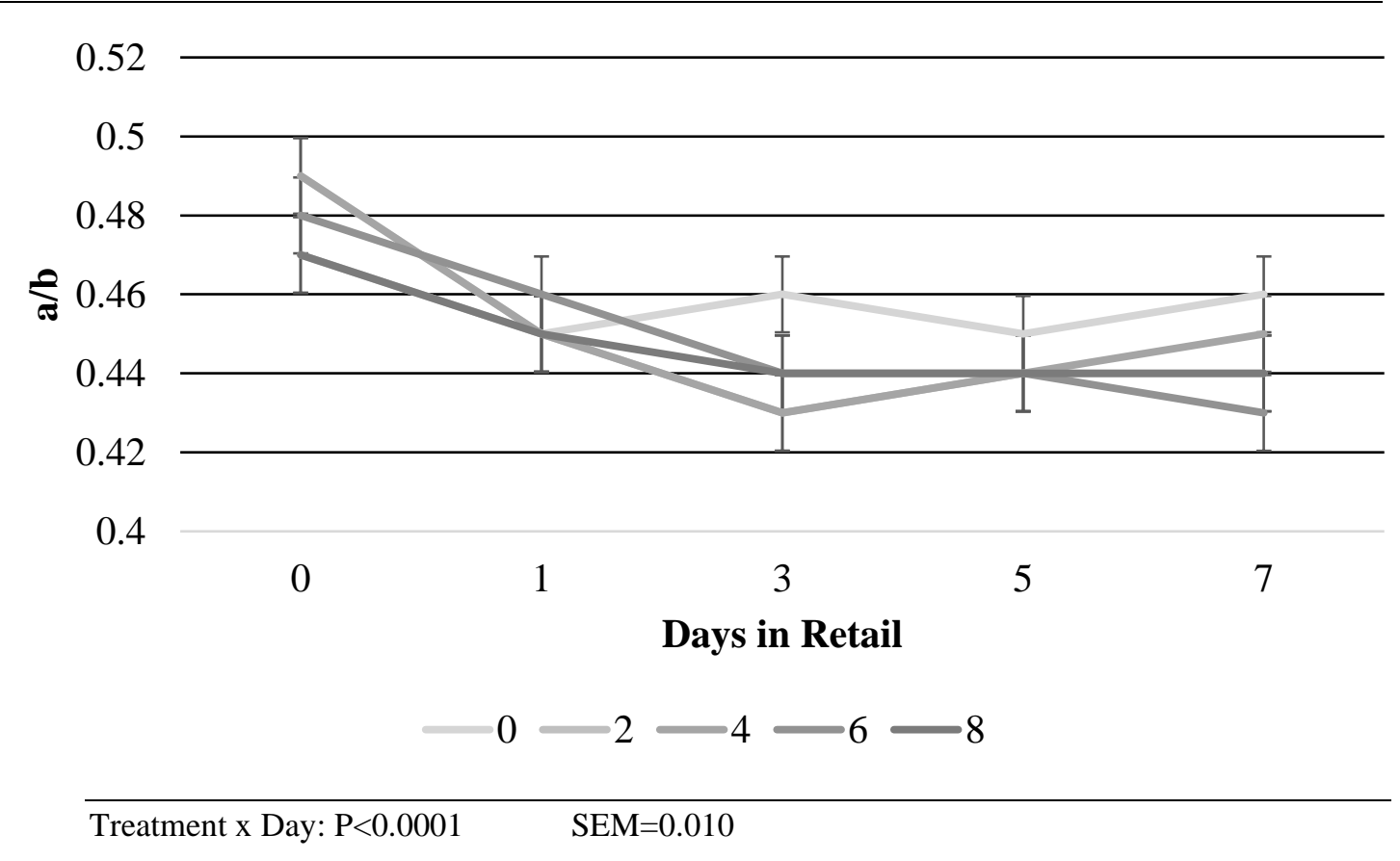


Figure 3.6. Saturation index values of chicken bratwurst from broilers fed high oleic soybean oil.

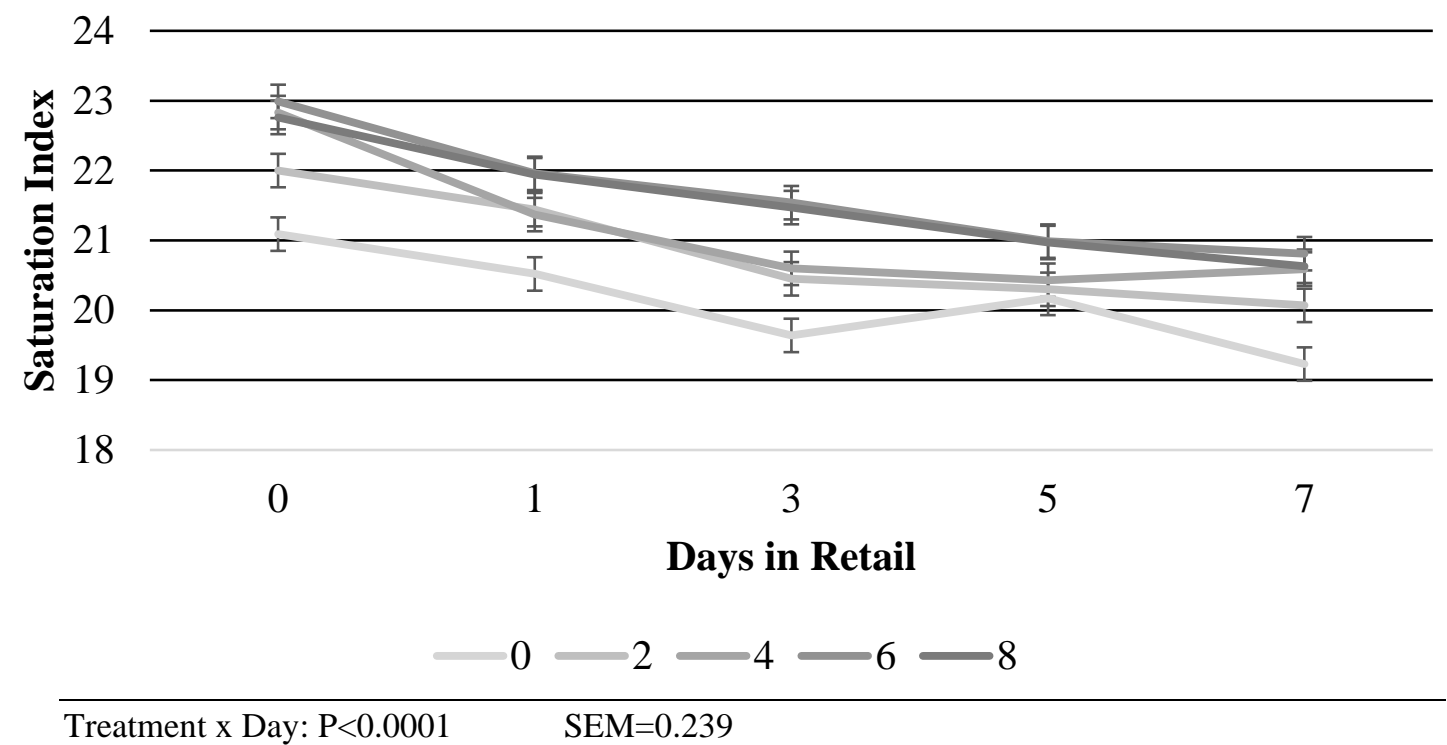


Figure 3.7. Hue angle values of chicken bratwurst from broilers fed high oleic soybean oil.

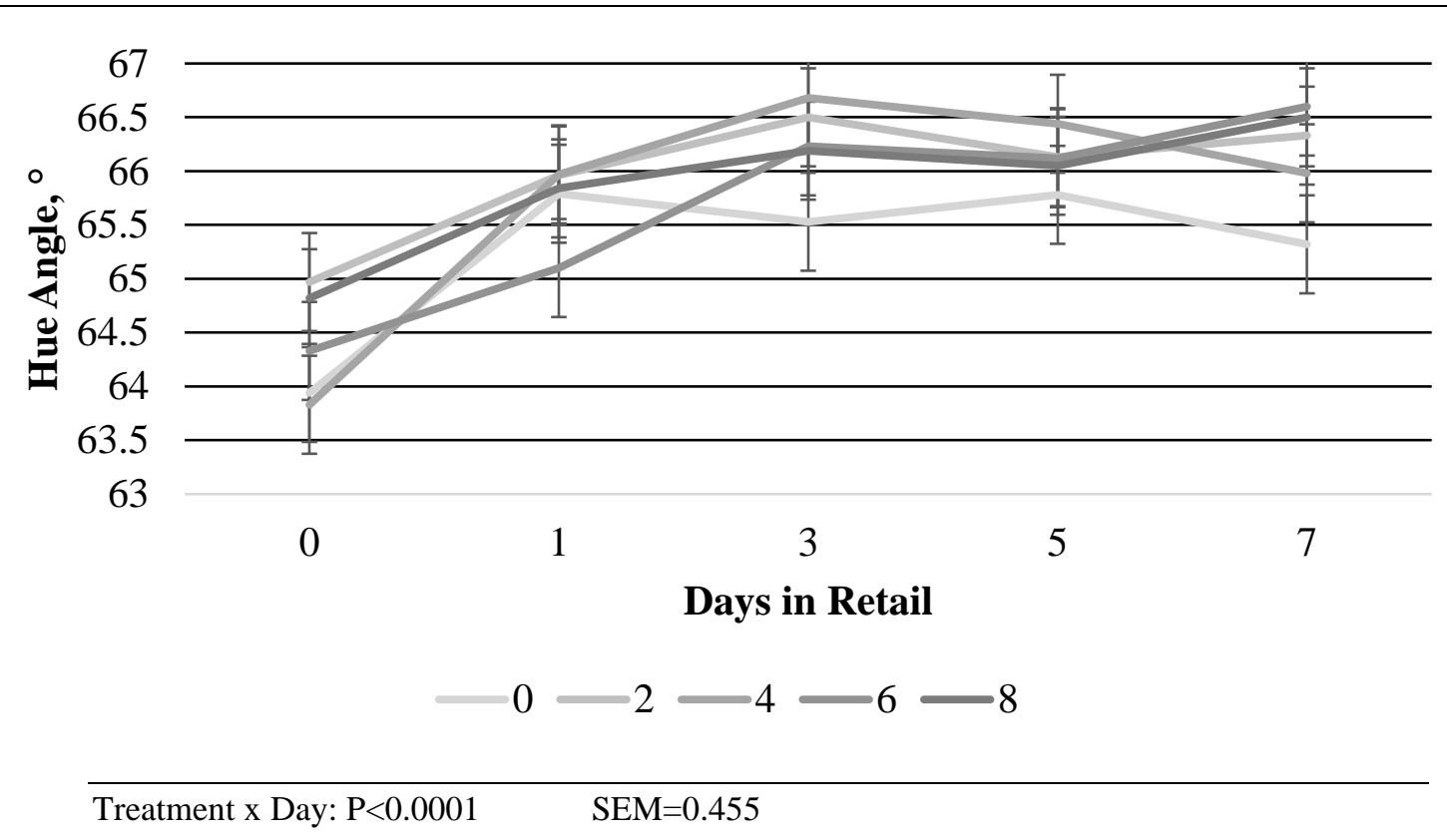


Table 3.10. Moisture and fat content of chicken bratwurst from broilers fed high oleic soybean oil.

\begin{tabular}{lccccccc}
\hline & \multicolumn{7}{c}{ Treatment Diets $^{1}$} \\
\cline { 2 - 8 } Item & $0 \%$ & $2 \%$ & $4 \%$ & $6 \%$ & $8 \%$ & SEM & P-value \\
\hline Moisture, \% & $71.60^{\mathrm{a}}$ & $70.36^{\mathrm{ab}}$ & $69.91^{\mathrm{ab}}$ & $69.28^{\mathrm{bc}}$ & $67.96^{\mathrm{c}}$ & 0.63 & 0.0089 \\
Fat, \% & $4.75^{\mathrm{c}}$ & $5.73^{\mathrm{b}}$ & $6.31^{\mathrm{b}}$ & $8.54^{\mathrm{a}}$ & $7.89^{\mathrm{a}}$ & 0.34 & $<0.0001$ \\
\hline
\end{tabular}

${ }^{1}$ Treatment percentages indicate amount of added High Oleic Soybean Oil 


\title{
CHAPTER 4
}

\section{INCLUSION OF DIETARY HIGH OLEIC SOYBEAN OIL ALTERS \\ FATTY ACID COMPOSTION OF EGG YOLK FAT AND \\ INCREASES EGG SIZE WITHOUT NEGATIVELY IMPACTING \\ EGG QUALITY IN WHITE LEGHORN LAYING HENS}

\begin{abstract}
The objective of this study was to determine the effects of dietary high oleic soybean oil inclusion on the hen performance, egg quality, and egg yolk fatty acid composition of White Leghorn laying hens. Laying hens $(n=192)$ were randomly sorted into 24 pens and randomly assigned to one of three treatments: $0.6 \%$ added conventional soybean oil $(\mathrm{CON}), 3 \%$ added high oleic soybean oil $(\mathrm{HO})$, and 3\% conventional soybean oil (SOY). Hens were fed ad libitum access for 32-weeks, force molted and then returned to treatment for laying cycle two. Feed refusal and pen weights were collected monthly and used to calculate average hen body weight (BW) and feed intake (FI). Eggs were collected daily to calculate average lay rate per hen. Eggs were sampled weekly to measure egg weight size. Eggs were sampled monthly, placed into cold storage for 0, 8, or 12 weeks, and then analyzed for color and fatty acid composition. Data were analyzed using PROC GLM procedure of SAS and significance was set at P-value $<0.05$. Hens on the HO diet
\end{abstract}


weighed more than hens on the CON and SOY diet $(\mathrm{P}=0.0002)$. No differences were observed between treatments for feed intake ( $\mathrm{P}=0.6941)$. Hens consuming the $\mathrm{HO}$ diet had a higher average daily lay rate compared to hens on the CON and SOY diets $(\mathrm{P}<0.0001)$. Egg weights were heavier for $\mathrm{HO}$ treatment compared to the CON and SOY treatments during the first laying cycle $(\mathrm{P}=0.0002)$. Diet changed the proportion of SFA, MUFA, and PUFA in egg yolk fat $(\mathrm{P}<0.001)$. The HO treatment decreased in total SFA, while the CON and SOY treatments resulted in no changes $(\mathrm{P}<0.0001)$. Total MUFA for HO treatment had an increase, while the SOY treatment decreased in total MUFA, and the CON treatment resulted in no change $(\mathrm{P}<0.0001)$. The HO treatment decreased in total PUFA, SOY treatment had a significant increase, and the CON treatment resulted in no change for total PUFA $(\mathrm{P}<0.0001)$. HO eggs had a significant increase in $\mathrm{C} 18: 1 \mathrm{n} 9(\mathrm{P}<0.0001)$. SOY eggs had a significant increase in $\mathrm{C} 18: 2 \mathrm{n} 6$ and $\mathrm{C} 18: 3 \mathrm{n} 3(\mathrm{P}<0.0001)$. Eggs from hens fed the HO diet resulted in higher $\mathrm{b}^{*}$ values (more yellow) and higher $\mathrm{a}^{*}$ values (more red) compared to eggs from SOY treatment $(\mathrm{P}<0.05)$. Subjective color measures recorded using the Roche yolk color fan found HO eggs had higher (more intense yellow-orange) Roche color fan scores compared to CON and SOY treatment eggs $(\mathrm{P}<0.0001)$ throughout time in cold storage. 


\section{INTRODUCTION}

Eggs are an economical source of protein and other nutrients needed by humans to achieve a healthy diet. Concerns have been brought up by consumers on the saturated fat content in eggs, this has led to the need to decrease amounts of saturated fats in egg yolks. It is known that monogastric animals take on fatty acid profiles in tissues that are similar to provided dietary lipid sources (Wood et al., 2008). Work has been done utilizing high oleic peanuts (Toomer et al., 2018) and high oleic sunflower oil (Cachaldora et al., 2005), in which the fatty acid profiles of egg yolks were shifted to increase total monounsaturated fatty acid (due to increase oleic acid content) and decrease total saturated fatty acids in egg yolk lipids. However, little research has been done with high oleic soybean oil and its effects on hen performance and egg quality. Therefore, the purpose of this study was to evaluate high oleic soybean oils effect on hen performance and egg quality parameters. 


\section{MATERIALS AND METHODS}

The University of Missouri Animal Care and Use Committee approved animal care and experimental protocols prior to initiation of this experiment (\#EX-10094).

\section{Experimental Design}

White Leghorn laying hens $(n=192)$ were randomly sorted into 24 pens, experimental unit is pen. Pens were randomly assigned to one of three treatment groups. Hens were housed in a curtain sided, climate-controlled facility through the duration of the laying cycle, with 14 hours of light provided daily.

The three treatment diets consisted of a control diet with $0.6 \%$ added conventional soybean oil (CON), 3\% added Plenish® (high oleic soybean oil) (HO), and 3\% conventional soybean oil (SOY). The control diet included $0.6 \%$ added oil for dust maintenance in the diet. All diets were formulated and balanced to meet NRC nutritional requirements (NRC, 1994). All animals were provided water and feed ad libitum. Feed was added to pens as needed, total weight of added feed was recorded to calculate total feed consumption.

Hens were fed for a 34-week laying cycle (239 days), while samples were collected. Hens were then force molted, by the removal of treatment diets and addition of a low nutritional value diet to induce molting. Hens were molted for five weeks to achieve a 18- 
$20 \%$ loss in body weight, and then returned to treatment diets for an additional three weeks to collect additional data during the second laying cycle.

\section{Data Collection}

Growth performance. Body weight and feed consumption of pens was recorded monthly from the start of the study to the end of the laying cycle. Pen weights and feed weight were used to calculate average hen body weight (BW) and feed intake (FI). Bird mortality records were used to adjust feed intake based on calculating bird days on feed.

Egg sampling. Daily shell eggs were collected to calculate daily lay rate. Weekly, shell eggs were sampled for weight measurements. Monthly, shell eggs were sampled for fatty acid analysis. Monthly, shell eggs were sampled, 1/3 of the pen was tested at 0 weeks in storage, 1/3 stored for 8 weeks in cold storage, and 1/3 were stored for 12 weeks in cold storage for subjective color measures, objective color measures, and lipid oxidation.

Egg yolk fatty acid. Egg yolk samples from pens were pooled and analyzed for fatty acid profiles at $0,1,3$, and 6 months of hens being on feed. Analysis were ran according to modified methodologies by Folch et al, (1957) and Morrison and Smith (1964). Approximately $500 \mathrm{mg}$ of sample was homogenized in chloroform:methanol $\left(\mathrm{CHCl}_{3}: \mathrm{CH}_{3} \mathrm{OH}, 2: 1, \mathrm{v} / \mathrm{v}\right)$ in a glass tube to extract lipids. Dehydrated samples were filtered through a sintered glass funnel fitted with a Whatman $2.4 \mathrm{~cm}$ GF/C filter.

A volume of $8 \mathrm{ml}$ of $0.74 \% \mathrm{KCl}$ was added to each sample and after two hours, two distinct layers formed. The upper phased was removed and discarded while the lower phase was evaporated to dryness with nitrogen in a water bath. At the point of dryness, $1 \mathrm{ml}$ of 
$0.5 \mathrm{~N} \mathrm{KOH}$ was added to each tube and heated for 10 minutes in a $70^{\circ} \mathrm{C}$ water bath. The addition of $\mathrm{KOH}$ initiates the saponification reaction, which hydrolyzes fatty acids from a triglyceride molecule. Following this, $1 \mathrm{ml}$ of $14 \% \mathrm{BF}_{3}$ in $\mathrm{MeOH}$ was added, samples were flushed with nitrogen and heated in the water bath for 30 minutes. Boron trifluoride is highly volatile and acts as an acid catalyst in the transesterification reaction that methylates the acid group on free fatty acids removing the net negative charge. The remaining molecule is known as a fatty acid methyl ester (FAME).

FAMEs are liquefied by adding $2 \mathrm{ml}$ of HPLC grade hexane and $2 \mathrm{ml}$ of $\mathrm{NaCl}$. Two distinct layers are formed; the upper layer is removed and added to $\sim 800 \mathrm{mg}$ of $\mathrm{Na}_{2} \mathrm{SO}_{4}$ to remove any moisture in the sample. At this point, 2 more $\mathrm{ml}$ of hexane was added to the tube containing $\mathrm{NaCl}$ and once more, the upper layer was removed and added to the tube containing $\mathrm{Na}_{2} \mathrm{SO}_{4}$. The hexane potion was removed from the salt and added to a labeled scintillation vial. The salt was rinsed once more with $1 \mathrm{ml}$ of hexane and the liquid was added to the vial. Samples were evaporated to dryness in a water bath at $70^{\circ} \mathrm{C}$ under nitrogen flow. Lastly, samples were reconstituted with $1 \mathrm{ml}$ HPLC grade hexane and transferred to gas chromatograph vials.

The stable FAMEs were loaded into a Varian 3,800 gas chromatographer (Varios, Pala Alto, CA) to determine fatty acid profiles. The column utilized was a fused silica capillary column (SPTM-2,560; $100 \mathrm{~m}$ x $0.25 \mathrm{~mm}$ x $0.2 \mu \mathrm{m}$ film thickness; Supelco, Bellefonte, PA). Temperature of the injector was held constant at $240^{\circ} \mathrm{C}$ and temperature of the flame-ionizer detector was held at $260^{\circ} \mathrm{C}$. The oven operated at $140^{\circ} \mathrm{C}$ for 5 minutes (temperature programmed $2.5^{\circ} \mathrm{C} /$ minute to $240^{\circ} \mathrm{C}$ and held for 16 minutes). Helium, the 
carries gas, was maintained at a constant pressure of 37 psi. Individual fatty acids were expressed as a percentage of the total area under the peaks.

Total saturated fatty acid (SFA), monounsaturated fatty acids (MUFA) and polyunsaturated fatty acid (PUFA) contents were calculated according to the following equations: $\mathrm{SFA}=(\mathrm{C} 14: 0+\mathrm{C} 16: 0+\mathrm{C} 17: 0+\mathrm{C} 18: 0+\mathrm{C} 20: 0) ; \mathrm{MUFA}=(\mathrm{C} 14: 1+\mathrm{C} 16: 1+$ $\mathrm{C} 17: 1+\mathrm{C} 18: 1 \mathrm{n} 9 \mathrm{t}+\mathrm{C} 18: 1 \mathrm{n} 9 \mathrm{c}+\mathrm{C} 18: 1 \mathrm{n} 7) ; \mathrm{PUFA}=(\mathrm{C} 18: 2 \mathrm{n} 6 \mathrm{t}+\mathrm{C} 18: 2 \mathrm{n} 6 \mathrm{c}+\mathrm{C} 18: 3 \mathrm{n} 6+$ $\mathrm{C} 18: 3 \mathrm{n} 3+\mathrm{C} 20: 4 \mathrm{n} 6+\mathrm{C} 20: 5 \mathrm{n} 3+\mathrm{C} 22: 4 \mathrm{n} 6+\mathrm{C} 22: 6 \mathrm{n} 3)$. The following equations were used to calculate total omega 3 and omega 6 fatty acid content: total omega $3=(\mathrm{C} 18: 3 \mathrm{n} 3+$ $\mathrm{C} 20: 5 \mathrm{n} 3+\mathrm{C} 22: 6 \mathrm{n} 3) ;$ total omega $6=(\mathrm{C} 18: 2 \mathrm{n} 6 \mathrm{t}+\mathrm{C} 18: 2 \mathrm{n} 6 \mathrm{c}+\mathrm{C} 18: 3 \mathrm{n} 6+\mathrm{C} 20: 4 \mathrm{n} 6+$ $\mathrm{C} 22: 4 \mathrm{n} 6)$.

Objective color measure. Monthly eggs were sampled, and objective color measures were recorded at 0,8 , and 12 weeks of cold storage. Objective color was measured by CIE system L* (lightness), a* (redness), and $\mathrm{b}^{*}$ (yellowness) using a HunterLab MiniScan Spectrocolorimeter (MiniScan XE; Hunter and Assoc., Reston, VA) with a $2.5 \mathrm{~cm}$ port and glass cover calibrated against a white tile. Instrumental color readings were utilized to calculate a/b ration, saturation index (SI), and hue angle (HA) values.

Subjective color measure. Monthly eggs were sampled, and subjective color measures were recorded at 0,8 , and 12 weeks of cold storage. At testing subjective color measures of egg yolks were recorded using the DSM Color fan, which consists of a series of 15 colored plastic tabs arranged as a fan corresponding to a range of yolk colors from light yellow to orange-red (1- light yellow, 15- orange-red). 
Lipid oxidation (TBARS). Lipid oxidation of egg yolk samples was measured using the method described by Tarladgis et al. (1960) with modifications from Fernando et al. (2003). Malonaldehyde, a by-product of oxidation, was measured to indicate the rate of oxidation that had occurred in each sample over a specified time period. Monthly pen eggs were sampled and stored in cold storage $\left(4^{\circ}\right)$ for 0,8 , or 12 weeks. Eggs were removed from storage and sampled for lipid oxidation. Duplicate 2-gram samples of egg yolks were placed into a $50 \mathrm{~mL}$ tube with $18 \mathrm{~mL}$ of perchloric acid. $50 \mu \mathrm{l}$ of butylated hydroxytoluene was added. Each tube was homogenized for 30 seconds using a Hamilton Beach hand blender. Following homogenization sample was filtered through Fisherbrand Filter Paper Whatman P4, into another $50 \mathrm{~mL}$ tube. $2 \mathrm{~mL}$ of sample was pipetted into a $25 \mathrm{~mL}$ glass tube along with $2 \mathrm{~mL}$ of TBA (0.02 M thiobarbituric acid in 90\% acetic acid). Samples were capped and vortexed. Samples were then placed into a $100^{\circ} \mathrm{C}$ water bath for 30 minutes. Color absorbance was measured at $531 \mathrm{~nm}$ using a Spectronic 20 (Bausch \& Lomb, Rochester, NY) spectrophotometer. Values of each reading were recorded and averaged for further calculation. Lipid oxidation was expressed in $\mathrm{mg} / \mathrm{kg}$ of malonaldehyde recovered and calculated using the recorded spectrophotometer averages and the give equation below.

\section{$\mathrm{mg} / \mathrm{kg}$ of malonaldehyde $=7.8 *$ spectrophotometer reading}

\section{Statistical Analysis}

Data were analyzed using SAS 9.4 (SAS inst., Cary, NC). Pen served as the experimental unit and the statistical model included the fixed effect of dietary treatment. The least squares mean, and standard error were determined for variable according to 
treatment. An analysis of variance of least squares means of treatments was conducted using PROC GLM, with a pairwise comparison used to detect potential differences between treatments. Level of significance was set at $\mathrm{P} \leq 0.05$.

\section{RESULTS}

\section{Hen performance}

Results for hen performance is outlined in Table 4.4. On average during the 32week laying cycle, hens on the CON diet weighed $1.76 \mathrm{~kg}$, HO hens weighed $1.81 \mathrm{~kg}$, and SOY hens weighed $1.75 \mathrm{~kg}$. Hens on the HO diet were heavier compared to hens on the CON diet and SOY diet $(\mathrm{P}=0.0002)$. There were no differences observed in feed intake (FI) between treatments $(\mathrm{P}=0.6941)$.

\section{Egg production}

Results for daily egg count are presented in Figure 4.1. Laying hens on HO diet had a higher average daily lay rate (0.949 eggs/hen/day), followed by hens on the CON treatment (0.932 eggs/hen/day) and hens on the SOY (0.908 eggs/hen/day) treatment having the lowest daily lay rate. $(\mathrm{P}<0.0001)$.

\section{Egg weight}

Results of egg weights are shown in Figure 4.2 and 4.3. Eggs from hens fed the HO treatment had heavier egg weight size compared the CON and SOY treatments during the first laying cycle $(\mathrm{P}=0.0002)$. There were no differences between treatments for egg weight size during the second laying cycle $(\mathrm{P}=0.5898)$. 


\section{Fatty acid analysis}

Analysis of the fatty acid profile of egg yolks (Table 4.5) showed significant differences $(\mathrm{P} \leq 0.05)$ between treatments for the following individual fatty acids: $\mathrm{C} 16: 0$, C16:1, C18:0, C18:1n9c, C18:1n7, C18:2n6c, C18:3n3, and C22:4n6. Measurable differences were present $(\mathrm{P} \leq 0.05)$. for total SFA, total MUFA, and total PUFA in fatty acid profiles of egg yolks.

Egg yolks from hens fed the HO treatment decreased in 16:0 after 1 month of feeding while CON saw no change and SOY treatments decreased after 1 month on feed and then increased after 3 and 6 months on feed. $(\mathrm{P}=0.0004)$. Egg yolks from hens fed the HO treatment decreased in 18:0 after 1 month on feed, while egg yolks from hens fed the SOY treatments increased in 18:0 and the CON resulted in no change over months on feed $(\mathrm{P}<0.0001)$. The HO treatment decreased in total SFA percent, while the CON and SOY treatments resulted in no changes $(\mathrm{P}<0.0001)$.

Egg yolks from hens fed the HO and SOY treatments decreased in 16:1 after 1 month of feeding compared to yolks from CON laying hens, which resulted in no change $(\mathrm{P}<0.0001)$. Egg yolks from hens fed the HO treatment resulted in a significant increase in 18:1n9c, while egg yolks from hens fed the SOY treatments decreased, and yolks from the $\mathrm{CON}$ hens resulted in no changes $(\mathrm{P}<0.0001)$. Egg yolks from hens fed the $\mathrm{HO}$ and SOY treatments resulted in a decrease in 18:1n7 after 1 month of feeding, while yolks from hens fed the CON diet decreased after 3 months on feed $(\mathrm{P}<0.0001)$. Total MUFA percentage for HO treatment increased, while the SOY treatment resulted in a decrease in total MUFA, and the CON treatment resulted in no change $(\mathrm{P}<0.0001)$. 
Egg yolks from hens fed the HO treatment saw a slight decrease in 18:2n6c over six months of feeding, while yolks from hens fed SOY treatments resulted in a significant increase, and yolks from CON resulted in no change $(\mathrm{P}<0.0001)$. Egg yolks from hens fed the HO treatments had an initial increase in 18:3n 3 after 1 month of feeding and then a decrease after 3 and 6 months of feeding, egg yolks from hens fed SOY resulted in a significant increase over the sampling periods, and egg yolks from CON treatment resulted in no change in $18: 3 \mathrm{n} 3(\mathrm{P}<0.0001)$. All treatments decreased in 22:4n6 over the sampling periods $(\mathrm{P}=0.0108)$. The $\mathrm{HO}$ treatment resulted in a slight decrease in total PUFA over 6 months of feeding, SOY treatment resulted in a significant increase, and the CON treatment resulted in no change in total PUFA $(\mathrm{P}<0.0001)$.

\section{Egg quality parameters}

\section{Objective color measure}

Analysis of objective color score is shown in Figures 4.4, 4.5, 4.6. Eggs from hens fed the HO diet had $b^{*}$ values higher (more yellow) compared to SOY eggs during 0 and 12 weeks of storage $(\mathrm{P}<0.05)$. No differences were observed for $\mathrm{L}^{*}$ values between treatments during any of the sampling periods $(\mathrm{P}>0.05)$. Eggs from hens fed the HO diet had higher (more red) $\mathrm{a}^{*}$ values compared to eggs from hens fed the SOY $\operatorname{diet}(\mathrm{P}<0.05)$.

\section{Subjective color measure}

Analysis of subjective color score is shown in Figure 4.7. Yolk color fan score for yolks from the HO treatment were higher compared to fan scores from yolks from hens fed the CON diet $(\mathrm{P}=0.0028)$ and the SOY $\operatorname{diet}(\mathrm{P}=0.0006)$. 


\section{Lipid oxidation}

Results for lipid oxidation are presented in Figure 4.8. Treatment did not impact lipid oxidation in egg yolk samples $(\mathrm{P}=0.7126)$.

\section{DISCUSSION}

Hens fed the HO diet were heavier compared to the CON and SOY treatments; however, feed intake was not different between treatments. HO birds were able to maintain body mass size on the same amount of feed compared to SOY and CON. This differs from previous research which has shown no difference in hen performance when supplemented with high-oleic sunflower oil (Cachaldora, et al., 2005; Alvarez, et al., 2005).

HO hens while consuming the same amount of feed produced heavier sized eggs during the first laying cycle compared to CON and SOY treatments. Studies done by Cachaldora et al. (2005) and Elkin et al. (2018) saw no differences in egg weight from hens supplemented with high-oleic sunflower oil and high oleic soybean, respectively. Laying hens on the HO treatment had a higher rate of lay (egg/hen/day) compared to the CON and SOY treatments. This differs from research done by Sangkaew et al. (2017), Elkin et al. (2018), and Toomer et al. (2019), where there was no difference in rate of lay when feeding high oleic sunflower oil, high oleic soybean oil and high oleic peanut oil, respectively. Inclusion of HO oil in laying hen diets lead to heavier weight eggs and a higher lay rate.

Fatty acid analysis of egg yolks showed that eggs from the HO treatment had increased total MUFA concentration, specifically due to increased levels of oleic acid (C18:1n9c) and decreased concentrations in SFA and PUFA. This is in line with work done 
utilizing high oleic soybean oil, high oleic peanut oil and high oleic sunflower oil, all of which saw an increase in oleic acid and total MUFA (Sangkaew et al., 2017; Elkin et al., 2018; Toomer et al., 2019). An increase in oleic acid is beneficial for a few reasons; increased MUFA concentrations have been the target of health-conscious individuals wanting low levels of SFA, high oleic oil contains high levels of tocopherols, naturally occurring antioxidants (Sangkaew et al., 2017). Fatty acid profiles from SOY treatment showed a decrease in total MUFA concentration and a significant increase in PUFA concentrations, due to the increase in linoleic acid $(\mathrm{C} 18: 2 \mathrm{n} 6 \mathrm{c})$. These results further support research that shows monogastric species take on fatty acid profiles in tissues, that are similar to those dietary fatty acids in the diet (Wood et al., 2008).

Egg yolks from hens fed the HO diet had more yellow-orange yolks compared to the CON and SOY diets according to the DSM color fan score. Objective measures agree with this, showing egg yolks from HO fed laying hens had more yellow-red yolks compared to CON and SOY. This is in line with work done by Toomer et al., where eggs produced from hens fed high-oleic peanut + corn diet, were a more intense yellow-orange compared to yolks from hens fed soybean meal + corn diet (2019). Indicating the addition of high-oleic soybean oil does not negatively affect egg yolk color.

\section{IMPLICATIONS}

The results from this study showed that dietary high oleic soybean oil altered the fatty acid composition of egg yolks and increased egg size without having a significant effect on egg 
quality parameters. The results suggest that including high oleic soybean oil will shift the proportion of fatty acids in egg yolk tissues, to include higher levels of beneficial monounsaturated fatty acids and decrease amounts of saturated fatty acids. Increase egg size is beneficial for producers who wish to sell premium size eggs. 
Table 4.1. Composition of laying hen treatment diets.

\begin{tabular}{|c|c|c|c|}
\hline \multirow[b]{2}{*}{ Ingredient $(\mathrm{kg})$} & \multicolumn{3}{|c|}{ Treatment Diets ${ }^{1}$} \\
\hline & $\mathrm{CON}$ & $\mathrm{HO}$ & SOY \\
\hline Corn & 566.12 & 545.45 & 545.45 \\
\hline SBM 48 & 189.74 & 189.74 & 189.74 \\
\hline Limestone & 83.94 & 83.94 & 83.94 \\
\hline Corn Distillers- Solubles & 45.45 & 45.45 & 45.45 \\
\hline Dical Phosphate & 11.10 & 11.10 & 11.10 \\
\hline Commodity Soybean Oil & 6.11 & - & 27.27 \\
\hline High Oleic Soybean Oil & - & 27.27 & - \\
\hline NB 3000 Vitamin Premix & 2.27 & 2.27 & 2.27 \\
\hline Salt & 2.83 & 2.83 & 2.83 \\
\hline \multirow[t]{2}{*}{ Methionine } & 1.52 & 1.52 & 1.52 \\
\hline & 909.09 & 909.09 & 909.09 \\
\hline Crude Protein, $\%$ & 15.83 & 16.50 & 15.88 \\
\hline Crude Fat, $\%$ & 1.86 & 4.86 & 3.49 \\
\hline Crude Fiber, $\%$ & 2.95 & 2.65 & 2.46 \\
\hline Moisture, \% & 9.40 & 9.39 & 9.41 \\
\hline Ash, $\%$ & 14.19 & 13.65 & 13.40 \\
\hline
\end{tabular}


Table 4.2. Fatty acid composition of laying hen treatment diets.

\begin{tabular}{lccc}
\hline & \multicolumn{3}{c}{ Treatment Diets $^{1}$} \\
\cline { 2 - 4 } Item & CON & HO & SOY \\
\hline C16:0 (Palmitic acid), & 13.94 & 9.43 & 12.73 \\
C18:0 (Stearic acid), \% & 2.89 & 3.35 & 3.18 \\
C18:1n9 (Oleic acid), \% & 25.00 & 53.43 & 23.61 \\
C18:1n7 (Vaccenic Acid), \% & 1.00 & 1.37 & 1.33 \\
C18:2n6 (Linoleic acid), \% & 54.78 & 28.30 & 54.11 \\
C18:3n3 (Alpha-Linolenic acid), \% & 2.89 & 2.74 & 5.04 \\
\hline${ }^{1}$ CON = Control, HO = 3\% high oleic soybean oil, SOY=3\% commodity soybean \\
oil
\end{tabular}


Table 4.3. Amino acid profiles of laying hen treatment diets.

\begin{tabular}{|c|c|c|c|c|}
\hline \multirow[b]{2}{*}{ Item, g } & & \multicolumn{3}{|c|}{ Treatment Diets ${ }^{1}$} \\
\hline & & $\mathrm{CON}$ & $\mathrm{HO}$ & SOY \\
\hline Taurine & & 0.16 & 0.15 & 0.14 \\
\hline Hydroxyproline & & 0.07 & 0.07 & 0.08 \\
\hline Aspartic Acid & & 1.55 & 1.57 & 1.50 \\
\hline Threonine & & 0.61 & 0.61 & 0.57 \\
\hline Serine & & 0.69 & 0.71 & 0.64 \\
\hline Glutamic Acid & & 2.86 & 2.93 & 2.83 \\
\hline Proline & & 0.97 & 1.00 & 1.01 \\
\hline Lanthionine & & 0.01 & 0.02 & 0.02 \\
\hline Glycine & & 0.66 & 0.67 & 0.66 \\
\hline Alanine & & 0.85 & 0.86 & 0.84 \\
\hline Cysteine & & 0.30 & 0.29 & 0.29 \\
\hline Valine & & 0.76 & 0.76 & 0.78 \\
\hline Methionine & & 0.46 & 0.40 & 0.44 \\
\hline Isoleucine & & 0.67 & 0.68 & 0.68 \\
\hline Leucine & & 1.43 & 1.44 & 1.41 \\
\hline Tyrosine & & 0.56 & 0.57 & 0.55 \\
\hline Phenylalanine & & 0.81 & 0.82 & 0.79 \\
\hline Hydroxylysine & & 0.03 & 0.04 & 0.03 \\
\hline Ornithine & & 0.01 & 0.01 & 0.01 \\
\hline Lysine & & 0.87 & 0.88 & 0.84 \\
\hline Histidine & & 0.42 & 0.42 & 0.42 \\
\hline Arginine & & 1.00 & 1.02 & 0.99 \\
\hline Tryptophan & & 0.20 & 0.21 & 0.18 \\
\hline & Total & 15.92 & 16.13 & 15.70 \\
\hline
\end{tabular}

${ }^{1} \mathrm{CON}=$ Control, $\mathrm{HO}=3 \%$ high oleic soybean oil, $\mathrm{SOY}=3 \%$ commodity soybean oil 


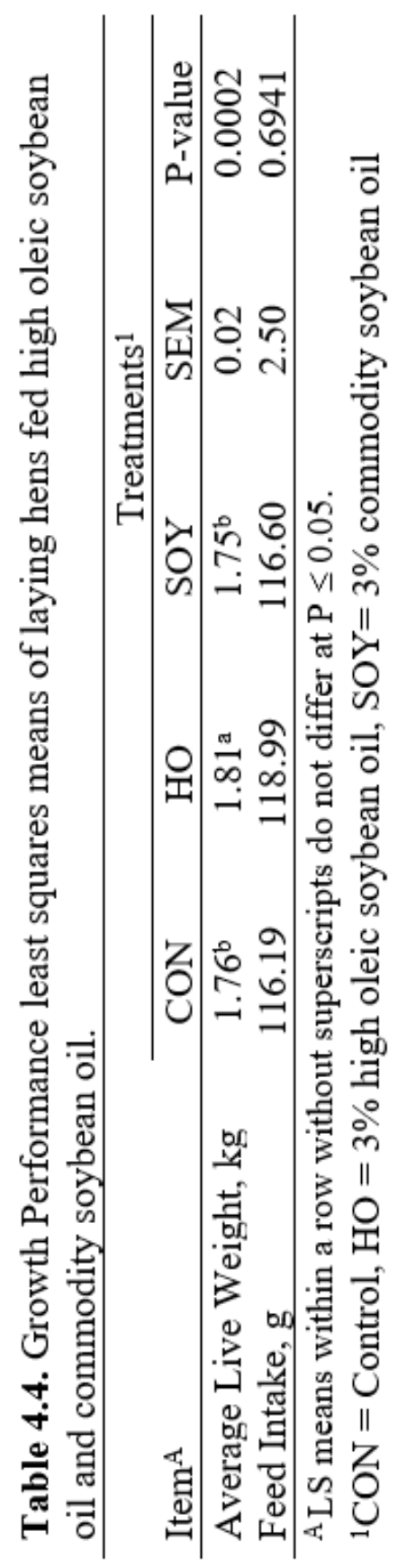


Figure 4.1 Average daily egg count of laying hens fed high oleic soybean oil and commodity soybean oil.

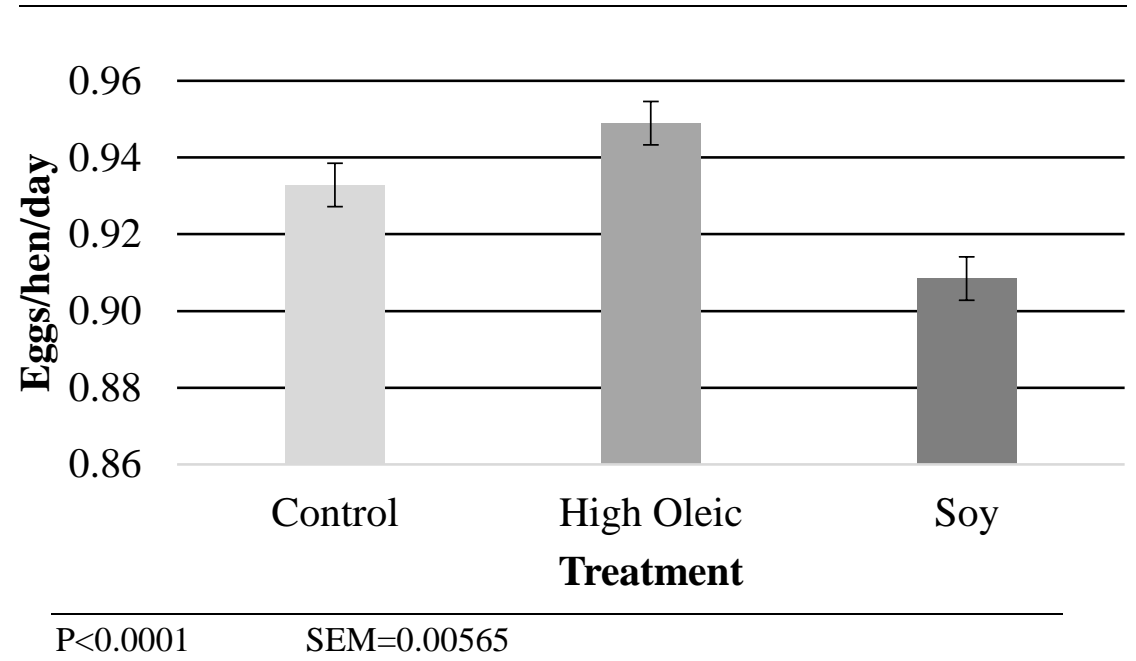


Figure 4.2 Average egg weight during laying cycle 1 of laying hens fed high oleic soybean oil and commodity soybean oil.

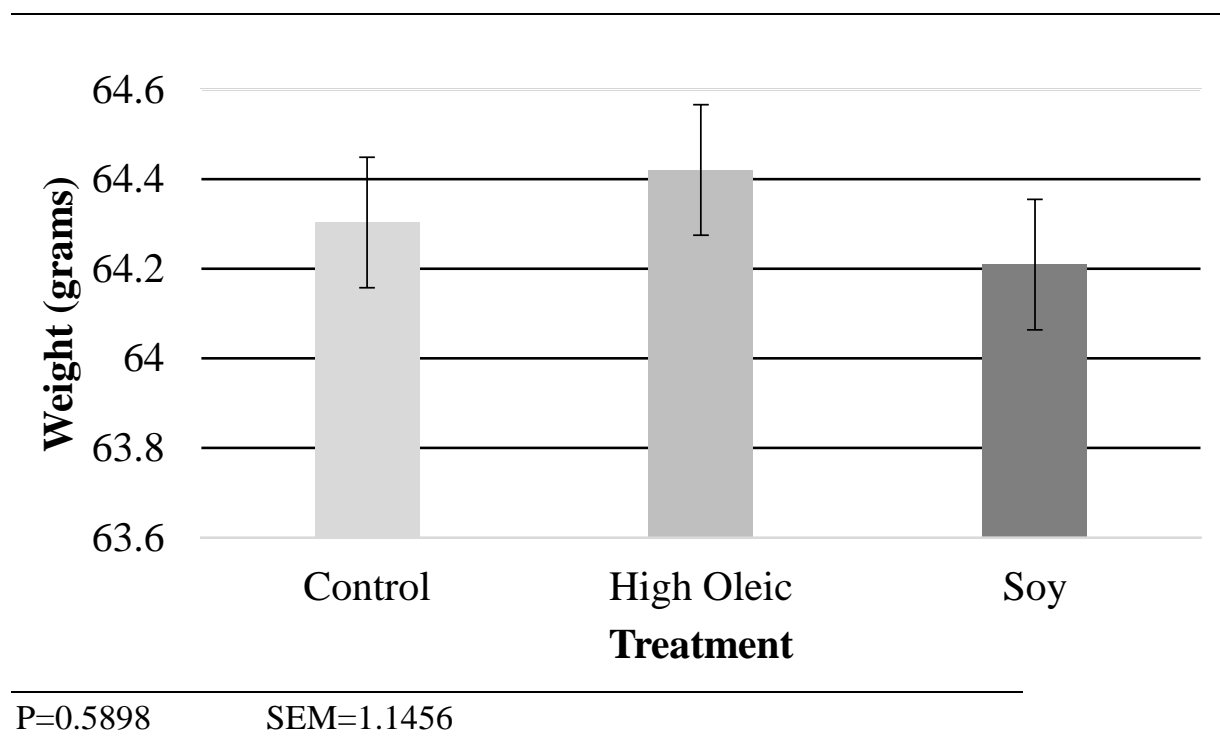


Figure 4.3 Average egg weight during laying cycle 2 of laying hens fed high oleic soybean oil and commodity soybean oil.

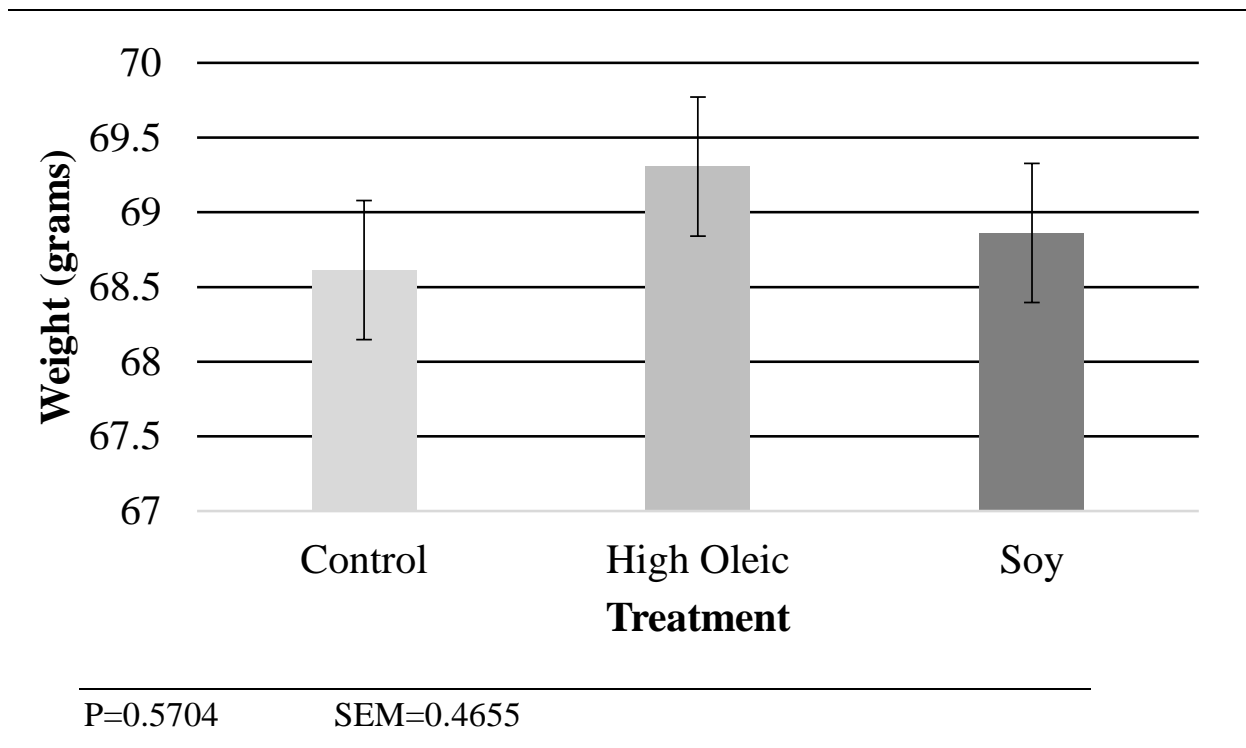




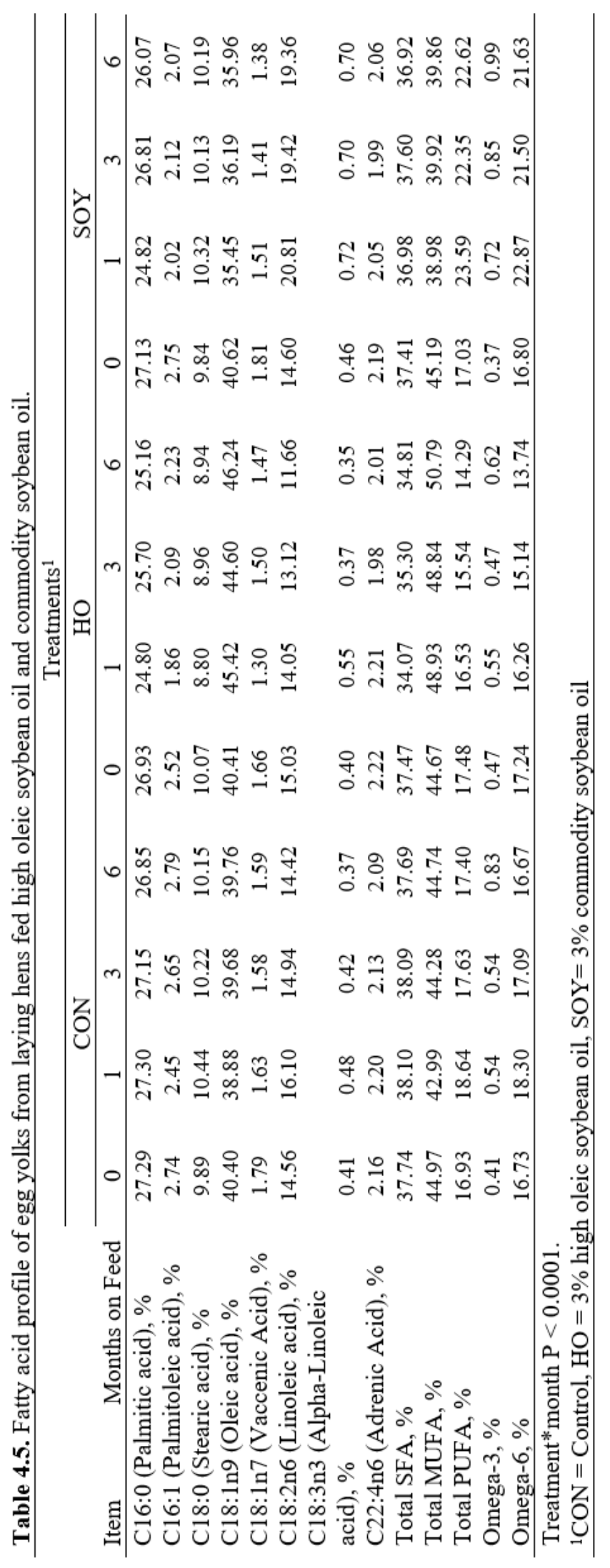


Figure 4.4. L* values of egg yolks from laying hens fed high oleic and commodity soybean oil, over weeks in cold storage.

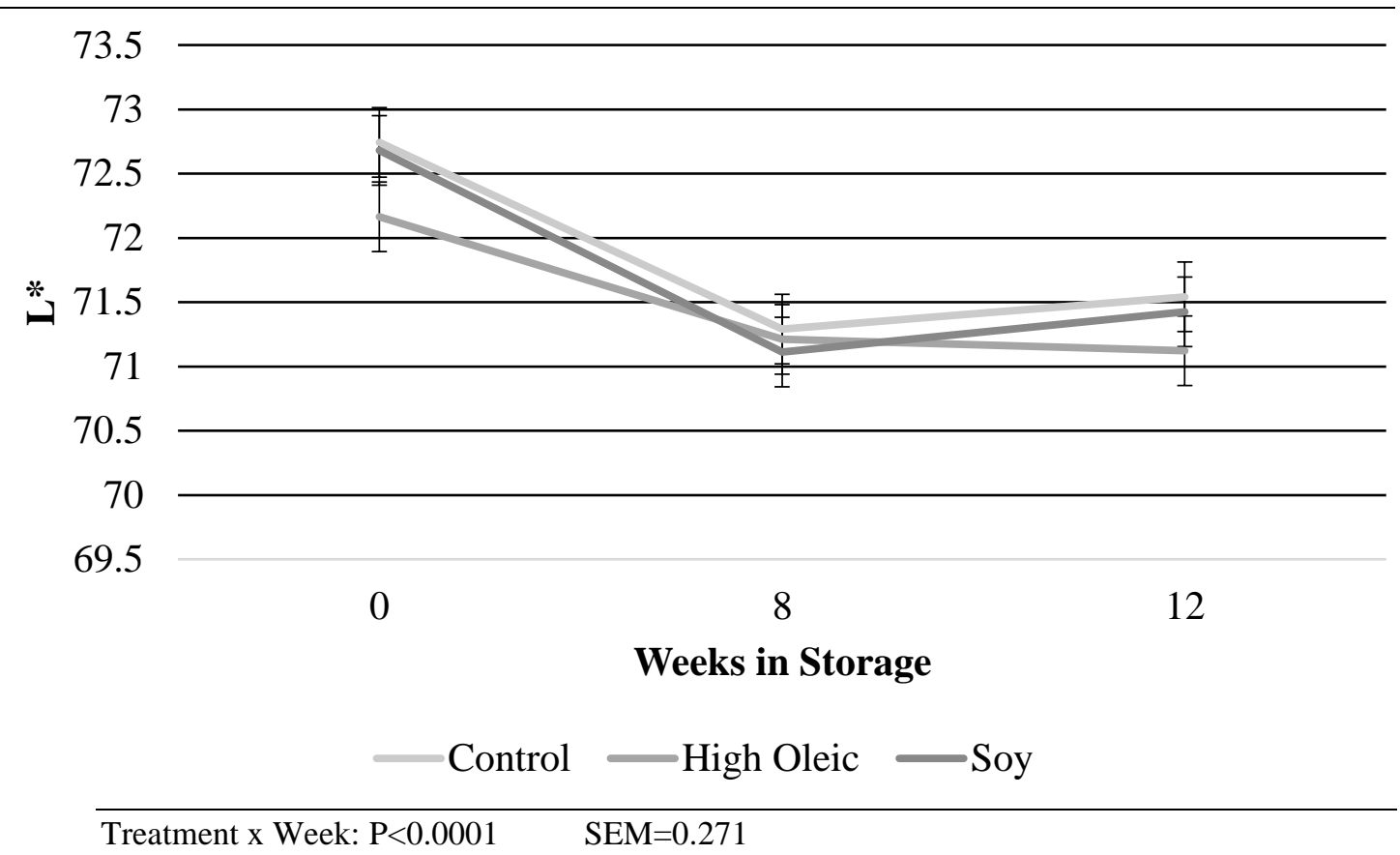


Figure 4.5. a* values of egg yolks from laying hens fed high oleic and commodity soybean oil, over weeks in cold storage.

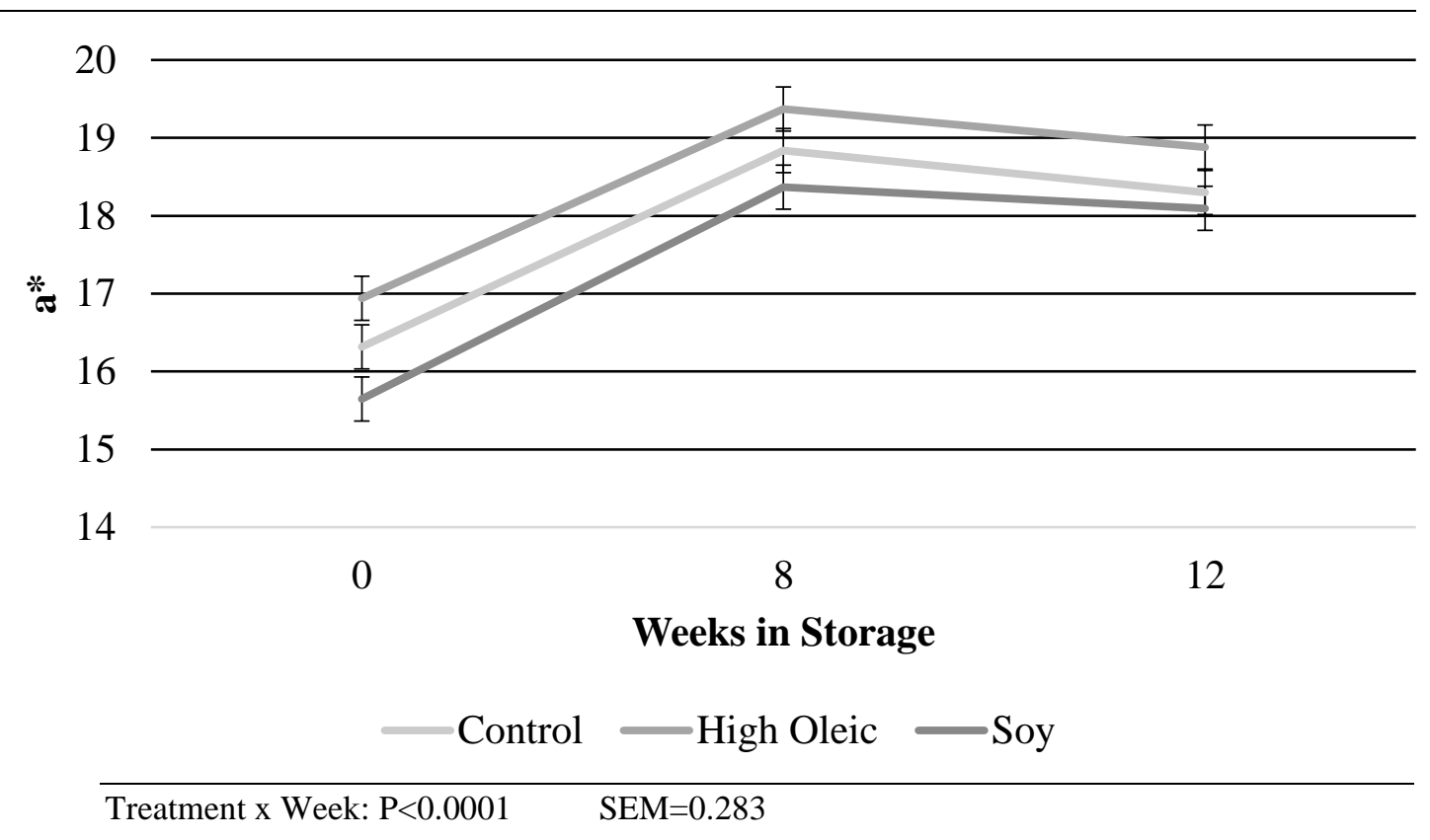


Figure 4.6. $b^{*}$ values of egg yolks from laying hens fed high oleic and commodity soybean oil, over weeks in cold storage.

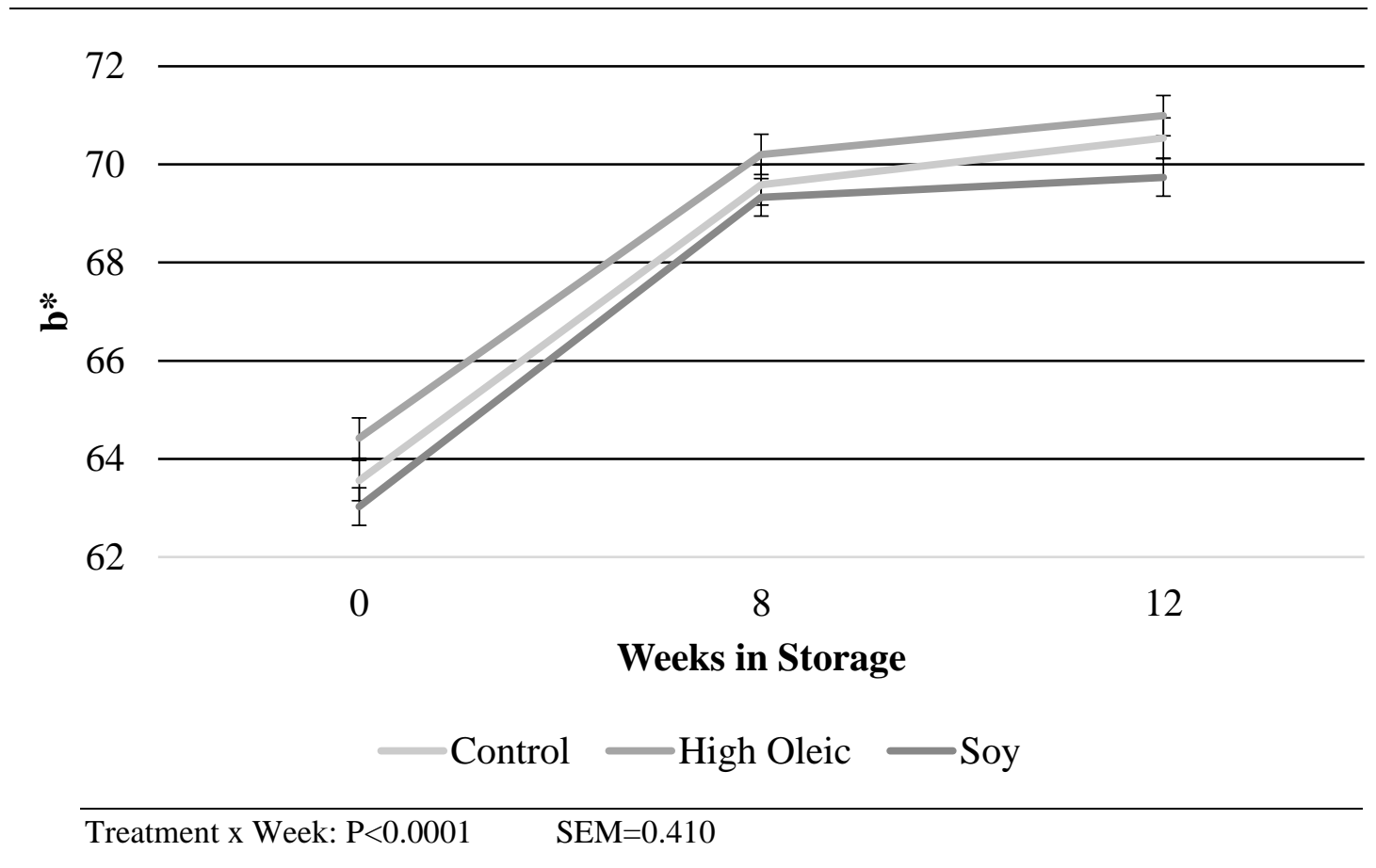


Figure 4.7. Roche color fan score values of egg yolks from laying hens fed high oleic and commodity soybean oil, over weeks in cold storage.

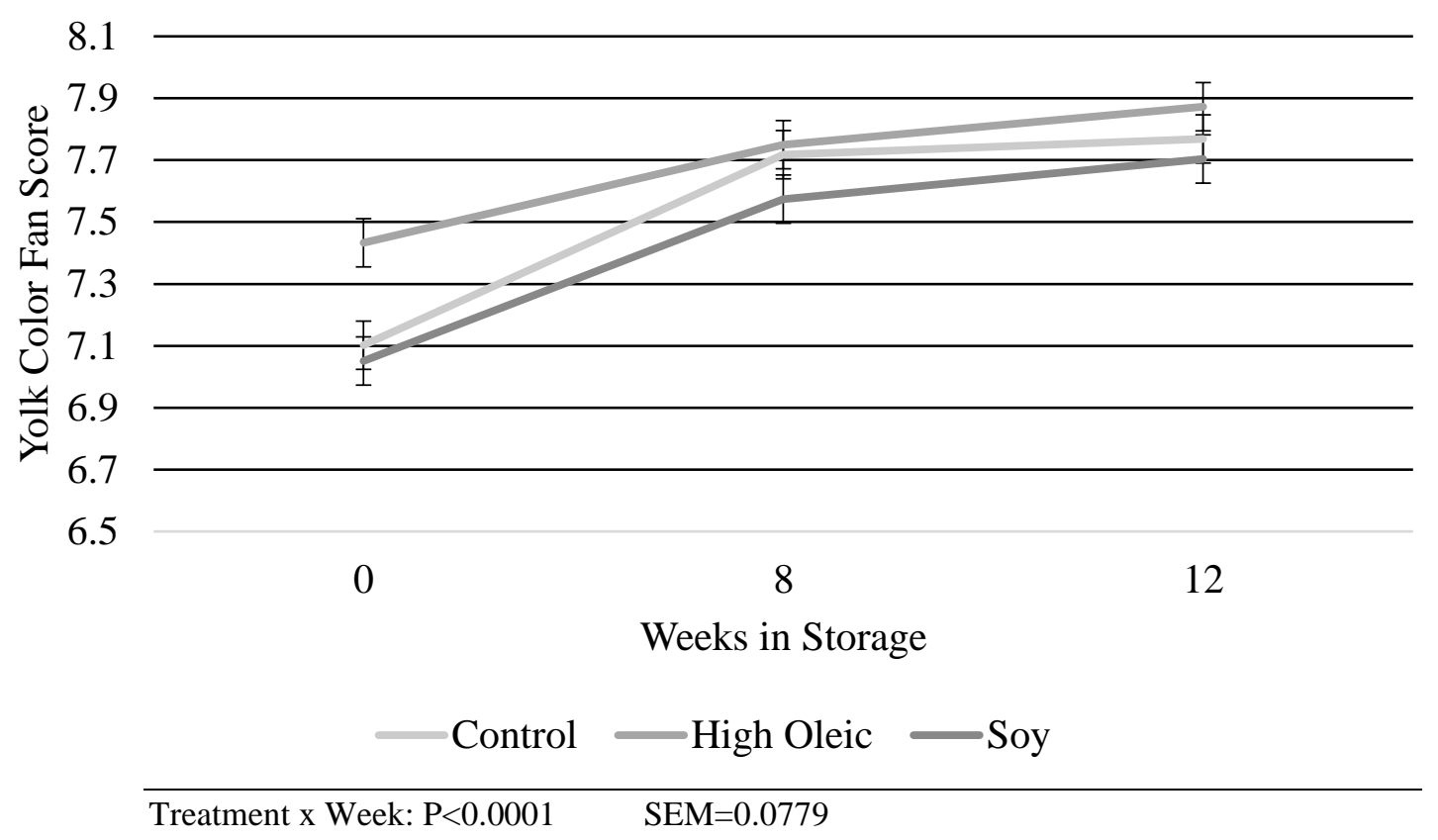


Figure 4.8. TBAR values of egg yolks from laying hens fed high oleic and commodity soybean oil.

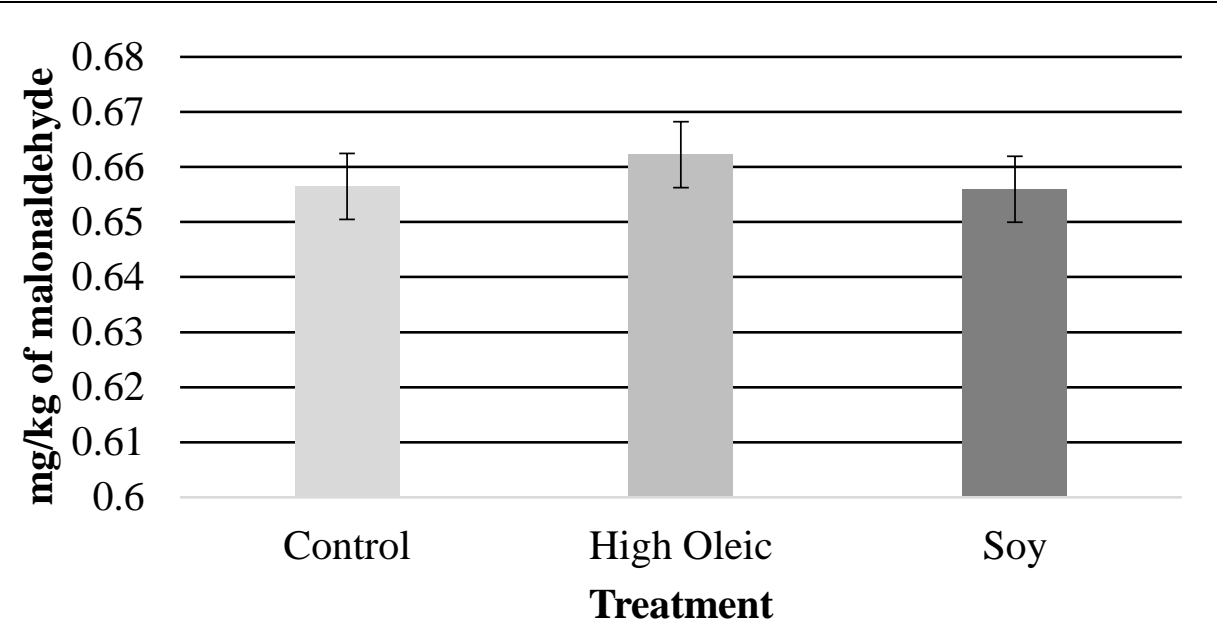

$\mathrm{P}=0.7126 \quad \mathrm{SEM}=0.0060$ 


\title{
CHAPTER 5
}

\section{INCLUSION OF DIETARY HIGH OLEIC SOYBEAN OIL REDUCES FEED INTAKE AND ALTERS FATTY ACID COMPOSTION OF EGG YOLK FAT WITHOUT NEGATIVELY IMPACTING EGG QUALITY IN RED SEX-LINK LAYING HENS}

\begin{abstract}
The objective of this study was to determine the effects of dietary high oleic soybean oil inclusion on the hen performance, egg quality, and egg yolk fatty acid composition of Red Sex Link laying hens. Laying hens $(n=192)$ were randomly sorted into 24 pens and randomly assigned to one of three treatments: $0.6 \%$ added conventional soybean oil (CON), 3\% added high oleic soybean oil (HO), and 3\% conventional soybean oil (SOY). Hens were fed ad libitum access for 34-weeks, force molted and then returned to treatment for laying cycle two. Feed refusal and pen weights were collected monthly and used to calculate average hen body weight (BW) and feed intake (FI). Eggs were collected daily to calculate average lay rate per hen. Eggs were sampled weekly to measure egg weight size. Eggs were sampled monthly, placed into cold storage for 0, 8, or 12 weeks, and then analyzed for color and fatty acid composition. Data were analyzed using PROC GLM procedure of SAS and significance was set at P-value $<0.05$. Hens on the SOY diet weighed more than hens on the $\mathrm{CON}$ diet $((\mathrm{P}=0.0481)$. Hens consuming the HO diet
\end{abstract}


consumed a lower amount of feed compared to the CON and SOY treatments $(\mathrm{P}=0.0245)$. Hens consuming the HO diet had a lower average daily lay rate compared to hens on the CON and SOY diets $(\mathrm{P}=0.0325)$. No differences were detected in egg weight size between treatments during the first or second laying cycle $(\mathrm{P}=0.1377, \mathrm{P}=0.7826)$. Diet changed the proportion of SFA, MUFA, and PUFA in egg yolk fat $(\mathrm{P}<0.001)$. The HO treatment resulted in a decrease in total SFA, while the CON and SOY treatments resulted in no changes $(\mathrm{P}<0.0001)$. Total MUFA for HO treatment increased, while the SOY treatment decreased in total MUFA, and the CON treatment resulted in no change $(\mathrm{P}<0.0001)$. The HO treatment decreased in total PUFA, SOY treatment resulted in a significant increase, and the CON treatment resulted in no change in total PUFA $(\mathrm{P}<0.0001)$. HO eggs had a significant increase in $\mathrm{C} 18: 1 \mathrm{n} 9(\mathrm{P}<0.0001)$. SOY eggs had a significant increase in $\mathrm{C} 18: 2 \mathrm{n} 6$ and $\mathrm{C} 18: 3 \mathrm{n} 3(\mathrm{P}<0.0001)$. Objective egg color measures saw an effect of weeks in storage $(\mathrm{P} \leq 0.05)$, but no treatment effects were observed. Subjective color measures recorded using the DSM Yolk color score fan found SOY eggs were a lighter yellow compared to $\mathrm{CON}$ and $\mathrm{HO}$ treatment eggs $(\mathrm{P}<0.0001)$ throughout time in cold storage. 


\section{INTRODUCTION}

Eggs are an economical source of protein and other nutrients needed by humans to achieve a healthy diet. Concerns have been brought up by consumers on the saturated fat content in eggs, this has led to the need to decrease amounts of saturated fats in egg yolks. It is known that monogastric animals take on fatty acid profiles in tissues that are similar to provided dietary lipid sources (Wood et al., 2008). Work has been done utilizing high oleic peanuts (Toomer et al., 2018) and high oleic sunflower oil (Cachaldora et al., 2005), in which the fatty acid profiles of egg yolks were shifted to increase total monounsaturated fatty acid (due to increase oleic acid content) and decrease total saturated fatty acids in egg yolk lipids. However, little research has been done with high oleic soybean oil and its effects on hen performance and egg quality. Therefore, the purpose of this study was to evaluate high oleic soybean oils effect on hen performance and egg quality parameters. 


\section{MATERIALS AND METHODS}

The University of Missouri Animal Care and Use Committee approved animal care and experimental protocols prior to initiation of this experiment (\#EX-10094).

\section{Experimental Design}

Red Sex Link laying hens ( $\mathrm{n}=192)$ were randomly sorted into 24 pens, experimental unit= pen. Pens were randomly assigned to one of three treatment groups. Hens were housed in a curtain sided, climate-controlled facility through the duration of the laying cycle, with 14 hours of light provided daily.

The three treatment diets consisted of a control diet with $0.6 \%$ added conventional soybean oil (CON), 3\% added Plenish® (high oleic soybean oil) (HO), and 3\% conventional soybean oil (SOY). The control diet included $0.6 \%$ added oil for dust maintenance in the diet. All diets were formulated and balanced to meet NRC nutritional requirements (NRC, 1994). All animals were provided water and feed ad libitum. Feed was added to pens as needed, total weight of added feed was recorded to calculate total feed consumption.

Hens were fed for a 32-week laying cycle (239 days), while samples were collected. Hens were then force molted, by the removal of treatment diets and addition of a low nutritional value diet to induce molting. Hens were molted for five weeks to achieve a 18- 
$20 \%$ loss in body weight, and then returned to treatment diets for an additional three weeks to collect additional data during the second laying cycle.

\section{Data Collection}

Hen performance. Body weight and feed consumption of pens was recorded monthly from the start of the study to the end of the laying cycle. Pen weights and feed weight were used to calculate average hen body weight (BW) and feed intake (FI). Bird mortality records were used to adjust feed intake based on calculating bird days on feed.

Egg sampling. Daily shell eggs were collected to calculate daily lay rate. Weekly, shell eggs were sampled for weight measurements. Monthly, shell eggs were sampled for fatty acid analysis. Monthly, shell eggs were sampled, 1/3 of the pen was tested at 0 weeks in storage, 1/3 stored for 8 weeks in cold storage, and 1/3 were stored for 12 weeks in cold storage for subjective color measures, objective color measures, and lipid oxidation.

Egg yolk fatty acid. Egg yolk samples from pens were pooled and analyzed for fatty acid profiles at $0,1,3$, and 6 months of hens being on feed. Analysis were ran according to modified methodologies by Folch et al, (1957) and Morrison and Smith (1964). Approximately $500 \mathrm{mg}$ of sample was homogenized in chloroform:methanol $\left(\mathrm{CHCl}_{3}: \mathrm{CH}_{3} \mathrm{OH}, 2: 1, \mathrm{v} / \mathrm{v}\right)$ in a glass tube to extract lipids. Dehydrated samples were filtered through a sintered glass funnel fitted with a Whatman $2.4 \mathrm{~cm}$ GF/C filter.

A volume of $8 \mathrm{ml}$ of $0.74 \% \mathrm{KCl}$ was added to each sample and after two hours, two distinct layers formed. The upper phased was removed and discarded while the lower phase was evaporated to dryness with nitrogen in a water bath. At the point of dryness, $1 \mathrm{ml}$ of 
$0.5 \mathrm{~N} \mathrm{KOH}$ was added to each tube and heated for 10 minutes in a $70^{\circ} \mathrm{C}$ water bath. The addition of $\mathrm{KOH}$ initiates the saponification reaction, which hydrolyzes fatty acids from a triglyceride molecule. Following this, $1 \mathrm{ml}$ of $14 \% \mathrm{BF}_{3}$ in $\mathrm{MeOH}$ was added, samples were flushed with nitrogen and heated in the water bath for 30 minutes. Boron trifluoride is highly volatile and acts as an acid catalyst in the transesterification reaction that methylates the acid group on free fatty acids removing the net negative charge. The remaining molecule is known as a fatty acid methyl ester (FAME).

FAMEs are liquefied by adding $2 \mathrm{ml}$ of HPLC grade hexane and $2 \mathrm{ml}$ of $\mathrm{NaCl}$. Two distinct layers are formed; the upper layer is removed and added to $\sim 800 \mathrm{mg}$ of $\mathrm{Na}_{2} \mathrm{SO}_{4}$ to remove any moisture in the sample. At this point, 2 more $\mathrm{ml}$ of hexane was added to the tube containing $\mathrm{NaCl}$ and once more, the upper layer was removed and added to the tube containing $\mathrm{Na}_{2} \mathrm{SO}_{4}$. The hexane potion was removed from the salt and added to a labeled scintillation vial. The salt was rinsed once more with $1 \mathrm{ml}$ of hexane and the liquid was added to the vial. Samples were evaporated to dryness in a water bath at $70^{\circ} \mathrm{C}$ under nitrogen flow. Lastly, samples were reconstituted with $1 \mathrm{ml}$ HPLC grade hexane and transferred to gas chromatograph vials.

The stable FAMEs were loaded into a Varian 3,800 gas chromatographer (Varios, Pala Alto, CA) to determine fatty acid profiles. The column utilized was a fused silica capillary column (SPTM-2,560; $100 \mathrm{~m}$ x $0.25 \mathrm{~mm}$ x $0.2 \mu \mathrm{m}$ film thickness; Supelco, Bellefonte, PA). Temperature of the injector was held constant at $240^{\circ} \mathrm{C}$ and temperature of the flame-ionizer detector was held at $260^{\circ} \mathrm{C}$. The oven operated at $140^{\circ} \mathrm{C}$ for 5 minutes (temperature programmed $2.5^{\circ} \mathrm{C} /$ minute to $240^{\circ} \mathrm{C}$ and held for 16 minutes). Helium, the 
carries gas, was maintained at a constant pressure of 37 psi. Individual fatty acids were expressed as a percentage of the total area under the peaks.

Total saturated fatty acid (SFA), monounsaturated fatty acids (MUFA) and polyunsaturated fatty acid (PUFA) contents were calculated according to the following equations: $\mathrm{SFA}=(\mathrm{C} 14: 0+\mathrm{C} 16: 0+\mathrm{C} 17: 0+\mathrm{C} 18: 0+\mathrm{C} 20: 0) ; \mathrm{MUFA}=(\mathrm{C} 14: 1+\mathrm{C} 16: 1+$ $\mathrm{C} 17: 1+\mathrm{C} 18: 1 \mathrm{n} 9 \mathrm{t}+\mathrm{C} 18: 1 \mathrm{n} 9 \mathrm{c}+\mathrm{C} 18: 1 \mathrm{n} 7) ; \mathrm{PUFA}=(\mathrm{C} 18: 2 \mathrm{n} 6 \mathrm{t}+\mathrm{C} 18: 2 \mathrm{n} 6 \mathrm{c}+\mathrm{C} 18: 3 \mathrm{n} 6+$ $\mathrm{C} 18: 3 \mathrm{n} 3+\mathrm{C} 20: 4 \mathrm{n} 6+\mathrm{C} 20: 5 \mathrm{n} 3+\mathrm{C} 22: 4 \mathrm{n} 6+\mathrm{C} 22: 6 \mathrm{n} 3)$. The following equations were used to calculate total omega 3 and omega 6 fatty acid content: total omega $3=(\mathrm{C} 18: 3 \mathrm{n} 3+$ $\mathrm{C} 20: 5 \mathrm{n} 3+\mathrm{C} 22: 6 \mathrm{n} 3) ;$ total omega $6=(\mathrm{C} 18: 2 \mathrm{n} 6 \mathrm{t}+\mathrm{C} 18: 2 \mathrm{n} 6 \mathrm{c}+\mathrm{C} 18: 3 \mathrm{n} 6+\mathrm{C} 20: 4 \mathrm{n} 6+$ C22:4n6).

Objective color measure. Monthly eggs were sampled, and objective color measures were recorded at 0,8 , and 12 weeks of cold storage. Objective color was measured by CIE system L* (lightness), a* (redness), and $b^{*}$ (yellowness) using a HunterLab MiniScan Spectrocolorimeter (MiniScan XE; Hunter and Assoc., Reston, VA) with a $2.5 \mathrm{~cm}$ port and glass cover calibrated against a white tile. Instrumental color readings were utilized to calculate a/b ration, saturation index (SI), and hue angle (HA) values.

Subjective color measure. Monthly eggs were sampled, and subjective color measures were recorded at 0,8 , and 12 weeks of cold storage. At testing subjective color measures of egg yolks were recorded using the DSM Color fan, which consists of a series of 15 colored plastic tabs arranged as a fan corresponding to a range of yolk colors from light yellow to orange-red (1- light yellow, 15- orange-red). 
Lipid oxidation (TBARS). Lipid oxidation of egg yolk samples was measured using the method described by Tarladgis et al. (1960) with modifications from Fernando et al. (2003). Malonaldehyde, a by-product of oxidation, was measured to indicate the rate of oxidation that had occurred in each sample over a specified time period. Monthly pen eggs were sampled and stored in cold storage $\left(4^{\circ}\right)$ for 0,8 , or 12 weeks. Eggs were removed from storage and sampled for lipid oxidation. Duplicate 2-gram samples of egg yolks were placed into a $50 \mathrm{~mL}$ tube with $18 \mathrm{~mL}$ of perchloric acid. $50 \mu 1$ of butylated hydroxytoluene was added. Each tube was homogenized for 30 seconds using a Hamilton Beach hand blender. Following homogenization sample was filtered through Fisherbrand Filter Paper Whatman P4, into another $50 \mathrm{~mL}$ tube. $2 \mathrm{~mL}$ of sample was pipetted into a $25 \mathrm{~mL}$ glass tube along with $2 \mathrm{~mL}$ of TBA ( $0.02 \mathrm{M}$ thiobarbituric acid in $90 \%$ acetic acid). Samples were capped and vortexed. Samples were then placed into a $100^{\circ} \mathrm{C}$ water bath for 30 minutes. Color absorbance was measured at $531 \mathrm{~nm}$ using a Spectronic 20 (Bausch \& Lomb, Rochester, NY) spectrophotometer. Values of each reading were recorded and averaged for further calculation. Lipid oxidation was expressed in $\mathrm{mg} / \mathrm{kg}$ of malonaldehyde recovered and calculated using the recorded spectrophotometer averages and the give equation below.

\section{$\mathrm{mg} / \mathrm{kg}$ of malonaldehyde $=7.8 *$ spectrophotometer reading}

\section{Statistical Analysis}

Data were analyzed using SAS 9.4 (SAS inst., Cary, NC). Pen served as the experimental unit and the statistical model included the fixed effect of dietary treatment. 
The least squares mean, and standard error were determined for variable according to treatment. An analysis of variance of least squares means of treatments was conducted using PROC GLM, with a pairwise comparison used to detect potential differences between treatments. Level of significance was set at $\mathrm{P} \leq 0.05$.

\section{RESULTS}

\section{Hen performance}

Results for hen performance is outlined in Table 5.4. On average during the 32week laying cycle, hens on the CON diet weighed $2.02 \mathrm{~kg}$, HO hens weighed $2.04 \mathrm{~kg}$, and SOY hens weighed $2.06 \mathrm{~kg}$. Hens on the SOY diet were heavier compared to hens on the CON diet $(\mathrm{P}=0.0481)$. Laying hens consuming the $\mathrm{HO}$ diet consumed a lower amount (112.53 grams) of feed compared to the CON (121.05 grams) and SOY (120.95 grams) treatments $(\mathrm{P}=0.0245)$.

\section{Egg production}

Results for daily egg count are presented in Figure 5.1. Laying hens on HO diet had a lower average daily lay rate $(0.871 \mathrm{eggs} / \mathrm{hen} / \mathrm{day})$ compared to hens on the CON $(0.893$ eggs/hen/day) and SOY (0.893 eggs/hen/day) treatments $(\mathrm{P}=0.0325)$.

\section{Egg weight}

Results of egg weights are shown in Figure 5.2 and 5.3. There were no differences seen in egg weight between treatment groups during the first or second laying cycle $(\mathrm{P}=$ 
$0.1377, \mathrm{P}=0.7826)$. There was a tendency during the first laying cycle for eggs from hens fed the SOY diet to be smaller, compared to eggs from hens fed HO diet ( $\mathrm{P}=0.0923)$.

\section{Fatty acid analysis}

Analysis of the fatty acid profile of egg yolks (Table 5.5) showed significant differences $(\mathrm{P} \leq 0.05)$ between treatments for the following individual fatty acids: $\mathrm{C} 16: 0$, C16:1, C18:0, C18:1n9c, C18:1n7, C18:2n6c, C18:3n3, and C22:4n6. Measurable differences were present $(\mathrm{P} \leq 0.05)$. for total SFA, total MUFA, and total PUFA in fatty acid profiles of egg yolks.

Egg yolks from hens fed the HO treatment had a decrease in 16:0 after 1 month of feeding while CON and SOY treatments resulted in no difference $(\mathrm{P}<0.0001)$. Egg yolks from hens fed the HO treatment had a decrease in 18:0 after 1 month on feed, while egg yolks from hens fed the SOY and CON treatments had an increase in 18:0 $(\mathrm{P}<0.0001)$. The HO treatment resulted in a decrease in total SFA percent, while the CON and SOY treatments resulted in no changes $(\mathrm{P}<0.0001)$.

Egg yolks from hens fed the $\mathrm{HO}$ and SOY treatments had a decrease in 16:1 after 1 month of feeding compared to yolks from CON laying hens, which resulted in no change $(\mathrm{P}<0.0001)$. Egg yolks from hens fed the HO treatment resulted in a significant increase in 18:1n9c, while egg yolks from hens fed the SOY treatments resulted in a decrease, and yolks from the $\mathrm{CON}$ hens resulted in no changes $(\mathrm{P}<0.0001)$. Egg yolks from hens fed the HO and SOY treatments decreased in 18:1n7, while yolks from hens fed the CON diet resulted in no changes $(\mathrm{P}<0.0001)$. Total MUFA percentage for $\mathrm{HO}$ treatment increased, 
while the SOY treatment decreased in total MUFA, and the CON treatment resulted in no change $(\mathrm{P}<0.0001)$.

Egg yolks from hens fed the HO treatment decreased in 18:2n6c after six months of feeding, while yolks from hens fed SOY treatments resulted in a significant increase, and yolks from $\mathrm{CON}$ resulted in no change $(\mathrm{P}<0.0001)$. Egg yolks from hens fed the HO and CON treatments resulted in an initial increase in 18:3n3 after 1 month of feeding and then a decrease after 3 and 6 months of feeding, egg yolks from hens fed SOY resulted in a significant increase over the sampling periods $(\mathrm{P}<0.0001)$. Egg yolks from hens fed the $\mathrm{HO}$ treatment resulted in no change in 22:4n6 after 1 month of feeding and then a decrease after 3 and 6 months of feeding, egg yolks from hens fed SOY and CON treatments resulted in no change $(\mathrm{P}=0.0285)$. The HO treatment decreased in total PUFA, SOY treatment resulted in a significant increase, and the CON treatment resulted in no change in total PUFA $(\mathrm{P}<0.0001)$.

\section{Egg quality parameters}

\section{Objective color measure}

Analysis of objective color score is shown in Figures 5.4, 5.5, 5.6. For L*, a*, and $b^{*}$ there were no differences observed between treatments during any of the sampling points $(\mathrm{P} \geq 0.05)$. However, there was a storage week interaction observed $(\mathrm{P} \leq 0.05)$. 


\section{Subjective color measure}

Analysis of subjective color score is shown in Figure 5.7. Yolk color fan score for yolks from the SOY treatment were lower (lighter yellow) compared to the $\mathrm{CON}$ and $\mathrm{HO}$ treatments $(\mathrm{P}=<0.0001)$ throughout time in cold storage.

\section{Lipid oxidation}

Results for lipid oxidation are presented in Figure 5.8. Treatment did not impact lipid oxidation in egg yolk samples $(\mathrm{P}=0.9075)$.

\section{DISCUSSION}

Hens fed the HO diet saw reduced feed intake, while maintaining similar body mass compared to CON and SOY treatments. This differs from previous research which has shown no difference in hen performance when supplemented with high-oleic sunflower oil (Cachaldora, et al., 2005; Alvarez, et al., 2005). Reduction in feed intake could be attributed to the SOY diet containing a high level of linoleic acid which has shown to increase ghrelin levels (Naughton et al., 2018). Ghrelin being a neuropeptide which promotes food intake.

HO hens while consuming less, continued to maintain egg weight size compared to CON and SOY treatments. Studies done by Cachaldora et al. (2005) and Elkin et al. (2018) saw no differences in egg weight from hens supplemented with high-oleic sunflower oil and high oleic soybean, respectively. Laying hens on the HO treatment had a lower rate of lay (egg/hen/day) compared to the CON and SOY treatments. This differs from research

done by Sangkaew et al. (2017), Elkin et al. (2018), and Toomer et al. (2019), where there 
was no difference in rate of lay when feeding high oleic sunflower oil, high oleic soybean oil and high oleic peanut oil, respectively. One major difference the current study has compared to these others, is housing of the laying hens. Laying hens on this study were kept in pens, on the floor as opposed to individual battery cages, which lead to increased number of cracked eggs that could not be recorded.

Fatty acid analysis of egg yolks showed that eggs from the HO treatment had increased total MUFA concentration, specifically due to increased levels of oleic acid $(\mathrm{C} 18: \ln 9 \mathrm{c})$ and decreased concentrations in SFA and PUFA. This is in line with work done utilizing high oleic soybean oil, high oleic peanut oil and high oleic sunflower oil, all of which saw an increase in oleic acid and total MUFA (Sangkaew et al., 2017; Elkin et al., 2018; Toomer et al., 2019). Levels of oleic acid in the HO eggs continued to increase as the duration on feed increased, indicating further research needs to be done to understand if a threshold value could be reached. An increase in oleic acid is beneficial for a few reasons; increased MUFA concentrations have been the target of health-conscious individuals wanting low levels of SFA, high oleic oil contains high levels of tocopherols, naturally occurring antioxidants (Sangkaew et al., 2017). Fatty acid profiles from SOY treatment showed a decrease in total MUFA concentration and a significant increase in PUFA concentrations, due to the increase in linoleic acid (C18:2n6c). These results further support research that shows monogastric species take on fatty acid profiles in tissues, that are similar to those dietary fatty acids in the diet (Wood et al., 2008).

Egg yolks from hens fed the SOY diet had lighter colored yolks compared to the CON and HO diets according to the DSM color fan score. This is in line with work done by Toomer et al., where eggs produced from hens fed high-oleic peanut + corn diet, were 
a more intense yellow-orange compared to yolks from hens fed soybean meal + corn diet (2019). Indicating the addition of high-oleic soybean oil does not negatively affect egg yolk color.

\section{IMPLICATIONS}

The results from this study showed that dietary high oleic soybean oil altered the fatty acid composition of egg yolks and reduced feed intake without having a significant effect on egg quality parameters. The results suggest that including high oleic soybean oil will shift the proportion of fatty acids in egg yolk tissues, to include higher levels of beneficial monounsaturated fatty acids and decrease amounts of saturated fatty acids. Reduced feed intake by hens fed high oleic soybean oil compared to commodity soybean oil gives producers an option to lower feed costs when feeding high oleic soybean oil. 
Table 5.1. Composition of laying hen treatment diets.

\begin{tabular}{|c|c|c|c|}
\hline \multirow[b]{2}{*}{ Ingredient (kg) } & \multicolumn{3}{|c|}{ Treatment Diets $^{1}$} \\
\hline & $\mathrm{CON}$ & $\mathrm{HO}$ & SOY \\
\hline Corn & 566.12 & 545.45 & 545.45 \\
\hline SBM 48 & 189.74 & 189.74 & 189.74 \\
\hline Limestone & 83.94 & 83.94 & 83.94 \\
\hline Corn Distillers- Solubles & 45.45 & 45.45 & 45.45 \\
\hline Dical Phosphate & 11.10 & 11.10 & 11.10 \\
\hline Commodity Soybean Oil & 6.11 & - & 27.27 \\
\hline High Oleic Soybean Oil & - & 27.27 & - \\
\hline NB 3000 Vitamin Premix & 2.27 & 2.27 & 2.27 \\
\hline Salt & 2.83 & 2.83 & 2.83 \\
\hline \multirow[t]{2}{*}{ Methionine } & 1.52 & 1.52 & 1.52 \\
\hline & 909.09 & 909.09 & 909.09 \\
\hline Crude Protein, $\%$ & 15.83 & 16.50 & 15.88 \\
\hline Crude Fat, \% & 1.86 & 4.86 & 3.49 \\
\hline Crude Fiber, $\%$ & 2.95 & 2.65 & 2.46 \\
\hline Moisture, \% & 9.40 & 9.39 & 9.41 \\
\hline Ash, $\%$ & 14.19 & 13.65 & 13.40 \\
\hline
\end{tabular}

${ }^{1} \mathrm{CON}=$ Control, $\mathrm{HO}=3 \%$ high oleic soybean oil, $\mathrm{SOY}=3 \%$ commodity soybean oil 
Table 5.2. Amino acid profiles of laying hen treatment diets.

\begin{tabular}{lccc}
\hline & \multicolumn{3}{c}{ Treatment Diets } \\
\cline { 2 - 4 } Item, g & CON & HO & SOY \\
\hline Taurine & 0.16 & 0.15 & 0.14 \\
Hydroxyproline & 0.07 & 0.07 & 0.08 \\
Aspartic Acid & 1.55 & 1.57 & 1.50 \\
Threonine & 0.61 & 0.61 & 0.57 \\
Serine & 0.69 & 0.71 & 0.64 \\
Glutamic Acid & 2.86 & 2.93 & 2.83 \\
Proline & 0.97 & 1.00 & 1.01 \\
Lanthionine & 0.01 & 0.02 & 0.02 \\
Glycine & 0.66 & 0.67 & 0.66 \\
Alanine & 0.85 & 0.86 & 0.84 \\
Cysteine & 0.30 & 0.29 & 0.29 \\
Valine & 0.76 & 0.76 & 0.78 \\
Methionine & 0.46 & 0.40 & 0.44 \\
Isoleucine & 0.67 & 0.68 & 0.68 \\
Leucine & 1.43 & 1.44 & 1.41 \\
Tyrosine & 0.56 & 0.57 & 0.55 \\
Phenylalanine & 0.81 & 0.82 & 0.79 \\
Hydroxylysine & 0.03 & 0.04 & 0.03 \\
Ornithine & 0.01 & 0.01 & 0.01 \\
Lysine & 0.87 & 0.88 & 0.84 \\
Histidine & 0.42 & 0.42 & 0.42 \\
Arginine & 1.00 & 1.02 & 0.99 \\
Tryptophan & 0.20 & 0.21 & 0.18 \\
\cline { 2 - 4 } & 15.92 & 16.13 & 15.70 \\
\hline COtan & 0.969 \\
\hline
\end{tabular}

${ }^{1} \mathrm{CON}=$ Control, $\mathrm{HO}=3 \%$ high oleic soybean oil, $\mathrm{SOY}=3 \%$ commodity soybean oil 
Table 5.3. Fatty acid composition of laying hen treatment diets.

\begin{tabular}{lccc}
\hline & \multicolumn{3}{c}{ Treatment Diets $^{1}$} \\
\cline { 2 - 4 } Item, \% & CON & HO & SOY \\
\hline C16:0 (Palmitic acid) & 13.94 & 9.43 & 12.73 \\
C18:0 (Stearic acid) & 2.89 & 3.35 & 3.18 \\
C18:1n9 (Oleic acid) & 25.00 & 53.43 & 23.61 \\
C18:1n7 (Vaccenic Acid) & 1.00 & 1.37 & 1.33 \\
C18:2n6 (Linoleic acid) & 54.78 & 28.30 & 54.11 \\
C18:3n3 (Alpha-Linolenic acid) & 2.89 & 2.74 & 5.04 \\
\hline${ }^{1}$ CON = Control, HO = 3\% high oleic soybean oil, SOY=3\% commodity \\
soybean oil
\end{tabular}




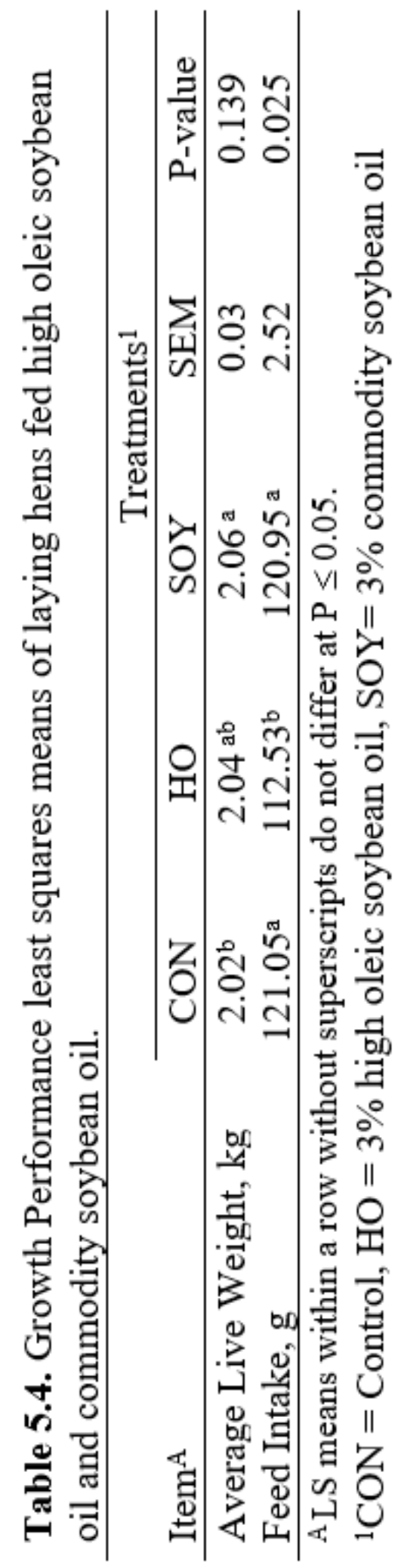


Figure 5.1 Average daily egg count of laying hens fed high oleic soybean oil and commodity soybean oil.

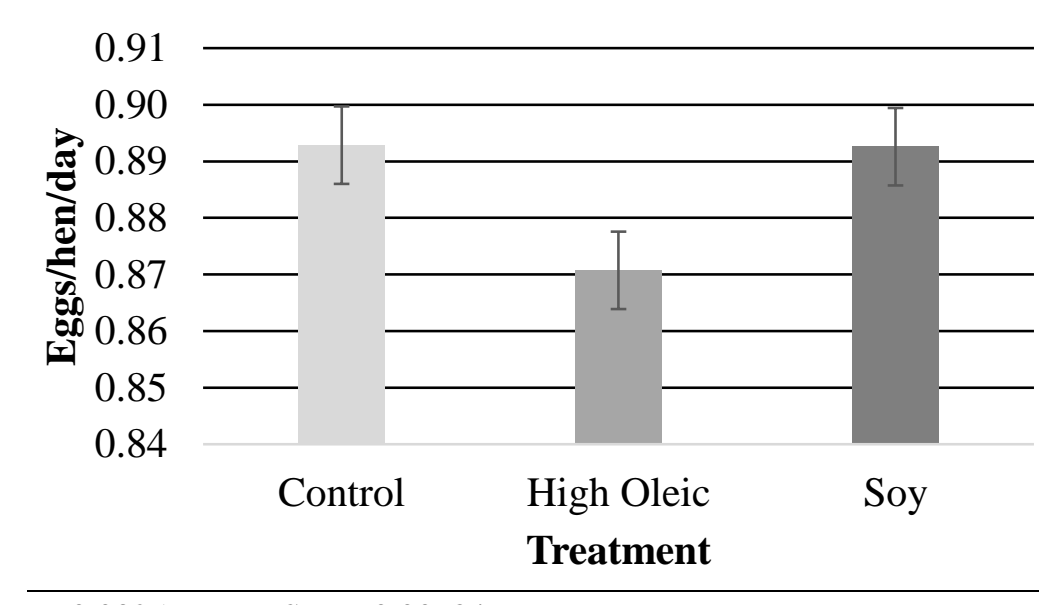

$\mathrm{P}=0.0325 \quad \mathrm{SEM}=0.00684$ 
Figure 5.2 Average egg weight during laying cycle 1 of laying hens fed high oleic soybean oil and commodity soybean oil.

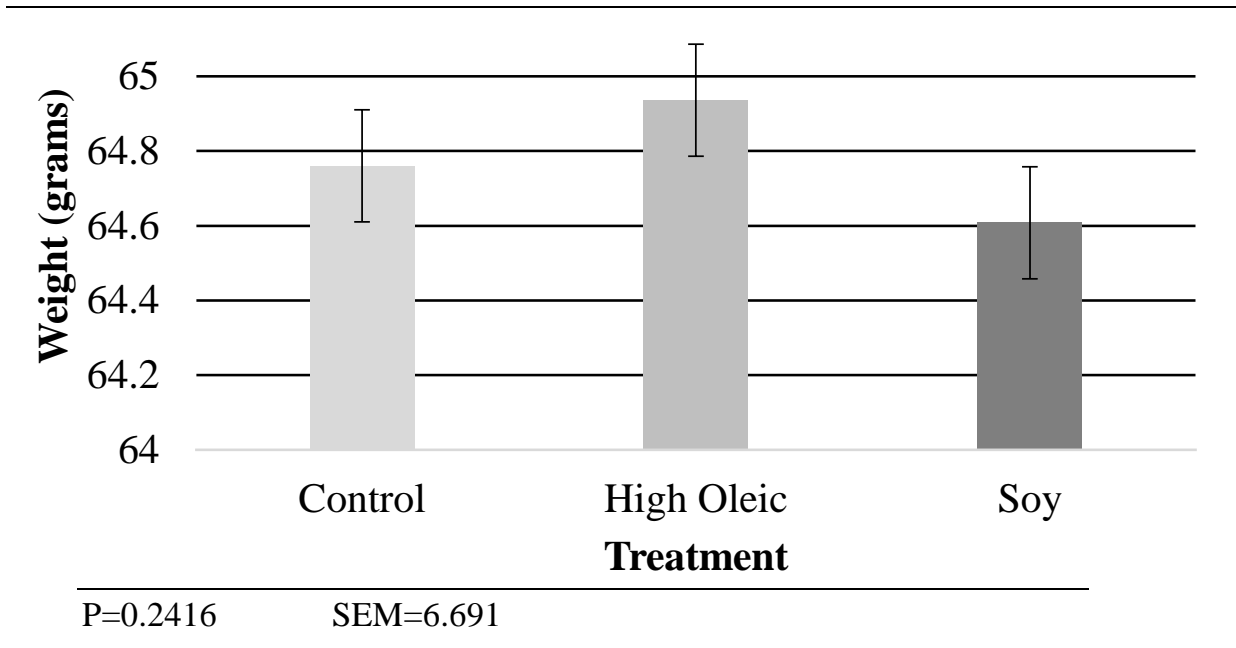


Figure 5.3 Average egg weight during laying cycle 2 of laying hens fed high oleic soybean oil and commodity soybean oil.

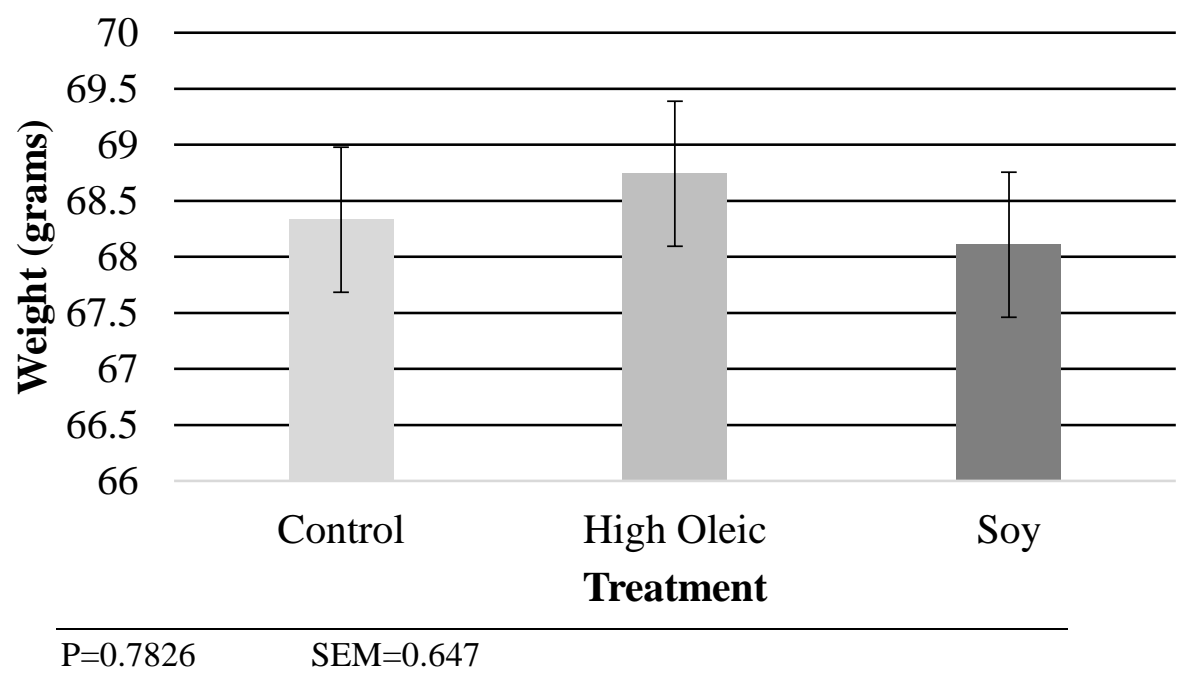




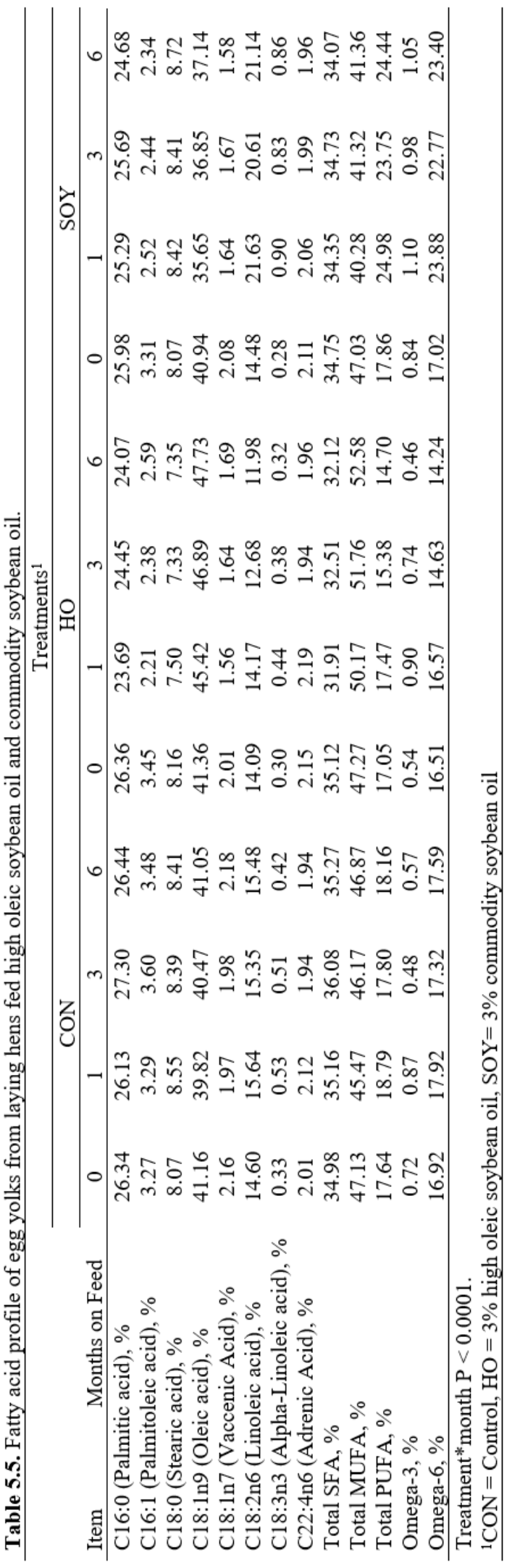


Figure 5.4. L* values of egg yolks from laying hens fed high oleic and commodity soybean oil, over weeks in cold storage.

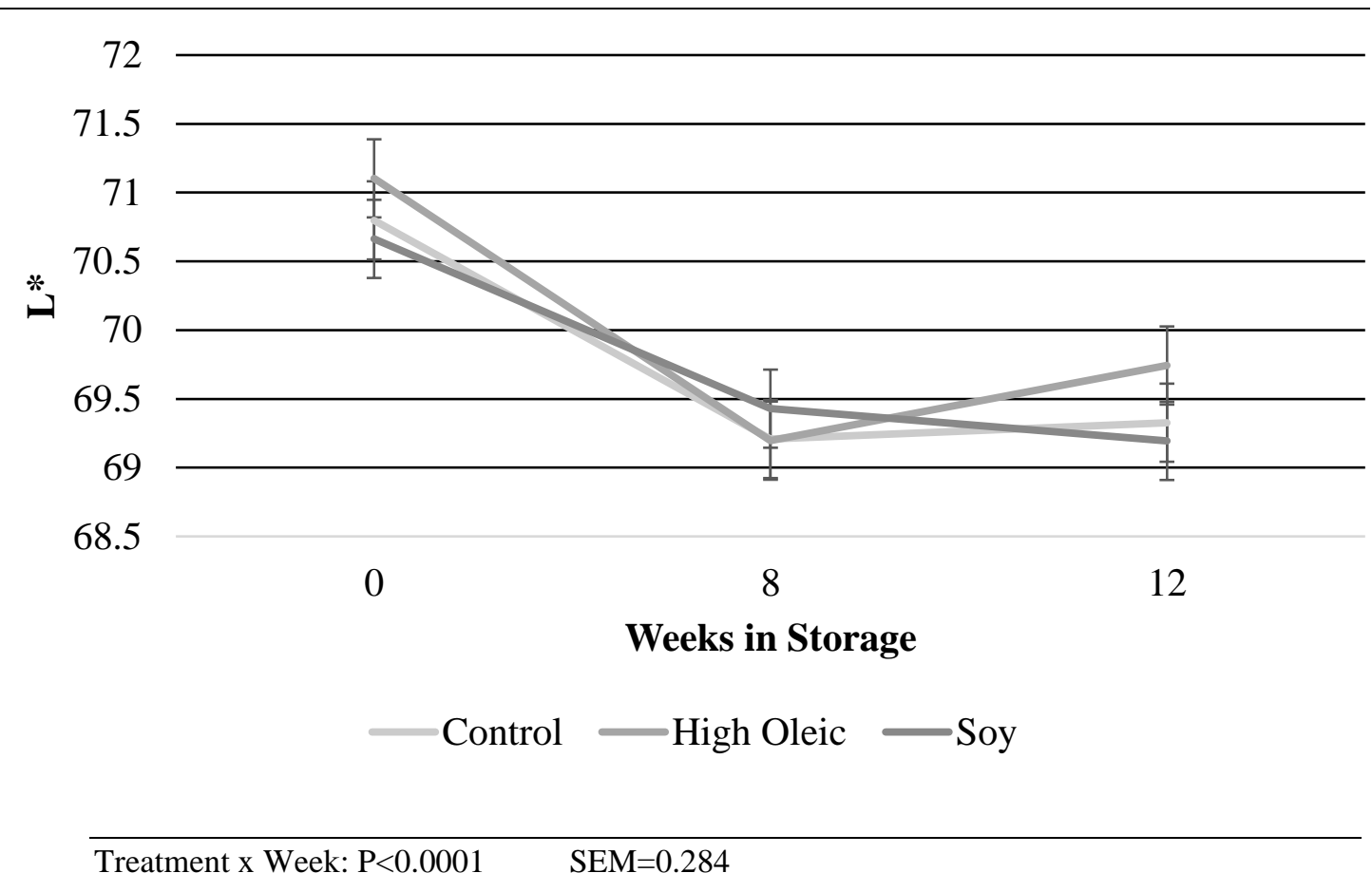

Treatment $x$ Week: $\mathrm{P}<0.0001 \quad$ SEM $=0.284$ 
Figure 5.5. a* values of egg yolks from laying hens fed high oleic and commodity soybean oil, over weeks in cold storage.

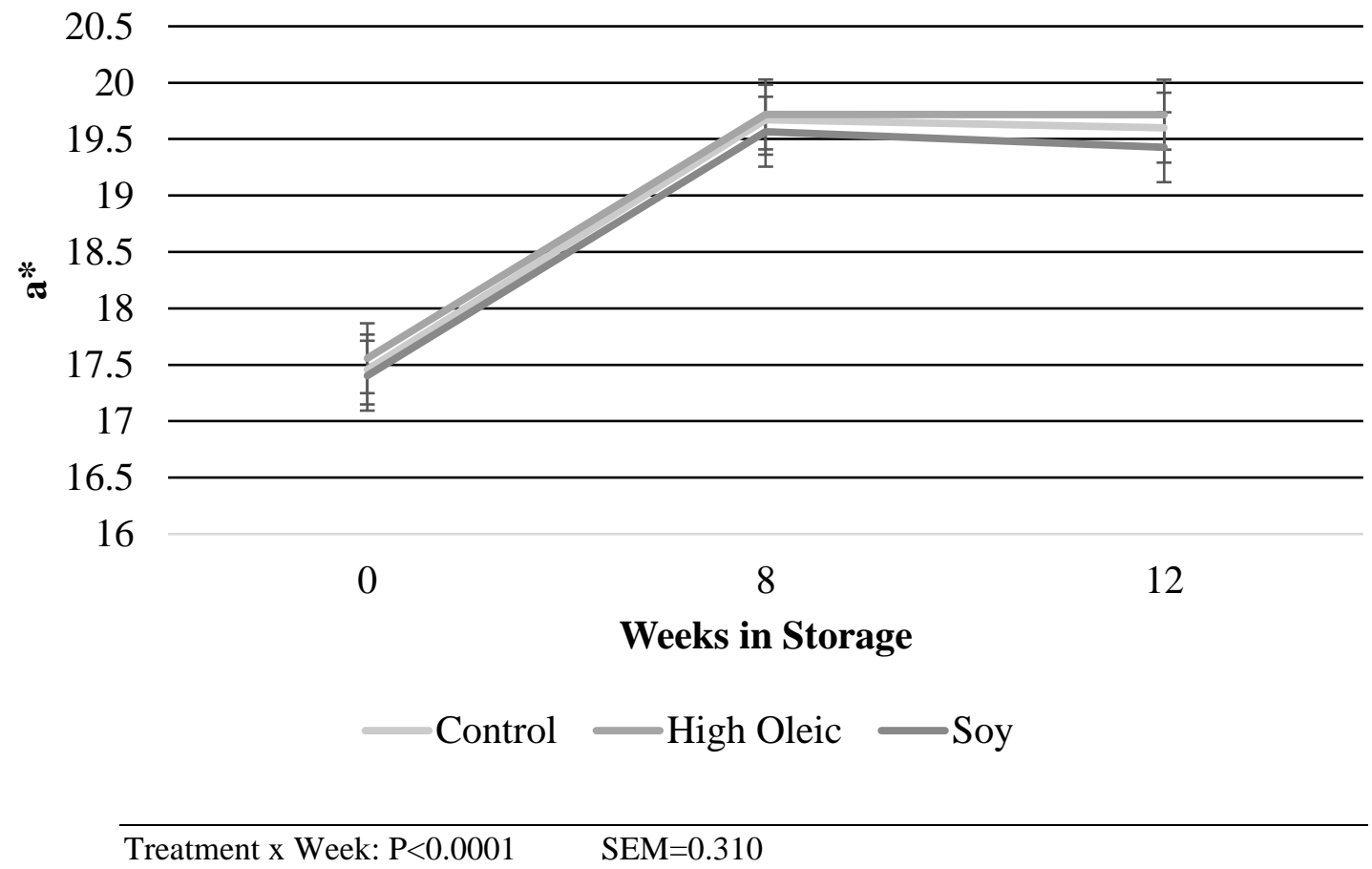


Figure 5.6. $b^{*}$ values of egg yolks from laying hens fed high oleic and commodity soybean oil, over weeks in cold storage.

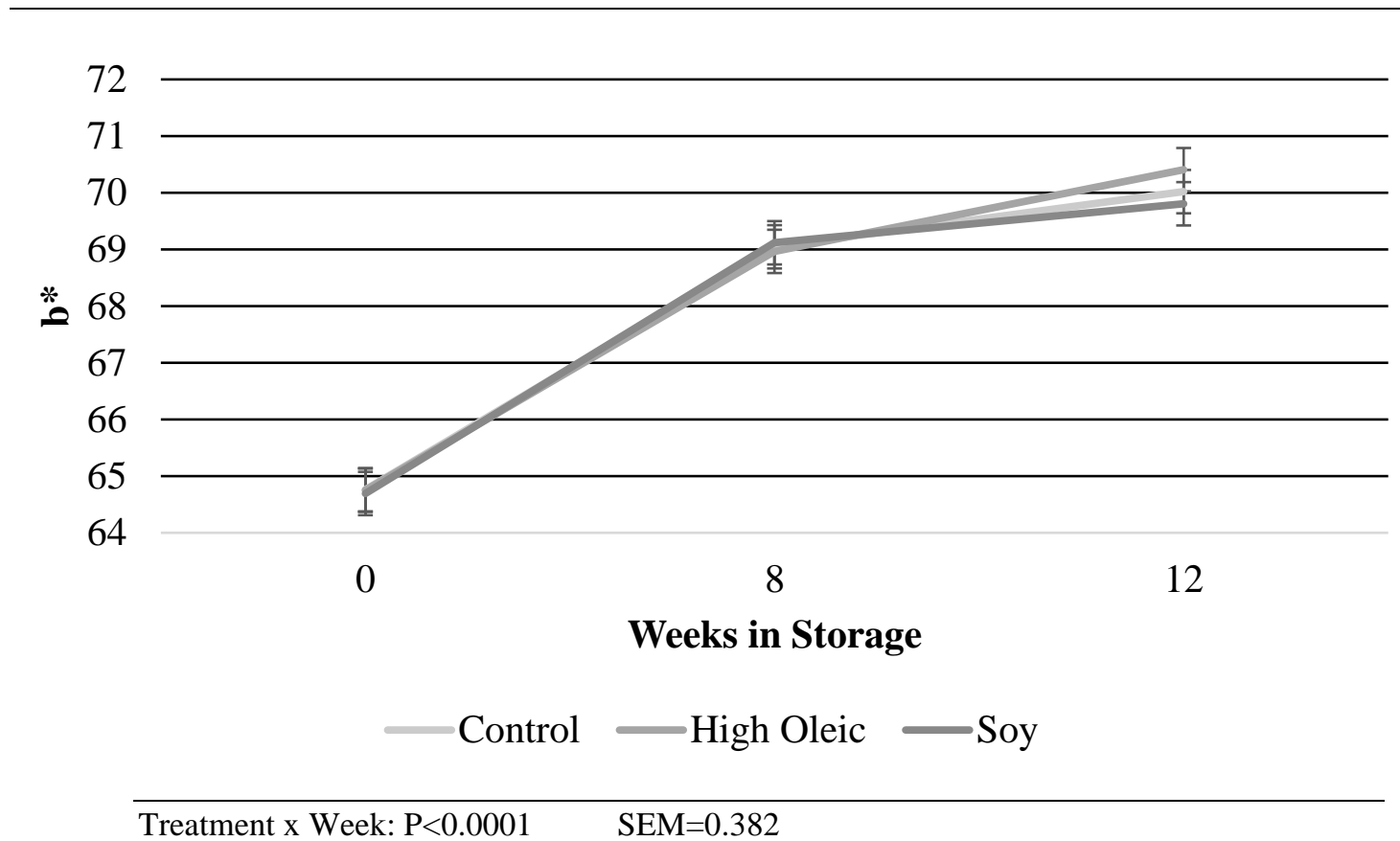

Treatment $\mathrm{x}$ Week: $\mathrm{P}<0.0001 \quad$ SEM=0.382 
Figure 5.7. Roche color fan score values of egg yolks from laying hens fed high oleic and commodity soybean oil, over weeks in cold storage.

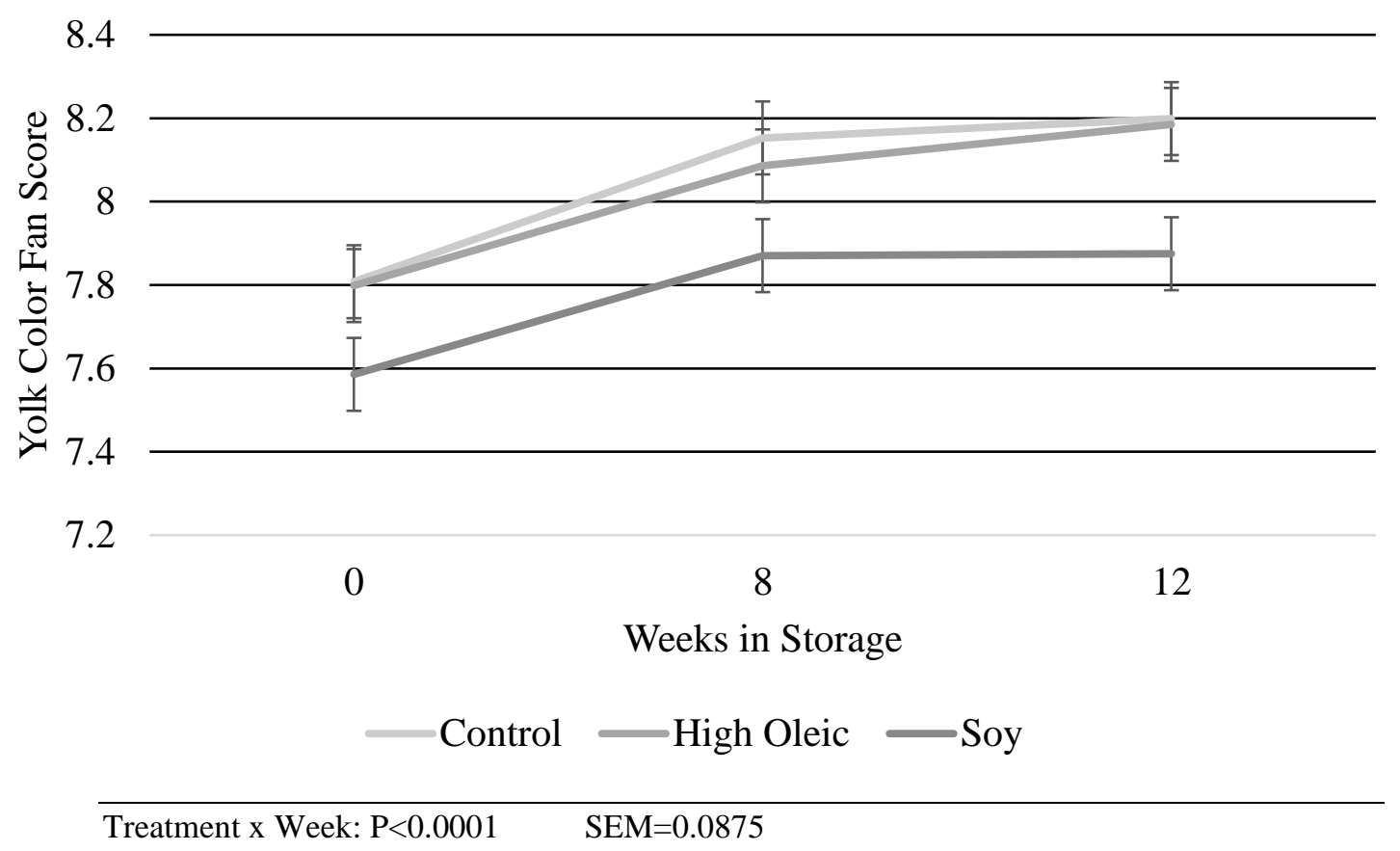


Figure 5.8. TBAR values of egg yolks from laying hens fed high oleic and commodity soybean oil.

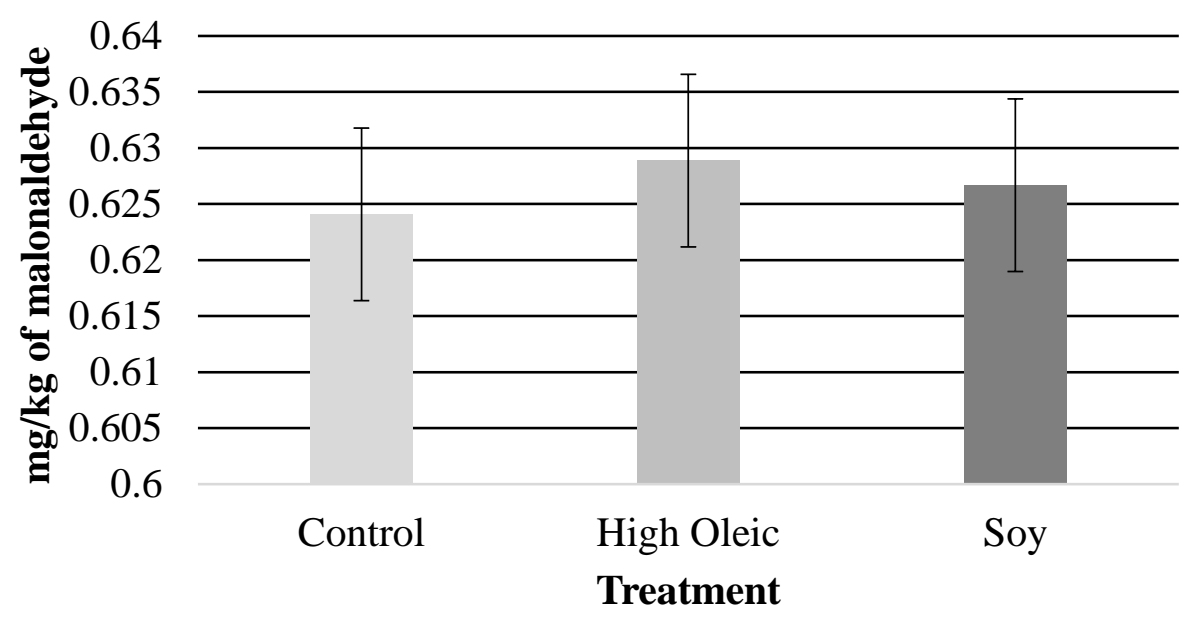

$\mathrm{P}=0.9075 \quad \mathrm{SEM}=0.0077$ 


\section{LITERATURE CITED}

Aberle, E. D., Forrest, J. C., Gerrard, D. E., \& Mills, E. W. (2012). Principles of Meat Science. $5^{\text {th }}$ ed. Kendall Hunt Publishing Company, Des Moines, Iowa.

Alonso, V., Najes, L. M., Provinicial, L., Guillen, E., Gil, M., Roncales, P., and Beltran, J. A. (2012). Influence of dietary fat on pork eating quality. Meat Science. 92: 366-373.

Andersen, H. J., Oksbjerg, N., Young, J. F., Therkildsen, M. (2005). Feeding and meat quality- a future approach. Meat Science. 70: 543-554.

Benz, J. M., Tokach, M. D., Dritz, S. S., Nelssen, J. L., DeRouchey, J. M., Sulabo, R. C., and Goodband, R. D. (2011). Effects of choice white grease and soybean oil on growth performance, carcass characteristics, and carcass fat quality of growingfinishing pigs. J. Anim. Sci. 89: 404-413.

Bou, R., Guardiola, F., Grau, A., Grimpa, S., Manich, A., Barroeta, A., and Codony, R. (2001). Influence of dietary fat source, $\alpha$-Tocopherol, and ascorbic acid supplementation on sensory quality of dark chicken meat. Poultry Science. 80: 800-807.

Boselli, E., Pacetti, R., Lucci, P., Lecce, G. D., and Frega, N. G. (2008). Supplementation with high-oleic sunflower oil and alpa-tocopheryl acetate: effects on pork meat lipids. Lipid Sci and Technol. 110: 381-391.

Cardenia, V., Rodriguez-Estrada, M. T., Cumella, F., Sardi, L, Casa, G., and Lercker, G. (2011). Oxidative stability of pork meat lipids as related to high-oleic sunflower oil and vitamin E diet supplementation and storage conditions. Meat Science. 88: 271-279.

Celebi, S. and Macit, M. (2008). The effects of sources of supplemental fat on performance, egg quality, and fatty acid composition of egg yolk in laying hens. $J$ Sci Food Agric. 88: 2382-2387.

Conrad, Z., Johnson, L. K., Roemmich, J. N., Juan, W., and Jahns, L. (2017). Time trends and patterns of reported egg consumption in the U.S. by sociodemographic characteristics. Nutrients. 9 (333) 1-12.

Daniel, C. R., Cross, A. J., Koebnick, C., and Sinha, R. (2010). Trends in meat consumption in the USA. Public Health Nutrition. 14(4), 575-583. 
Engel, J. J., Smith, J. W., Unruh, J. A., Goodband, R. D., O’Quinn, P. R., Tokach, M. D., and Nelssen, J. L. (2001). Effects of choice white grease or poultry fat on growth performance, carcass leanness, and meat quality characteristics of growingfinishing pigs. J. Anim. Sci. 79: 1491-1501.

Feddern, V., De Pra, M. C., Mores, R., Nicoloso, R. S., Coldebella, A., and Abreu, P. G. (2017). Egg quality assessment at different storage conditions, seasons and laying hen strains. J. Sci and Agrotech. 41(3): 322-333.

Filardi, R., Junqueira, O. M., Laurentiz, A. C., Casartelli, E. M., Rodrigues, E. A., and Araujo, L. F. (2005). Influence of different fat sources on the performance, egg quality, and lipid profile of egg yolks of commercial layers in the second laying cycle. J. Appl. Poult Res. 14: 258-264.

Geiker, N. R., Larsen, M. L., Dyerberg, J., Stender, S., and Astrup, A. (2017). Egg consumption, cardiovascular diseases and type 2 diabetes. European Journal of Clinical Nutrition. 72: 44-26.

Godfray, C. H., Aveyard, P., Garney, T., Hall, J. W., Key, T. J., Lorimer, J., Pierrehumbert, R. T., Scarborough, P., Spingmann, M., and Jebb, S. A. (2018). Meat consumption, health, and the environment: A review. Science Magazine. 361: 1-8.

Gonzalez, N., Marques, M., Nadal, M., and Domingo, J. L. (2020). Meat consumption: which are the current global risks? A review of recent (2010-2020) evidences. Food Research International 137: 109341.

Guenther, P. M., Jensen, H. H., Batres-Marquez, P. S., and Chen, C. (2005). Sociodempgraphic, knowledge, and attitudinal factors related to meat consumption in the United States. J. Am. Diet Assoc. 105: 1266-1274.

Hayat, Z., Cherian, G., Pasha, T. N., Khattak, F. M., and Jabbar, M. A. (2010). Oxidative stability and lipid components of eggs from flax-fed hens: effect of dietary antioxidants and storage. Poultry Science. 89: 1285-1292.

Hugo, A. and Roodt, E. (2007). Significance of porcine fat quality in meat technology: a review. Food Reviews International. 23: 175-198.

Hugo, A., Els, S. P., Witt, F. H., Van der Merwe, H. J., and Fair, M. D. (2009). Effect of dietary lipid sources on lipid oxidation of broiler meat. SA J Ani Sci. 39: 149-452.

Huth, P. J., Fulgoni, V. L., and Larson, B. T. (2015). A systematic review of high-oleic vegetable oil substitution for other fats and oils on cardiovascular disease risk factors: implications for novel high-oleic soybean oils. Adv. Nutr. 6: 74-93. 
Irandoust, H., Samie, A. H., Rahmani, H. R., Edriss, M. A., and Mateos, G. G. (2012). Influence of source of fat and supplementation of the diet with vitamin $\mathrm{E}$ and $\mathrm{C}$ on performance and egg quality of laying hens from forty four to fifty six weeks of age. Ani Feed Sci and Technol. 177: 75-85.

Johnson, L. R. (2007). Digestion and Absorption. Gastrointestinal Physiology, $7^{\text {th }}$ Ed., Chapter 11, p. 107-125.

Kim, J. H., Lee, H. K., Yang, T. S., Kang, H. K., and Kil, D. Y. (2019). Effect of different sources and inclusion levels of dietary fat on productive performance and egg quality in laying hens raised under hot environmental conditions. AsianAustralas J Anim Sci. 32-9: 1407-1413.

Ledvinka, Z., Zita, L., and Klesalova, L. (2012). Egg quality and some factors influencing it: a review. Scientia Agriculturae Bohemica. 43: 46-52.

Lusk, J. L., Tonsor, G. T., Schroeder, T. C., and Hayes, D. J. (2018a). Effect of government quality grade labels on consumer demand for pork chops in the short and long run. Food Policy. 77: 91-102.

Lusk, J. L. (2018b). Consumer preferences for and beliefs about slow growth chicken. Poultry Science. 97 (12): 4159-4166.

Maltin, C., Balcerzak, D., Tilley, R., and Delday, M. (2003). Determinants of meat quality: tenderness. Proceedings of the Nutrition Society. 62: 337-347.

Mancini, R. and Hunt, M. (2005). Current research in meat color. Meat Science. 71: 100121.

Maw, S. J., Fowler, V. R., Hamilton, M., and Petchey, A. M. (2003). Physical characteristics of pig fat and their relation to fatty acid composition. Meat Science. 63: 185-190.

Mir, N. A., Rafiq, A., Kumar, F., Singh, V., and Shukla, V. (2017). Determinants of broiler chicken meat quality and factors affecting them: a review. J Food Sci Technol. 54(10): 2997-3009.

Mitchaothai, J., Yuangklang, C., Wittayakun, S., Vasupen, K., Wongsutthavas, S., Srenanul, P., Hovenier, R., Everts, H., and Beyen, A. C. (2007). Effect of dietary fat type on meat quality and fatty acid composition of various tissues in growingfinishing swine. Meat Science. 76: 95-101.

Nelson, R. H. and Cox, M. M. (2013). Lehninger: Principles of Biochemistry. $6^{\text {th }}$ Edition. Worth Publishing, New York, NY.

Naughton, S. S., Hanson, E. D., Mathai, M. L., McAinch, A. J., (2018). The acute effect of oleic or linoleic acid containing meals on appetite and metabolic markers; a pilot study in overweight or obese individuals. Nutrients. 
Ortiz, L. T., Alzueta, C., Rebole, A., Rodriguez, M. L., Arija, I., and Brenes, A. (2006). Effect of dietary high-oleic acid and conventional sunflower seeds and their refined oils on fatty acid composition of adipose tissue and meat in broiler chickens. J. Ani. And Feed Sci. 7: 83-95.

Pereira, A., Vidal, T. F., Abreu, V., Zapata, J., Freitas, E. R. (2011). Type of dietary lipids and storing time on egg stability. Cienc. Technol. Aliment. 31-4: 984-991.

Realini, C. E., Duran-Montge, P., Lizardo, R., Gispert, M., Oliver, M. A., and EsteveGarcia, E. (2010). Effect of source of dietary fat on pig performance, carcass characteristics and carcass fat content, distribution and fatty acid composition. Meat Science. 85: 606-612.

Rentfrow, G., Sauber, T. E., Allee, G. L., and Berg, E. P. (2003). The influence of diets containing either conventional corn, conventional corn with choice white grease, high oil corn, or high oil high oleic corn on belly/bacon quality. Meat Science. 64: 459-466.

Rondoni, A., Asioli, D., and Millan, E. (2020). Consumer behaviour, perceptions, and preferences towards eggs: a review of the literature and discussion of industry implications. Food Sci and Technol. 106: 391-401.

Ruiz, J. A., Guerrero, L., Arnau, J., Guardia, M. D., and Esteve-Garcia, E. (2001). Descriptive sensory analysis of meat from broilers fed diets containing vitamin $\mathrm{E}$ or B-carotene as antioxidants and different supplemental fat. Poultry Science. 80: 976-982.

Sanz, M., Flores, A., Ayala, P. P., and Lopez-Bote, C. J. (1999). Higher lipid accumulation in broilers fed on saturated fats than in those fed on unsaturated fats. British Poultry Science. 40: 95-101.

Stephenson, E. W., Vaughn, M. A., Burnett, D. D., Paulk, C. B., Tokach, M. D., Dritz, S. S., DeRouchey J. M., Goodband, R. D., Woodworth, J. C., and Gonzalez, J. M. (2016). Influence of dietary fat source and feeding duration on finishing pig growth performance, carcass composition, and fat quality. J. Anim. Sci. 94: 2851-2866.

Tartrakoon, W., Tartrakoon, T., and Kitsupee, N. (2016). Effects of the ratio of unsaturated fatty acid to saturated fatty acid on the growth performance, carcass and meat quality of finishing pigs. Animal Nutrition 2: 79-85.

Tavarez, M. A., Boler, D. D., Bess, K. N., Zhao, J., Yan, F., Dilger, A. C., McKeith, F. K., and Killefer, J. (2011). Effect of antioxidant inclusion and oil quality on broiler performance, meat quality, and lipid oxidation. Poultry Science. 90: 922-930.

Teixeira, A. and Rodrigues, S. (2021). Consumer perceptions towards healthier meat products. Current Opinion in Food Science 40: 147-154. 
Tikk, K., Tikk, M., Aaslyng, M. D., Karlsson, A. H., Lindahl, G., and Andersen, H. J. (2007). Significance of fat supplemented diets on pork quality- Connections between specific fatty acids and sensory attributes of pork. Meat Science. 77: 275286.

Toomer, O. T., Livingston, M., Wall, B. Sanders, E., Vu, T., Malheiros, R. D., Livingston, K. A., Carvalho, L. V., Ferket, P. R., and Dean, L. L. (2020). Feeding high-oleic peanuts to meat-type broiler chickens enhances the fatty acid profile of the meat produced. Poultry Science. 99: 2236-2245.

Toomer, O. T., Livingston, M., Wall, B. Sanders, E., Vu, T., Malheiros, R. D., Livingston, K. A., Carvalho, L. V., Ferket, P. R. (2019a). Meat quality and sensory attributes of meat produced from broiler chickens fed a high oleic peanut diet. Poultry Science. 98: 5188-5197.

Toomer, O. T., Hulse-Kemp, A. M., Dean, L. L., Boykin, D. L., Malheiros, R., and Anderson, K. E. (2019b). Feeding high-oleic peanuts to layer hens enhances egg yolk color and oleic fatty acid content in shell eggs. Poultry Science. 98: 17321748.

United States Department of Agriculture- Economic Research Service (USDA-ERS). (2021). USDA-ERS Situation and Outlook Report. https://www.ers.usda.gov/webdocs/outlooks/100721/ldp-m-321.pdf?v=4452.3

Viveros, A., Ortiz, L. T., Rodriguez, M. L., Rebole, A., Alzueta, C., Arija, I., Centeno, C., and Brenes, A. (2009) Interaction of dietary high-oleic -acid sunflower hulls and different fat sources in broiler chickens. Poultry Science. 88: 141-151.

Wood, J. D., Enser, M., Fisher, A. V., Nute, G. R., Richardson, R. I., and Sheard, P. R. (1999). Manipulating meat quality and composition. Proceedings of the Nutrition Society. 58: 363-370.

Wood, J. D., Richardson, R. I., Nute, G. R., Fisher, A. V., Campo, M. M., Kasapidou, E., Sheard, P. R., and Enser, M. (2003). Effects of fatty acids on meat quality: a review. Meat Science. 66: 21-32. 